\title{
LOS OBISPOS Y LA HISTORIA DE LA IGLESIA EN AREQUIPA
}

\author{
POR \\ ÁlVARo EsPINOZA DE LA BoRDA \\ Universidad Católica SP
}

\section{RESUMEN}

En el presente artículo se realiza una síntesis de las historia de la diócesis de Arequipa desde sus orígenes hasta los momentos actuales. La evolución de esta localidad lo que nos permite es fijar la propia evolución de la vida sur del Perú, $y$ los diferentes retos a los que se ha tenido que enfrentar.

PALABRAS CLAVE: Arequipa, mundo colonial, Edad contemporánea.

\section{Abstract}

This article is a synthesis of the history of the Church in Arequipa from his beginning to the present. The evolution of this country let us to know the evolution of the life in the south of Peru and the different challenges that Arequipa had surpassed.

KEY WORDS: Arequipa, colonial world, Contemporary Age.

\section{LA IGLESIA EN AREQUIPA}

Arequipa, en el sur del Perú, es una ciudad con un profundo sentido religioso que la ha hecho ser llamada la Roma del Perú. Apuntaba Víctor Andrés Belaunde, «Arequipa en su vivencia histórica ha sido y es uno de los pueblos más religiosos de América»1. En este sentido, la Iglesia es, sin lugar a dudas, p. 71

1 Víctor BELAUNDE, Andrés. Trayectoria y Destino, Memorias, Lima, Ediventas. 1967. Tomo I, 
una de las forjadoras de la identidad cultural arequipeña, por ser el catolicismo uno de sus elementos constitutivos.

Antigua sede episcopal, Arequipa dependía eclesiásticamente de los prelados del Cusco cuando fue fundada en 1540, hasta su elevación a obispado a principios del siglo XVII. La diócesis fue creada inicialmente en $1577^{2}$, pero esta erección fue frustrada por la oposición del obispo del Cusco, Sebastián de Lartaun, quien defendió tenazmente su jurisdicción. Ello sólo fue posible décadas después, cuando el 20 de julio de 1609 se produjo la creación definitiva por el Papa Paulo V y ya en 1611 designó al dominico fray Cristóbal Rodríguez como su primer obispo, efectuándose la división en 1614. Dicha creación corresponde al proceso de Consolidación de la fe cristiana en el Perú, que se operó a partir de esa centuria como sostiene el padre Enrique Fernández S.J. ${ }^{3}$

Comprendía una extensa jurisdicción eclesiástica, pues estaba asentada sobre la base de los «términos» de la ciudad de Arequipa, que abarcaba desde el pueblo de Acarí por el norte, 'hasta el río Loa (actualmente Chile) por el sur. Ya en 1879 se le anexaron las 8 parroquias que conformaban la provincia de La Unión - creada en 1839 - antes parte de los obispados de Cusco y Ayacucho. ${ }^{4} \mathrm{~A}$ su vez, perdería sus provincias sureñas arrebatadas por Chile.

Arequipa fue elevada a la categoría de Arquidiócesis metropolitana el 23 de mayo de 1943 al haberse dividido la provincia eclesiástica de Lima y creado tres nuevas en lo que fue dicha sede. Tiene como diócesis sufragáneas a Puno, Moquegua-Tacna y las prelaturas de Juli, Caravelí, Ayaviri y Chuquibamba.

Actualmente solo conserva unas cuantas provincias, habiéndose creado en su antigua jurisdicción diócesis y prelaturas que la han reducido.

Sus obispos han desempeñado papel fundamental en su evolución histórica. La importancia que para Arequipa tiene el conocimiento de sus diocesanos la señalaba el recientemente fallecido monseñor Fernando Vargas Ruiz de Somocurcio S.J., quien decía: «... muchos de sus pastores destacaron especialmente por su santidad de vida, así como por sus cualidades intelectuales y de gobierno orientadas a la búsqueda de una organización más eficaz para el servicio del pueblo de Dios, expresado en particular en la vivencia de un intenso amor pre-

2 Fue designado obispo el dominico fray Antonio de Hervias. La presentación, firmada el 15 de octubre de 1576 fue transcrita y publicada por Pedro José RADA Y GAMIO en El Arzobispo Goyeneche y Apuntes para la Historia del Perú. Roma, Imprenta Políglota Vaticana, 1917. Tomo I, pp. 186-188, Nota al pie.

3 Enrique FERnÁNDEZ García S.J., Perú Cristiano. Primitiva evangelización de Iberoamérica y Filipinas, 1492-1600, e Historia de la Iglesia en el Perú, 1532-1900, Lima, PUCP, 2000, p. 229.

${ }_{4}$ Manuel Segundo Ballón, Mapa de la Diócesis de Arequipa. Lima, Litografia Carlos Fabbri, 1913, pp. 19-20.

Fundaciones Hispanas

Hispania Sacra 57 (2005) 
ferencial por los pobres y necesitados, y al celo por llevar el Evangelio hasta los más alejados poblados bajo su cuidado» ${ }^{5}$.

$\mathrm{Al}$ respecto dice el historiador José Antonio Benito: «El Episcopado ha sido en la historia de América el verdadero artífice de la organización y creación de la Iglesia. Su labor se refleja en los numerosos concilios provinciales y sínodos diocesanos convocados, así como en las visitas pastorales y fundaciones (pueblos, seminarios, hospitales), sus aportaciones culturales (sermones y pastorales, donación de libros, creación de colegios y la propia Universidad)» ${ }^{6}$.

Para el notable pensador cristiano Víctor Andrés Belaunde el factor principal del alto grado de moralidad colectiva, existente entonces, fue la elevada calidad de los Obispos. Decía: «Aquí cabe hablar de la influencia paradigmática de la Jerarquía. Los principios morales de una sociedad se encarnan siempre en personalidades superiores, que son así los factores vivos de la ética social, los mantenedores del ambiente espiritual, los pilares sobre los que reposa la comunidad, constituida por instituciones y normas que precisamente por no tener el carácter coactivo del Estado, encarnan la influencia moderadora y eficaz que determina la conducta colectiva ${ }^{7}$.

La cristianización del Perú, ha escrito el padre Enrique Fernández S.J., fue rápida, fulminante; y pudo ser «tan acelerada por la totalidad de medios, recursos y empeños institucionales y personales comprometidos en la empresa» ${ }^{8}$. La labor de los obispos, ocupa dentro de ellos, lugar preponderante.

Afirma el historiador jesuita Armando Nieto Vélez: «Una de las primeras obligaciones de los obispos consistía en evangelizar a los naturales. Así lo dicen explícitamente los reyes en las reales cédulas. Reciben los obispos, en consecuencia con la gravedad del encargo, singulares privilegios, justificados por las distancias entre las diócesis americanas y Roma; y con el uso de tales dispensas los actos de gobierno podían ejecutarse con mayor expedición y celeridad»?

En el caso de Arequipa tal afirmación se cumple plenamente. Su accionar ha sido el que marcó el devenir de la Iglesia a lo largo del tiempo. Por tanto, para conocer su pasado es necesario estudiar a sus prelados.

\footnotetext{
${ }^{5}$ Fernando VARgas RUIZ DE SOMOCURCIO S.J., «Discurso de Clausura del Primer Congreso Peruano de Historia Eclesiástica», en: La evangelización del Perú Siglos XVI y XVII. Actas del Primer Congreso Peruano de Historia Eclesiástica, Arequipa, 1990, p. 71.

6 José Antonio Benito Rodríguez, Arequipa Católica, la Roma del Perú. Apuntes históricos. Arequipa, 1998, p. 12.

7 Víctor Andrés Belaunde, Peruanidad. Lima. Fondo del Libro del Banco Industrial del Perú, 1983, p. 248.

8 Enrique FERNÁNDEZ GaRCÍA S.J., Perú Cristiano..., p. 75.

9 Armando Nieto VÉlez S.J., «La Iglesia Católica en el Perú», en: Historia del Perú. Lima, Editorial Juan Mejía Baca, 1981. Tomo XI, p. 460.
} 
Desde 1619 , con algunos lapsos de interrupción, ${ }^{10}$ se han sucedido una serie de obispos que han regido esta diócesis. Sobre sus prelados se ha escrito varios estudios en diferentes épocas y utilizando diversas fuentes. Pero estos trabajos adolecen de falta de organicidad por haber sido elaborados sin tener en cuenta a la Iglesia como institución y como pueblo; es por ello que proponemos una periodificación, aunque de carácter provisional todavía, que nos permita tener una idea más precisa sobre la evolución de la vida de la Iglesia en Arequipa.

Pero antes, es necesario revisar las fuentes para su historia y realizar un comentario de las historias que se han hecho sobre ella.

\subsection{Las Fuentes}

Son de variada índole e importancia. Las encontramos en diferentes archivos y variada bibliografía.

\subsubsection{Los Archivos}

Sin lugar a dudas el Archivo Arzobispal de Arequipa es el que reúne el mayor número de documentos sobre el pasado de la Iglesia en esta provincia eclesiástica. Su fondo se halla clasificado en cuatro secciones: Curia diocesana, Catedral y Cabildo eclesiástico, Vicarías y Libros Parroquiales. Data desde comienzos del siglo XVII hasta el XX, la documentación del XVI ha desaparecido sea por pérdidas, sustracciones o destrucción en el incendio de 1620 . Corresponde a los actuales departamentos peruanos de Arequipa, Moquegua y Tacna y a las hoy provincias chilenas de Arica, Tarapacá e Iquique.

También en el Archivo Regional de Arequipa hay documentos de índole eclesiástica. Cuenta con la serie Obispado que comprende diez legajos, cuyo contenido tiene que ver fundamentalmente con juicios de tipo administrativo y civil.

El Archivo Arzobispal de Lima cuenta con un importante conjunto de documentos relacionados a la antigua diócesis de Arequipa en su serie Causas de Apelaciones de Arequipa con más de dos centenares de expedientes distribuidos en 31 legajos de los que la archivera Laura Gutiérrez Arbulú ha hecho un catálogo publicado en la Revista del Archivo Arzobispal de la ciudad del Misti ${ }^{11}$.

10 Arequipa estuvo sin prelado entre 1614 a 1619,1708 a 1717,1741 a 1743,1753 a 1757,1763 a 1764,1770 a 1772,1786 a 1788,1805 a 1810.

${ }^{11}$ Los expedientes son 275 correspondientes a los años 1616 hasta 1905. El Catálogo fue publicado en el número 4 de la Revista del Archivo Arzobispal de Arequipa del año 1997.

Fundaciones Hispanas

Hispania Sacra 57 (2005) 
Otro repositorio documental que contiene información sobre la diócesis arequipense es el Archivo General de la Nación. En sus series Títulos de Propiedad, Superior Gobierno, Real Audiencia (Causas civiles y criminales), Juzgado de Aguas y Junta de Temporalidades (Haciendas, Administrativo, Cuentas de Haciendas, Colegios, Cuentas de Colegios, Comisiones, Correspondencia); existe abundante documentación, sobre propiedades jesuíticas en su mayoría, que permitirán conocer la actividad económica de los institutos religiosos ${ }^{12}$. Tiene también, en su serie Tribunal Eclesiástico, documentos de interés.

La Biblioteca Nacional cuenta a su vez con crecido número de documentos relacionados a Arequipa, dentro de los que hay expedientes en torno a temas eclesiásticos. Su Colección de Manuscritos es de carácter general, recopilando documentación de diversos lugares y distintas épocas de los más variados te$\operatorname{mas}^{13}$.

Más información sobre Arequipa y la evolución de la Iglesia hay en España. Para los interesados en los prelados arequipenses y los miembros de su cabildo eclesiástico puede encontrarse en el Archivo General de Simancas sus nombramientos ${ }^{14}$. En tanto que en el Archivo General de Indias en Sevilla disponemos la más variada documentación, toda vez que en ejercicio del Regio Patronato la corona española supervisaba y aprobaba todas las funciones eclesiásticas a través de las autoridades peninsulares y virreinales, que daban cuenta de ello al Consejo de Indias.

\subsubsection{Las Recopilaciones Documentales}

Son fundamentales, pues facilitan el acceso a documentos que muchas veces no son de fácil acceso a los investigadores. Así, las recopilaciones y transcripciones del Padre Barriga nos han permitido contar con la relación de 1649 (1940) y los escritos de Echeverría (1952).

Para la historia de la Iglesia en el Perú contamos con algunas compilaciones como la de monseñor Emilio Lissón titulada «La Iglesia de España en el Perú» publicada en cuatro volúmenes entre 1943 y 1946 en Sevilla. El estudioso argentino Roberto Levillier aparte de las colecciones sobre «Gobernantes

12 Puede verse Alejandro MÁlaga MEdina, Indice de los Manuscritos Arequipeños existentes en el Archivo General de la Nación. Arequipa, Editorial El Sol, 1974.

13 Alejandro MÁlaGa MEDINA, «Indice de Documentos de valor histórico para Arequipa», en: Humanitas 1. Universidad Nacional de San Agustín. Arequipa, 1963, pp. 141-188.

14 José Antonio BENITO RoDRíGUEZ, «Perú en el Archivo General de Simancas (A.G.S.)», en: Boletín del Instituto Riva Agüero 21, 1994. Lima, 1997, pp. 289-316. Allí se encuentran los títulos de obispos, deanes, chantres, maestrescuelas, tesoreros, etc. 
del Perú», «Audiencia de Lima» y «Audiencia de Charcas», tiene también «Organización de la Iglesia y órdenes religiosas en el Virreynato del Perú en el siglo XVI» en dos volúmenes impresos en 1919.

El padre Víctor M. Barriga, fue sin duda, el más preocupado en rescatar documentación en sus colecciones «Documentos para la historia de Arequipa» (3 volúmenes), «Memorias para la historia de Arequipa» (4 volúmenes) y «Los Mercedarios en el Perú» (5 volúmenes).

También podemos mencionar «Fuentes Documentales para la Historia de Arequipa». T.I El Obispo P.J. Chaves de la Rosa y T.II Propiedades Jesuitas editados en 1975 y 1978 por el doctor Alejandro Málaga Medina.

\subsubsection{Las Crónicas}

Dado nuestro tema, las crónicas a él relacionadas, son las conventuales. Sus autores han sido calificados de historiadores y costumbristas del Virreinato por Julián Santisteban Ochoa, quien les señala como características el ser de segunda mano y presentar «churriguerescas crónicas monásticas o discusiones metafísico aristotélicas $\rangle^{15}$. Por desdicha -dice Vargas Ugarte- en las Crónicas de Convento muchas veces se omitió o se postergó la labor evangelizadora $y$ en vez de historia se tejieron menologios o actas capitulares ${ }^{16}$.

Pero conviene resaltar como rasgo principal, el crecido caudal de noticias que contienen acerca de la historia del reino, que reunieron para explicar las obras de sus respectivas órdenes, además del propósito edificante que tenían. ${ }^{17}$

Con todo cabe señalar las crónicas de los agustinos fray Antonio de la Calancha y Bernardo de Torres. Para los franciscanos está la obra de fray Diego de Córdova Salinas y la de fray Diego de Mendoza que escribió sobre la provincia de San Antonio de los Charcas. En tanto que los dominicos cuentan con la obra de fray Juan Meléndez. Los mercedarios no alcanzaron a publicar una de la categoría de los anteriores, pero podemos mencionar la todavía inédita crónica del arequipeño fray Francisco de Miranda Valcárcel en que historia a la provincia del Cusco de la que dependían los conventos mistianos de esa orden.

A su vez está la anónima «Historia de la Compañía de Jesús de Arequipa y Relación de la reventazón del volcán de Omate» publicada por primera vez como folletín por el diario arequipeño «El Deber» en 1899 y luego en el tomo

\footnotetext{
15 Julián Santisteban OchoA, Los Cronistas del Perú. Cusco, 1946 p. 150.

16 Rubén VARGaS UgarTe S.J., Manual de Estudios Perianistas. Lima, Imprenta Gil, 1959 p. 177.

17 Pedro BenVEnUtTo MuRRIETA, y Guillermo LohmanN Villena, Los cronistas de convento. París, 1938 p. 10.
} 
II de la «Historia General de la Compañía de Jesús en la Provincia del Perú» por el P. Francisco Mateos S.J. en 1944.

También debemos citar a las «Noticias cronológicas de la gran ciudad del Cuzco» de Diego de Esquivel y Navia que contiene interesantes datos sobre los primeros tiempos de la Iglesia arequipeña. Todas ellas han de ser confrontadas con la documentación de la época.

\subsubsection{Las Historias}

Las primeras historias de Arequipa fueron elaboradas por sacerdotes en las que se tuvo siempre presente a los diferentes pastores del pueblo cristiano arequipeño; es el caso de los denominados «Historiadores Primitivos», a decir de Manuel Ladislao Cabrera Valdés. Y como bien señala este autor «escribieron en interés de la Iglesia y principalmente les ocupó las historias de los Obispos» ${ }^{18}$.

La primera es la elaborada por orden del Obispo Ortega Sotomayor en 1649, vienen luego la de Ventura Travada de 1750, la de Francisco Xavier Echeverría y Morales de 1803, la del Cura de Cayma, Juan Domingo de Zamácola y Jáuregui de 1823 y la del Deán Juan Gualberto Valdivia de 1847.

Conocemos además, aunque referencialmente, el «Teatro histórico de la Iglesia de Arequipa» de Ortega Sotomayor y la «Razón de los Obispos de Arequipa» de Chaves de la Rosa.

\section{a) La Relación del Obispado de Arequipa de 1649}

El primer informe sobre la diócesis que conocemos es el elaborado por Francisco de Palacio Alvarado, secretario del obispo Pedro Ortega Sotomayor a fines de 1649 publicado por el polígrafo Marcos Jiménez de la Espada en sus «Relaciones Geográficas de Indias» $(1885)^{19}$. Una segunda versión fue realizada por Horacio H. Urteaga y Carlos A. Romero en 1925 dentro del tomo V de la Segunda Serie de la «Colección de Libros y Documentos referentes a la

18 Ladislao CABReRa VAldÉs, Documentos Primitivos del Cabildo. Colección de algunos Documentos sobre los primeros tiempos de Arequipa. Arequipa, Tipografia Caritg \& Rivera, 1924 p. 187. Eran estos Ventura Travada, Francisco X. Echeverría, Juan D. Zamácola y Juan G. Valdivia.

19 Marcos JiMÉNEZ DE LA ESPADA, Relaciones Geográficas de Indias. Madrid, 1885. Tomo II. La transcribe bajo el título de «Relación del Obispado de Arequipa», e indica que se trata de una copia que se conserva en la Biblioteca Nacional de Madrid, colección de Juan Bautista Muñoz, tomo 66, folios 270 a 274.

Fundaciones Hispanas Hispania Sacra 57 (2005) 
Historia del Perú $»^{20}$. Este mismo documento lo incluye el padre Víctor M. Barriga en «Arequipa y sus Blasones» $(1940)^{21}$.

Dichas versiones son prácticamente iguales, difiriendo solamente una de otra en el título asignado por los compiladores. La divergencia entre la primer y segunda versión en el uso distinto de mayúsculas y la omisión de alguna que otra conjunción como también la forma de consignar cantidades o años en números o en letras, entre estas dos y la tercera.

El verdadero autor de la relación fue Francisco de Palacio Alvarado, que como hemos indicado era secretario del obispo, quien la realizó por encargo de Ortega Sotomayor, razón por la que se ha atribuido ser obra de este último según apunta con acierto el desaparecido doctor Guillermo Galdos ${ }^{22}$, quien aclara con algún detalle el asunto.

Como bien señalaba Víctor Sánchez Moreno Bayarri «se ciñe como las demás Relaciones, al formulario especialmente preparado en cumplimiento de la Real Ordenanza, según la cual, la Corona disponía la recolección de datos completos sobre sus posesiones de ultramar» ${ }^{23}$.

No se trata pues de un estudio, sino que corresponde a un informe administrativo solicitado por las autoridades peninsulares y según indicaba Jiménez de la Espada es de las que se hicieron para el maestro Gil González Dávila y se ajusta perfectamente a un formulario elaborado para ese respecto ${ }^{24}$.

Se ocupa de los cinco primeros obispos que ha tenido Arequipa durante los ya más de tres siglos de creación de esta circunscripción eclesiástica. Luego pasa a ocuparse de los canónigos de la catedral y de los conventos establecidos en la ciudad, de los límites del obispado y una breve descripción de los pueblos que lo componían y algunos de los más notables sucesos acaecidos hasta ese momento. Pese a su brevedad, tiene una gran importancia por los datos que proporciona y por haberse elaborado a poco más de un siglo de fundada la ciudad.

Debió basar su informe en los datos que pudo recopilar en el archivo de la curia y en los recuerdos de los contemporáneos a los hechos, que en ese mo-

\footnotetext{
20 Aquí figura con el epígrafe de «Relación del Obispado de Arequipa, hecha por su Obispo, el Iltmo. Dn. Pedro Ortega de Sotomayor».

${ }^{21}$ Víctor M. BARRIGA, Arequipa y sus Blasones. Arequipa, Editorial La Colmena, 1940. Lo transcribe con el título de «Relación de Arequipa y sus primeros obispos hecha por Dn. Pedro Ortega de Sotomayor».

22 Guillermo Galdos Rodríguez, Cronistas e Historiadores de Arequipa Colonial. Arequipa, Fundación Manuel J. Bustamante de la Fuente / Universidad Nacional de San Agustín, 1993, p. 66

23 Víctor SÁNCHEZ-MORENO BAYARRI, Arequipa Colonial y las Fuentes de su Historia. Estudio Crítico. Aserprensa, Lima.1987, p. 109. XII.

${ }^{24}$ Marcos JiMÉNEZ DE LA ESPADA, Relaciones Geográficas de Indias..., Tomo II, Apéndice II, p.
}

Fundaciones Hispanas

Hispania Sacra 57 (2005) 
mento todavía vivían. Y, según Sánchez Moreno, tal vez en Cieza o Garcilaso, sobre los primeros tiempos de Arequipa ${ }^{25}$.

La información que contiene es: año de fundación de la ciudad y el de la erección del obispado, los obispos que gobernaron hasta ese momento, la catedral y sus canónigos, parroquia y doctrinas, conventos, hospital, límites de la diócesis, poblaciones, seminario y cosas notables (volcanes, temblores, riquezas naturales).

\section{b) «El Suelo de Arequipa convertido en Cielo» de Travada.}

La primer historia de Arequipa fue escrita por el sacerdote Ventura Antonio Fernández de Córdova y Peredo, conocido como Ventura Travada, nacido en la histórica ciudad del Misti un 4 de julio de 1695 y muerto en la misma en abril de 1758.

Su obra a decir de Francisco Mostajo «es la historia matriz de Arequipa, equivalente a las crónicas sustanciosas e infantiles a la vez. Es la más antigua y la más sabrosa. Tiene de historia y tiene de poema. Entre los floreos de su decir y los datos que comunica a la posteridad, la leyenda suele solazarse, pero también regodéanse juiciosos conceptos y lucen rasgos de donoso ingenio» ${ }^{26}$. Cabrera Valdés observa su «prodigalidad en metáforas» y los yerros que cometió; pero reconoce que su libro «es agradable», agregando que contiene noticias importantes sobre la vida social de su época, anécdotas curiosas y las biografías de sus obispos ${ }^{27}$.

Por su parte Víctor N. Benavente manifestó: «Trabajo interesante por la amena y original descripción, el estilo y la prodigalidad en el dato histórico y el comentario... Manejó muy bien el castellano clásico y sus profundos conocimientos de cultura general ${ }^{28}$.

$\mathrm{Al}$ respecto dicen los doctores A. Málaga Medina y E. Quiroz Paz Soldán: «Estamos ante un libro de excelente prosa, que linda con la poesía, y en cuyo contenido hay testimonio de cronista y aporte de investigador del pasado. Se trata, en todo caso, de un libro de historia. El primero de la historiografia de Arequipa» ${ }^{29}$.

\footnotetext{
25 V. SÁNCHEZ MORENO, Arequipa Colonial..., p. 109.

${ }^{26}$ Francisco Mostajo, «Aportes para la historia de Arequipa». (Travada) en: Eusebio QUIROZ PAZ SOLDÁN y Álvaro ESPINOZA DE LA BORDA, (Compiladores) Francisco Mostajo. Antología de su Obra. Arequipa, Cervesur. 2002. Tomo IV, p. 53.

27 L. CABRERA VALDÉs, Documentos Primitivos..., p. 190.

28 Víctor N. BENAVENTE, Historia sintética de Arequipa. Arequipa, Imprenta Portugal, 1940, p. 93.

29 Alejandro MÁlaGA MEDINA y Eusebio QUIROZ PAZ SOLDÁN, «Ventura Travada y Córdova: sacerdote e historiador». en: Revista Peruana de Historia Eclesiástica, 4. Cuzco, 1995, p. 219.
} 
Existió más de una copia de esta obra, siendo una de ellas realizada por Zamácola, a la que puso por título «Historia General de Arequipa» y se ha supuesto erróneamente que era su autor. «La copia de Travada, hecha por el cura de Cayma, tiende a confundirse con la obra que él había escrito, y además porque la copia lleva ese título. Para no pocas personas, el libro es de Zamácola y no de Travada», señala el doctor Quiroz Paz Soldán ${ }^{30}$.

Ha sido editada varias veces, aunque no correctamente, la primera fue la realizada en 1877 por el coronel Manuel de Odriozola en el tomo X de su «Colección de Documentos Literarios». ${ }^{31}$ La segunda edición corresponde a la del diario católico «El Deber» de 1923, en base a la de 1877, pero cometiendo el grave error de asignarle el título de «Historia General de Arequipa»"32. En 1958 Vladimiro Bermejo en la colección «Festival del Libro Arequipeño», publicó una selección con algunos capítulos de la primera parte ${ }^{33}$.

A 1993 corresponde la lujosa edición facsimilar hecha por el editor Ignacio Prado Pastor con un estudio del doctor Eusebio Quiroz P.S.

Con respecto a los obispos, buscaba rescatarlos del olvido. Escribía: «...será necesario exponer en el sus preciosas vidas para que no se pierdan entre el polvo de los siglos las noticias de sus luces, para este fin daré las que he podido descubrir de sus virtudes.... $\rangle^{34}$.

Hace referencias a sus fuentes, como en el caso del obispo Villagómez, cuando alude la fecha de su toma de posesión, cita de Francisco Echave «Estrella de Lima», contraponiéndola a la dada por el Maestro Dávila ${ }^{35}$. Asimismo menciona al archivo de esta "Santa Iglesia». Según se aprecia, debió haberse informado primeramente en las crónicas conventuales, algunas de las cuales cita.

Autor al que menciona repetidas veces es Gil González Dávila y su «Teatro Eclesiástico». Cita además al agustino Calancha, como también la crónica del fraile de la misma orden Bernardo de Torres, criticándola severamente por sus errores. Puede apreciarse a su vez, referencias a la «Lima fundada» de Pedro Peralta.

\footnotetext{
30 Eusebio QUIROZ PAZ SOLDÁN, Nota Introductoria a la edición facsimilar de Suelo de Arequipa convertido en cielo. Lima, Ignacio Prado Pastor editor, 1993, p. XXXVI.

31 Odriozola suprimió algunas partes y no incluyó los textos en latín, que Travada escribiera a manera de notas marginales.

32 Esto ha llevado a que serios investigadores caigan en el error, como el caso de Rivera Serna cuando hace el recuento de la producción histórica en provincias, al hacer mención de Travada, lo consigna como autor de una Historia general... Cfr. Raúl RIVERA SERNA, «Historia de la historia». en: Historia del Perú. T.X Procesos e Instituciones. Lima, Editorial Juan Mejía Baca, 1981, p. 312.

33 Se ocupaba de los capítulos donde Travada describía las principales características geográficas de Arequipa y su jurisdicción; no tocando en absoluto la Segunda Parte del libro que trataba sobre los obispos.

34 Suelo de Arequipa convertido en cielo. Lima, 1993, p. 253.

35 Ibídem, p. 262.
} 
Sin duda, hubo de consultar también los libros del cabildo eclesiástico, pues sin ellos no habría podido citar muchas fechas y nombres. Debió haber tenido a la vista el proceso de beatificación de la monja Ana de los Angeles ${ }^{36}$, dado que narra diversos pasajes de su vida, trayéndolos a colación en los casos de algunos de los obispos. Otras fuentes que menciona son los rótulos de los retratos de los obispos que se encontraban en la sacristía de la catedral.

De acuerdo a ello, podemos afirmar que Travada consultó la bibliografía existente en ese momento y que completó su historia con diversos tipos de fuentes que pudo revisar. Don Guillermo Galdos acertadamente señalaba que «donde debió encontrar Travada material suficiente es en los archivos del Cabildo Eclesiástico y en el de la Curia» ${ }^{37}$.

En «Suelo de Arequipa convertido en cielo», se ocupa en primer lugar de historiar el pasado de la ciudad y de la fundación del obispado para luego describir la jurisdicción arequipeña. La segunda parte de la obra corresponde al estudio de la catedral y la vida de los obispos, ocupándose luego de los miembros del cabildo eclesiástico y de los templos de la ciudad, enumeración que la elaboró en forma del zodiaco. «De esta manera logra representar la historia de la ciudad de Arequipa dentro de un esquema simbólico que le permite asimilar la condición de la Ciudad Celestial a la historia misma de Arequipa» ${ }^{38}$.

Travada fue muy ingenioso al convertir a Arequipa en una reproducción de la ciudad celestial, echó mano para ello de la mitología y los clásicos de la antigüedad, equiparando los símbolos zodiacales con el número simbólico del cristianismo y los templos y conventos arequipeños. Para mostrar mejor su idea, dispuso las casas religiosas de acuerdo a criterios jerárquicos, cronológicos y simbólicos haciendo corresponder los valores zodiacales y las cualidades de cada orden religiosa. Ello le confiere un sentido místico, que da a su obra un carácter peculiar que no ha sido igualado por los escritores que le siguen, los cuales basan sus esquemas en el documento administrativo de 1649, aunque considerando temas abordados por el primer historiador de Arequipa.

A pesar de lo recargado de su estilo, «Suelo de Arequipa convertido en cielo» constituye la obra que abrió un camino dentro del campo de la historia de Arequipa, la historia de su Iglesia, tan importante dentro de la vida del pueblo arequipeño.

\footnotetext{
${ }^{36} \mathrm{El}$ proceso fue abierto en 1686 a pocos meses del fallecimiento de la religiosa, y remitido a Europa en 1702; pese a lo cual recién sería beatificada el 2 de febrero de 1985 por Juan Pablo II en su visita a Arequipa.

${ }^{37}$ G. Galdos R., Cronistas e Historiadores de Arequipa Colonial..., p. 131.

38 Ignacio PRADO PASTOR, Nota del Editor. en: Suelo de Arequipa convertido en cielo. Lima, P.L. Villanueva, 1993, p. XXIV.
} 


\section{c) La documentada obra de Francisco Xavier Echeverría y Morales}

Natural de Pica en la antigua provincia peruana de Tarapacá, entonces dentro de la jurisdicción de las autoridades políticas y religiosas de Arequipa. Fue éste, miembro del cabildo eclesiástico arequipeño, dentro del que alcanzó el arcedianato.

$\mathrm{Su}$ obra es una de las primeras historias de Arequipa. El manuscrito está datado el año 1804, pero en las dos ediciones realizadas por V.M. Barriga, observamos que abarca hasta el obispo Goyeneche. En nota a pie de página señalaba el editor: «Todos los datos que aparecen en esta obra después del año 1804 , en que el autor terminó de escribirla, fueron agregados por el mismo» ${ }^{39}$. En el caso de Goyeneche, también en nota, apuntaba «está escrita en el manuscrito con letra distinta parece autobiografía, escrita en 1827, pues el Arcediano Echeverría falleció el 19 de noviembre de $1826 »^{40}$. Había nacido en 1748.

«La Memoria de la Santa Iglesia de Arequipa» de Echeverría es con justicia considerada como una de las mejor documentadas. A decir de Ladislao Cabrera Valdés «fue, al parecer, el primero que examinó los Libros del Archivo del Cabildo; pues cita con toda exactitud las fechas y páginas referentes a los sucesos dignos de nota» ${ }^{41}$.

Decía Zegarra Meneses, era Echeverría «el historiador más consistente, mejor conformado de la Arequipa colonial. Fue el que hizo mayor labor de investigación, y cada una de sus aseveraciones fue fruto de un paciente estudio en archivos y protocolos y de la lectura de los antiguos cronistas, especialmente Garcilaso y el P. Juan Meléndez». Y agregaba, «tuvo entre sus singulares méritos, el de haber sido excepcionalmente cuidadoso y veraz $\rangle^{42}$.

Ha sido conocida tardíamente. Señalaba el padre Barriga en el prólogo que escribiera, «ha permanecido inédito salvo los primeros capítulos que fueron publicados en Lima» o a través de la obra del Deán Valdivia que «lo extractó en su mayor parte en la sección segunda de sus 'Fragmentos para la Historia de Arequipa', siguiendo el mismo plan y añadiéndole muy poco» ${ }^{43}$.

Hay hasta tres ediciones, aunque incompleta la primera. A 1880 corresponde la realizada por el estudioso arequipeño Mariano Felipe Paz Soldán, quien dentro de la «Revista Peruana» incluyó algunos capítulos de la obra del canó-

\footnotetext{
39 «Memoria de la Santa Iglesia de Arequipa», en: Memorias para la Historia de Arequipa. Arequipa, Imprenta Portugal, 1952. Tomo IV, p. 215 nota 93. Eran Gonzaga de la Encina y Goyeneche.

40 Ibídem., p. 216 nota 94.

41 L. CABRERA VALDÉS, Documentos Primitivos..., p. 188.

42 Guillermo ZEgARRA MENESES, Arequipa, en el paso de la Colonia a la República. Arequipa, Cuzzi y Cía., 1973, p. 135.

${ }^{43}$ Memorias para la Historia de Arequipa...., Tomo IV, sp. (Prólogo). 
nigo tarapaqueño. La segunda fue la que salió en la «Revista Universitaria» de la universidad San Agustín en 1949 y 1951, de acuerdo a la transcripción paleográfica realizada por el padre Víctor M. Barriga ${ }^{44}$.

La tercera y última, fue también realizada por el religioso mercedario, esta vez, dentro de su Biblioteca Arequipa en el tomo IV de las «Memorias para la Historia de Arequipa», hecha en los talleres de la imprenta Portugal el año $1952^{45}$.

Si bien el título de esta obra indica una temática eclesiástica, su contenido va más allá. Se ocupa en la Primera Parte de hacer una descripción de todas las provincias - partidos - que componían el obispado; mientras que la segunda es el estudio de la Iglesia en Arequipa representada en su catedral, su seminario, sus obispos y los miembros de su cabildo.

Debió basarse en los documentos que se guardaban en los archivos de la curia, de escribanos y del ayuntamiento; la gran profusión de datos, cifras y fechas, que se observa así lo indica. Al referirse al obispo Ugarte y Saravia, por ejemplo, menciona que dejó para la fundación del convento de carmelitas 22000 pesos, a la catedral 4000, al cabildo eclesiástico 2000, y al monasterio de catalinas otros $4000^{46}$, tales cifras no las pudo haber consignado si es que no tuvo los originales o copias a la vista.

Sostiene Sánchez Moreno que se inspiró para escribir su obra en «Tesoros verdaderos de las Indias» del dominico Juan Meléndez, de fines del siglo $\mathrm{XVII}^{47}$. Probablemente, debió haber consultado a Travada, pero aporta nuevos datos y es más preciso en señalar fechas.

Echeverría se ocupa primero de hacer la descripción de la ciudad, luego de las casas religiosas en ella establecidas y la erección y delimitación de la diócesis. Trata después de los alrededores y de las provincias de la circunscripción arequipeña. Al igual que Travada, trata de la catedral, del seminario, de

\footnotetext{
${ }^{44}$ En la Revista de la Universidad San Agustín apareció en tres entregas, en los números 29 y 30 correspondientes a los dos semestres de 1949, que contenían la primera parte del libro; mientras que la tercera entrega es la que salió en el 34 (segundo semestre de 1951), y contenía la segunda parte de la «Memoria» donde están las biografias de los obispos. Señalaba el doctor César Guardia Mayorga director de la revista: «En esta labor hemos contado con la eficaz cooperación del Reverendo Padre Víctor M. Barriga, quien nos ha proporcionado el original para su publicación».

45 En estas ediciones no se consignó los mapas de los siete partidos que componían el obispado, hechos por Echeverría, según indicaba el Padre Barriga.

46 Memoria de la Santa Iglesia de Arequipa..., pp. 203-204. La donación la hizo ante Alonso Laguna el 30 de octubre de 1645.

47 Y agregaba refiriéndose a Meléndez: «Como es natural tratándose de un trabajo tan voluminoso, en sus páginas los historiadores del período colonial mistiano supieron encontrar anotaciones oportunas para sostener sus apreciaciones, según ocurrió, por ejemplo, con los escritos de Travada y Echeverría» V. SÁNCHEZ MORENO, Arequipa Colonial..., p. 81.
} 
sus obispos, obispos de origen arequipeño y de sus canónigos, cerrando con la enumeración de arequipeños que sirvieron en otras diócesis.

$\mathrm{Si}$ «Suelo de Arequipa...» se estructura en torno a la fundación del monasterio de Santa Rosa, hecho que eleva a Arequipa a ciudad celestial, siendo su artífice un obispo; Echeverría por su parte, historia a la Iglesia, ocupando los prelados lugar privilegiado.

\section{d) La Noticia de Arequipa del presbitero Antonio Pereyra y Ruiz}

Aunque al igual que la relación del obispado de Arequipa de 1649, no corresponde a una historia la «Noticia de la Muy Noble y Muy Leal ciudad de Arequipa», escrita en 1816 por el presbítero de origen canario Antonio Pereyra Pacheco y Ruiz (1790-1858), por la calidad de información que proporciona es muy útil para conocer el estado de la diócesis en las primeras décadas del siglo $\mathrm{XIX}^{48}$.

Pereyra llegó en 1810 a Arequipa acompañando al obispo Gonzaga de la Encina y retornó a su tierra cuando falleció el prelado en 1816, año en que también terminó de escribir su «Noticia».

Conocida tardíamente en 1983, a través del estudio filológico que le hiciera Enrique Carrión Ordóñez, ya era mencionada por Lostaunau ${ }^{49}, \mathrm{Barriga}^{50}, \mathrm{y}$ Zegarra Meneses ${ }^{51}$.

$\mathrm{Su}$ autor se ocupa primero de realizar una breve descripción de la ciudad y las características de sus habitantes; para elaborar luego una relación de las provincias de Arequipa. A través de ella muestra el estado en que se encontraba la Iglesia en ese momento, ocupándose incluso de algunas ceremonias y prácticas religiosas como la Reseña, la Colecta, entre otras.

Hace referencia a algunas obras de los obispos Aguado, Chaves de la Rosa y Gonzaga de la Encina; pero no se ocupa mayormente de los prelados.

Don Guillermo Galdos le observó algunos equívocos y deslices, además de sus juicios que califica de poco edificantes y progresistas llenos de prejuicios y simpatías político-religiosos. Pero que con todo - dice- es un trabajo utiliza-

48 Dice Enrique Carrión Ordóñez en «La lengua en un texto de la Ilustración»: «Su importancia es menor que las de otras descripciones contemporáneas... Pero el momento que vivía la ciudad está considerado como uno de los más importantes de su historia» Lima, P.U.C.P. 1983, p. 9.

49 Alejandro LOSTAUNAU, «El desconocido manuscrito de Pereyra y Ruiz sobre Arequipa», en: Fénix 9 Biblioteca Nacional del Perú. Lima, 1946.

50 Víctor M. BARRIGA, «Un nuevo libro sobre la historia de Arequipa». en: El Deber. Arequipa 8-IV-1946.

51 Guillermo Zegarra MEneses, Arequipa, en el paso de la Colonia a la República. (1973).

Fundaciones Hispanas

Hispania Sacra 57 (2005) 
ble, esquemático y con algunos aportes de interés, precisa por tanto de una revisión crítica ${ }^{52}$.

Cita pocas fuentes que son Hipólito Unanue, Juan D. Zamácola, Tadeo Haenke, Tomás de Iriarte, Gregorio Funes, Espinosa el Lunarejo y san Agustín. Buena parte de su información sobre Arequipa procede al parecer del cura Zamácola.

Quizás lo más interesante de su obra sea la colección de dibujos que realizara para ilustrarla.

\section{e) «Fragmentos para la Historia de Arequipa» del Deán Valdivia}

Juan Gualberto Valdivia, «el Deán Caudillo» como lo denominara Guillermo Quedas, fue otro de los estudiosos de Arequipa.

Nacido en Tambo a fines del siglo XVIII (1796-1884) fue una de las personalidades más destacadas de su tiempo. «Es un gran personaje en la historia arequipeña por su extraordinaria actividad en diversos campos protagónicos, fue sacerdote, educador, científico y político. Historiador, abogado y periodista. Su presencia resulta evidente en toda empresa orientada a servir al pueblo y a la juventud arequipeñas.... $\rangle^{53}$.

El libro es un compendio de los acontecimientos ocurridos a la llegada de Colón, pasando por la relación de los Incas, para luego proceder a realizar una descripción sucinta de Arequipa y de todas las provincias que la componían durante la Colonia, detallando su fundación; pormenorizando además, las instituciones religiosas establecidas en ella y sus dignidades.

Ha recibido fuertes críticas al estar constituida, precisamente, por fragmentos de otras obras. Mas, como apuntaba Carlos Moreyra «no puede ser enjuiciada superficialmente y menos esta obra que es, según propia declaración, extracto de varios autores y de manuscritos antiguos y modernos que se cuida de no mencionar, pero que han quedado evidenciados al publicarse un siglo después la obra del arcediano de la catedral de Arequipa Dr. Francisco Xavier Echeverría en cuyo manuscrito entró a saco todo lo referente a la historia local» ${ }^{54}$.

Mario Arenas Figueroa señala que ues el primer libro con datos sobre la historia de Arequipa» ${ }^{55}$. En efecto, esta compilación fue la primer obra de ca-

\footnotetext{
52 G. Galdos R., Cronistas e Historiadores de Arequipa Colonial..., pp. 315-316.

53 Eusebio QUIROZ PAZ SOLDÁN, «La biografia del Deán Juan Gualberto Valdivia a los doscientos años de su nacimiento», en: Revista del Archivo Arzobispal de Arequipa, 3, 1996, p. 43.

54 Carlos MOREYRA y PAZ SOLdÁN, Bibliografia Regional Peruana..., p. 61.

55 Mario ARENAS FIgUEROA, El Deán Valdivia Símbolo de la Arequipa Republicana. Lima, Imprenta Lumbre, 1996, p. 109.
} 
rácter histórico sobre Arequipa que se imprimió en $1847^{56}$. De mediados de la decimonovena centuria es la obra del Deán Valdivia y cobra gran importancia por ser la primera en haber llegado a la imprenta ${ }^{57}$.

Para Zegarra Meneses tiene poca importancia, por su falta de originalidad y la poca coordinación de esos fragmentos ${ }^{58}$. Sin embargo, «ha ejercido muy grande influencia en el siglo XIX y aún a comienzos del XX, ya que es el primero de tal género que se publicó en nuestra ciudad, con temas arequipeños y regionales. De él han bebido la esencia del conocimiento histórico, con posterioridad a 1847, relativo a Arequipa, otros arequipeños... $)^{59}$.

Como bien señalaba el recordado doctor Guillermo Galdos: «Lo importante... es la oportunidad que se publicó y en el hecho de que sirvió de base para otros estudios y comentarios». Y agregaba «El hecho de que por más de tres cuartos de siglo se tuvieran como obra de consulta obligada, avala la oportunidad de su publicación y premia el esfuerzo de su autor por poner al alcance de los estudiosos y sobre todo de la juventud mistiana decimonónica un tratado elemental de su pasado, con fallas y todo» ${ }^{60}$.

El mismo título de la obra indica que este libro es una compilación de autores diversos, en cuya parte correspondiente a los pastores que han regido el obispado, sigue fielmente a Echeverría. No es que se trate de una copia ad pedem litterae, pero si consigna la misma información del Arcediano, aunque en otro estilo.

\subsubsection{Los Episcopologios}

Son varias las obras que se han encargado de historiar a sus obispos, antes puestos al frente de un extenso territorio, hoy el reducido ámbito de las provincias de Arequipa, Caylloma e Islay. Las hay desde la relación hecha durante el episcopado del obispo Ortega Sotomayor hasta el documentado estudio del canónigo Santiago Martínez. Algunas son breves relaciones o estudios y otras extensas historias; unas están especialmente dedicadas a recordar a estas dignidades eclesiásticas, mientras que otras, - la mayoría - forman parte de

56 Juan Gualberto VALDIVIA, Fragmentos para la Historia de Arequipa extractados de varios autores y manuscritos antiguos y modernos y de las narraciones de los contemporáneos. Arequipa, Imprenta Mariano H. Moreno, 1847.

57 Con ocasión de cumplirse el Bicentenario de su nacimiento en 1996 se hizo una reedición de sus obras.

58 Guillermo ZegarRa MENESES, Arequipa, en el paso de la Colonia a la República..., p. 141.

${ }^{59}$ Guillermo GALDOS RODRÍGUEZ, «El Deán Valdivia ante la historiografia arequipeña». en: Revista del Archivo Arzobispal de Arequipa, 3 Arequipa, 1996, pp. 136.

60 Ibídem, pp. 137-138.

Fundaciones Hispanas

Hispania Sacra 57 (2005) 
obras escritas en torno a Arequipa. Al primer grupo corresponden las ya estudiadas relaciones de Travada, Echeverría, Zamácola y Valdivia. En tanto que al segundo, pertenecen las obras de Polo, Cateriano y Martínez.

Cada uno de estos autores historia la vida y el desempeño episcopal de los obispos que hubo hasta la fecha en que escribieron - a excepción de Cateriano- sus respectivas obras.

En este caso consideramos sólo a los estudios dedicados específicamente a los prelados. El de José Toribio Polo de 1854, de Mariano Ambrosio Cateriano en 1908 y finalmente de monseñor Santiago Martínez de $1933^{61}$.

\section{a) Los Apuntes de Juan Domingo de Zamácola y Jáuregui}

El sacerdote de origen vasco Juan Domingo de Zamácola y Jáuregui, (1746-1823) cura de Cayma durante largos años, fue autor de varios escritos de carácter histórico, entre los cuales se encuentra una relación de los obispos mistianos.

Este opúsculo ha recibido variedad de títulos; en la relación de sus obras que hiciera Cateriano figura como «Erección de la iglesia Catedral de Arequipa y datos biográficos de los señores obispos que la han regido», mientras que Galdos la denomina «Serie cronológica de los Iltmos. Obispos que han gobernado la Iglesia de Arequipa». Y, aparece como «Biografías de los señores obispos...» en la edición que hiciera la Revista Católica en $1878^{62}$.

Asimismo, esta relación y su «Descripción pasajera pero verídica de Arequipa» fueron impresas como «Apuntes para la historia de Arequipa» en 1888. Es por eso que dice el padre Antonio Unzueta OCD: «Son dos escritos perfectamente diferenciados; cada uno lleva su título y prefacio propios. Pero el au-

61 Dante Zegarra López en su «Diccionario histórico biográfico de Arequipa» (2002) ha hecho una biografia de los obispos Manuel Segundo Ballón (Fascículo $\mathrm{N}^{\circ}$ 2, p. 23-24), Juan de la Cruz Calienes (fasc. $\mathrm{N}^{\circ} 4$, p. 61), José Sebastián de Goyeneche (fasc. $\mathrm{N}^{\circ} 12$, pp. 188-190), Mariano Holguín (fasc. $\mathrm{N}^{\circ} 14$, pp. 214-215), Leonardo J. Rodríguez Ballón (fasc. $\mathrm{N}^{\circ}$ 25, pp. 396-397), Luis Sánchez Moreno Lira (fasc. $N^{\circ} 26$, p. 412), Fernando Vargas Ruiz de Somocurcio (fasc. $N^{\circ} 29$, pp. 460-461), la del designado obispo Juan Manuel Vargas (fasc. $\mathrm{N}^{\circ} 29$, p. 463), y de los obispos auxiliares José Lucas Barranco (fasc. $\mathrm{N}^{\circ} 2$, pp. 25-26) y Juan Manuel Moscoso y Peralta (fasc. $\mathrm{N}^{\circ} 19$, pp. 295-296).

62 Juan Doming. ZAMÁCOLA Y JÁUREGUI, «Biografías de los señores obispos que han gobernado la diócesis de Arequipa, desde la fundación de esta iglesia catedral, por bula de Su Santidad Paulo IV, de agosto de 1609, hasta 1827, escritas por...» en: Revista Católica Arequipa, 1878. Zamácola es también autor de Vida de Monseñor Manuel Abad Illana. Obispo de Arequipa, 1793. Universidad Nacional de San Agustín. Arequipa, Centro de Estudios Arequipeños, 1997. 
tor quiso unirlos en una única obra por tener ambos un denominador común: Arequipa» ${ }^{63}$.

La más conocida de las dos ediciones es la realizada en 1888, por el entonces cura del Sagrario José María Carpenter, hecha en la imprenta de La Bolsa y consta de 96 páginas.

«Biografías de los señores obispos que han gobernado la diócesis de Arequipa, desde la fundación de esta iglesia catedral, por bula de Su Santidad Paulo IV, de agosto de 1609 , hasta 1877 , escritas por...» es como titula la relación publicada por la Revista Católica a lo largo del año $1878^{64}$.

Como observamos presenta un error al indicar que la relación de diocesanos comprende hasta 1877 cuando debe de ser 1823, en que fue concluida, año también de la muerte del autor.

La edición de 1888 ha sido duramente criticada por Carlos Moreyra Paz Soldán en su «Bibliografía Regional Peruana», donde dice: "Al término de estas biografías aparecen cuatro más de los prelados sucesores de Goyeneche, indudablemente redactados por el señor Carpenter aunque no se menciona en el texto. Este no es el único reparo que, desde el punto de vista bibliográfico, cabe hacer al editor, pues, en varias partes se advierten intercalaciones escritas por otras plumas e igualmente, en la portada, junto al título se designa el año 1804 , como fecha del manuscrito, lo cual está en contradicción con lo declarado por el propio autor al final de la biografía del obispo Goyeneche 'que con ella termina su labor' señalando el 3 de mayo de $1823 \|^{65}$.

Como bien señala Moreyra «los apuntes biográficos de los obispos son antecedidos por el recuerdo de las vicisitudes y demoras que sufrió la ciudad, antes que la erección del obispado tuviese efecto, por la oposición del obispo del Cuzco... ${ }^{66}$ Escribe Cabrera Valdés: «Sus noticias referentes a la fundación y primera edad de Arequipa, son deficientes. En cambio, las relativas a la época en que vivió son preciosas» ${ }^{67}$.

Por su parte, Zegarra Meneses observa que sus obras «se hallan escritas con un estilo llano, escueto, objetivo, sin mayor vuelo ni detenimiento en la inves-

63 Antonio UnZUeta ECHEVARRÍA, Juan Domingo de Zamácola y Jáuregui y su obra social, cultural y literaria en el Perú (Siglo XVIII). Vitoria-Gasteiz, Gobierno Vasco, 1992, p. 135.

${ }_{64}^{6}$ REVISTA CATÓLICA, № 16 . Arequipa, 19 de enero de 1878, p. 43. El doctor Alejandro López de Romaña, presidente de la Hermandad del Señor San José, institución que a través de su sección de Prensa y Propaganda, editaba esta revista, reconocía la importancia que para la historia de Arequipa y del Perú en general, tenían los manuscritos de Zamácola.

65 Carlos Moreyra y PAZ SOldÁn, Bibliografia Regional Peruana (Colección Particular). Lima, Librería Internacional del Perú, 1967, p. 65.

66 Carlos MOREYRA y PAZ SOLDÁN, Bibliografia Regional Peruana..., Ibídem.

67 L. CABRera VAldÉs, Documentos Primitivos..., p. 191. 
tigación o el análisis; pero con un don de claridad, precisión y síntesis realmente admirables. Sus cuadros y relatos más hacen pensar en un escritor del día, que sabe aquilatar el valor del tiempo... Y más que un historiador porque no ahondó mayormente en el pasado, fue un cronista porque su enfoque fue el presente» ${ }^{68}$.

Francisco Mostajo, refiriéndose a Zamácola escribía: «es uno de los padres de su historia, (de Arequipa) con Travada y con Echeverría. Aquel imaginativo y gongórico, éste bien documentado y congruente, y el párroco de Cayma, discreto, sobrio y veraz. Fue muy amigo de Echeverría y ambos tuvieron a Travada como mentor para sus biografías diocesanas, ... Echeverría historió lo pasado y Zamácola, salvo esas biografías, prefirió generalmente, historiar lo contemporáneo» ${ }^{69}$.

Una detenida revisión de la relación elaborada por el notable cura de Cayma, nos permite apreciar que se abstuvo de mencionar los autores a los que recurrió en su búsqueda. Para Galdos: su más importante fuente «es, evidentemente, 'El suelo de Arequipa...' de Travada. Y agrega: «la influencia más notable..., proviene también de aquella primera historia arequipeña, pozo de cuyas cristalinas aguas bebieron todos los historiadores diocesanos del Obispado. Zamácola, como Echeverría, agregó de su propia cosecha las biografías que era menester para actualizar la relación cronológica de los prelados» ${ }^{70}$.

También entre sus fuentes están las de tipo oral; así en el caso del obispo Bravo del Rivero menciona: «Fue sufrido, que me contó un familiar suyo, hombre de toda verdad, que en una ocasión toleró con la mayor paciencia, los atrevimientos de un eclesiástico particular... $\rangle^{71}$.

Echeverría y Zamácola escribieron contemporáneamente, desconocemos si intercambiaron información, pero debieron consultar las mismas fuentes, aunque las del segundo, parecen limitarse a las de carácter religioso, en tanto que Echeverría consultó también el archivo del municipio y de algunos escribanos.

68 Guillermo ZEGARRA MENESES, Arequipa, en el paso de la Colonia a la República..., p. 134.

69 Francisco MOSTAJO, «Páginas de Cayma. Elogio de Zamácola». en: Eusebio QUIROZ PAZ SoldÁN, y Álvaro EsPINOZA DE LA BORDA, (Compiladores) Francisco Mostajo. Antología de su obra..., Tomo II, p. 112.

70 G. Galdos R., Cronistas e Historiadores de Arequipa Colonial..., p. 151-152.

71 Revista CatóliCA, N42. Arequipa, 6 de julio de 1878, p. 12. 
b) José Toribio Polo y sus «Apuntes sobre la historia eclesiástica de Arequipa» $^{72}$

José Toribio Polo fue un historiador de la segunda mitad del siglo XIX y los primeros años del XX. De «fiel y genuino continuador de nuestros historiógrafos coloniales» lo calificó Riva Agüero ${ }^{73}$; agregando que lo atrajo de preferencia las antigüedades eclesiásticas. Porras, por su parte, afirmaba que fue «autor de pacientes ensayos sobre historia eclesiástica» ${ }^{74}$.

Nació en Ica en 1841, radicándose luego en Lima, donde estudió, entre otros, en el seminario de Santo Toribio, siguiendo los cursos de filosofía escolástica e historia de la Iglesia. Dividió sus ocupaciones entre la enseñanza, la historia y el archivo; integró también la burocracia estatal, desempeñando diversos cargos dentro de ella. Falleció en 1918.

Polo investigó sobre variados temas de la historia peruana. Colaboró asiduamente en el Boletín de la Sociedad Geográfica de Lima, de la que fue miembro, sobre temas de historia económica y religiosa ${ }^{75}$. Como muchos investigadores de su generación «prefirió el género biográfico orientado a los personajes eclesiásticos» ${ }^{76}$. Polo reunía los materiales para la historia de la Iglesia Peruana, principal tarea de su vida, según Riva Agüero ${ }^{77}$.

A su formación y entorno familiar muy ligado a la Iglesia corresponde su inclinación a temas eclesiásticos. «Polo frecuentó siempre con amor los anexos y dependencias de catedrales criollas, y gastó buena parte de su vida entre los severos infolios de las bibliotecas episcopales y el ambiente polvoroso de los archivos diocesanos $\rangle^{78}$.

Originalmente los «Apuntes sobre la historia eclesiástica de Arequipa», habrían aparecido en el diario capitalino La Sociedad el año $1871^{79}$. Riva

72 José TORIBIO POLO, Apuntes sobre la historia eclesiástica de Arequipa. en: Documentos Literarios del Perú. Lima, Imprenta del Estado, 1877. Tomo XI.

73 José de la Riva AGÜERO, «D. José Toribio Polo». en: Mercurio Peruano, Año I, Vol. I, N². Sanmarti, Lima, 1918, p. 125.

${ }^{74}$ Raúl PORRAS BARRENECHEA, Fuentes Históricas Peruanas (Apuntes de un curso universitario). Lima, Juan Mejía Baca \& P.L. Villanueva Editores, 1954, p. 263.

75 Raúl RIVERA SERNA, Historia de la historia..., p. 305.

76 Joseph Dager afirma esto en base a que de diez artículos que publicó en la Revista Histórica, 6 corresponden a biografias y de ellas 4 son de clérigos. Joseph DAGER ALVA, «José Toribio Polo y la Revista Histórica». en: Revista Histórica, Tomo XXXIX. Academia Nacional de la Historia, Lima, 1999 p. 303.

77 José de la RIVA AgüEro, D. José Toribio Polo..., p. 129.

78 Ibídem, p. 215.

79 Así señalaba el coronel Manuel Odriozola en la advertencia que antecedía al estudio en el tomo XI de sus «Documentos Literarios del Perú», p. 315.

Fundaciones Hispanas

Hispania Sacra 57 (2005) 
Agüero decía que en «El Ciudadano, periódico que editó en Huaraz ese año, los publicó por primera vez, y luego los reprodujo ampliados en Lima en dos oportunidades ${ }^{80}$.

José Toribio Polo dio inicio a su estudio con unos breves acápites sobre la descripción de la ciudad, etimología de su nombre, fundación, títulos, erección de la diócesis, extensión, catedral y cabildo eclesiástico.

Su relación se compone de veintiún prelados desde la erección del obispado hasta el que se desempeñaba en ese momento.

En la edición de Odriozola se ha adjuntado al texto la crítica que realizara sobre la obra Mariano Ambrosio Cateriano, que suscitó una polémica con el historiador iqueño y que a la vez sirviera a éste para corregir algunos de los errores en que incurrió ${ }^{81}$. Esta discusión fue calificada de «corta y serena» por Riva Agüero ${ }^{82}$.

«Polo concilió con características propias los enfoques producidos por los historiadores arequipeños, 'Primitivos' y 'Modernos', en el tratamiento del pasado eclesiástico de la Blanca Ciudad» ${ }^{83}$. Basaba sus asertos en autores que consultó en sus investigaciones «cuya sola relación nos permite conocer a los historiadores que en el siglo XIX servían de obligada fuente de consulta a los estudiosos dedicados al conocimiento del pasado arequipeño» ${ }^{84}$. Pudo así, armar su relación.

Los autores que menciona son Travada, González Dávila (Teatro eclesiástico de Indias), Antonio Alcedo (Diccionario histórico geográfico de las Indias Occidentales), Solórzano y Pereyra (Política Indiana); cronistas como Valera, Calancha, Torres, Meléndez, Córdova, Remón, y Salmerón; y escritores posteriores como Unanue y Valdivia. Como podemos apreciar Polo se valió de fuentes de gran importancia pero de carácter secundario.

$\mathrm{Su}$ análisis nos lleva a afirmar que la criticada obra de José Toribio Polo habría tenido como modelo a Travada, pero con una estructura parecida a la relación de 1649 .

\footnotetext{
80 José de la RIVA AgÜERo, D. José Toribio Polo..., p. 129.

81 Con el título de «Rectificaciones históricas» Mariano A. Cateriano escribió en el periódico La Bolsa un artículo haciendo varias observaciones al escrito de José T. Polo. Este aceptó los juicios del historiador arequipeño pero según manifestaba «cumple a mi deber manifestar la causa de estos: y creo alcanzaré a probar que, en ciertos casos, no soy yo el que ha incurrido en error, sino mas bien mi ilustrado crítico». Aludía Polo a que en la reimpresión de sus «Apuntes» se había omitido consignar el 'Catálogo' de obras consultadas lo cual habría ayudado a conocer el origen de sus asertos.

82 José de la Riva AgÜero, D. José Toribio Polo..., p. 129.

83 V. SÁNCHEZ MORENO, Arequipa Colonial..., p. 275.

84 Ibídem, p. 276.
} 
Cateriano le formuló diez observaciones que Polo señaló como causa la distinta interpretación que hicieron ambos estudiosos de varios hechos. Se basaban en la inclusión de algunos nombres en la relación, asuntos de competencia jurisdiccional, litigios, fechas y lugares.

Polo, a pesar de aceptar algunos errores, mantuvo su posición en otros, motivando una réplica por parte de Cateriano, en la que ponderaba su franqueza y desprendimiento.

El mayor mérito de José Toribio Polo creemos que se encuentra en haber dado a conocer a los prelados arequipeños a nivel nacional, complementando la versión de Valdivia que era la única conocida hasta ese momento.

c) Mariano Ambrosio Cateriano y sus «Memorias de los Iltmos. Srs. Obispos de Arequipa» ${ }^{85}$

Arequipeño de nacimiento, Cateriano fue periodista, docente, magistrado, historiador y escritor que viviera entre dos siglos (1829-1915), siendo testigo y actor de muchos acontecimientos históricos, de algunos de los cuales se ocupa en sus obras.

Como un clásico de la historia eclesiástica arequipeña lo ha reconocido el historiador Eusebio Quiroz, por revelarse en su obra como un estudioso comprometido con sus ideas católicas y con su trabajo historiográfico. ${ }^{86}$ Estuardo Núñez resalta su producción intelectual de tipo religioso y social, entre las que es fundamental «Memorias de los Obispos de Arequipa». ${ }^{87}$

Para Moreyra se «revela en el autor un profundo sentido religioso que se solaza en las virtudes de los hombres que empuñaron el báculo para conducir la grey arequipeña, así aparezcan sombras humanas en su carácter y destino». Y agrega: «el autor relata vidas puestas al servicio de la fe con vigor de estilo, severa investigación y fervor de creyente. Es justo señalar que se trata de una obra de calidad, de sello personal.... $\rangle^{88}$

${ }^{85}$ Ha alcanzado dos ediciones, la primera de 1908 y en 1998 la Universidad de San Agustín de Arequipa realizó una edición que compila muchos de los trabajos de Cateriano, entre ellas la «Memoria...».

${ }^{86}$ Eusebio QUIROZ PAZ SOLDÁN, «Mariano Ambrosio Cateriano: Un clásico de la historia eclesiástica arequipeña». en: Revista del Archivo Arzobispal de Arequipa, 5, 1998-2000. Script, Arequipa, 2001, p. 155.

87 «Estuardo Núñez, Mariano Ambrosio Cateriano y sus Tradiciones arequipeñas». en: Tradiciones de Arequipa o Recuerdos de Antaño. Lima, Librería Studium, 1973, p. 8.

88 Carlos MOREYra y PAZ SOLdÁn, Bibliografia Regional Peruana..., p. 44.

Fundaciones Hispanas

Hispania Sacra 57 (2005) 
La importancia de este libro dentro de la producción historiográfica de Cateriano, es excepcional dice E. Quiroz quien, citando a Sánchez Moreno, señala que este libro sintetiza el sentido de sus inquietudes históricas. Para el doctor Quiroz, las «Memorias», resultan ser los Recuerdos de los obispos, hechos por un historiador ${ }^{89}$ «Fue el primer laico - dijo Mostajo- que se atrevió a los archivos catedralicios, porque no escribió de segunda mano» ${ }^{90}$.

A diferencia de otros autores, la relación de obispos que proporciona Cateriano, no incluye los prelados que se desempeñaron hasta el momento de la publicación de la obra en 1908; sino que termina con Juan Ambrosio Huerta, quien murió en 1897, es decir, detiene su estudio a fines del siglo XIX ${ }^{91}$.

Su motivación al escribir este libro fue «dar a conocer..., algunos escritos que salieron de la pluma de esos egregios prelados, como pastorales, edictos, informes, cartas que, inéditos y desconocidos hasta hoy, habrían desaparecido..., entre el polvo o consumidos por la polilla», según anotaba. ${ }^{92} \mathrm{La}$ idea que tenía sobre la historia era que se trataba del recuerdo crítico de personajes ya desaparecidos.

Señalaba como sus fuentes a Travada, Zamácola y Valdivia; al parecer, ignoraba la existencia de Echeverría. Además, la Guía del Perú de Unánue, el Diccionario histórico biográfico de Mendiburu, aparte de monseñor Tovar y sus «Apuntes para la historia eclesiástica del Perú». Pero también consultó fuentes de carácter primario que se evidencia a lo largo de la obra.

Sus obras fueron reeditadas en 1998 en un volumen donde se reunieron la mayor parte y lleva un estudio preliminar del ya citado doctor Quiroz Paz Soldán.

\footnotetext{
89 Eusebio Quiroz PAZ SoldÁN, Mariano Ambrosio Cateriano..., p. 145.

90 Francisco MOSTAJO, Elogio de los historiadores de Arequipa que fueron catedráticos de la Universidad Nacional de San Agustín. En: Eusebio QUIROZ PAZ SOLDÁN, y Álvaro ESPINOZA DE LA BORDA, (Compiladores) Francisco Mostajo. Antología de su Obra..., Tomo VI, p. 71

91 Mariano Ambrosio CATERIANo, Memorias de los Ilustrísimos Señores Obispos de Arequipa, desde la erección de esta iglesia hasta nuestros días. Tipografia Quiroz, Arequipa, 1908 p. 275. Indicaba como motivo de esta abstención: «no creemos sea de nuestra competencia ocuparnos de estos dos dignísimos prelados (Ballón y Holguín) que aun no han pasado del catálogo de los vivos a las columnas de la necrología. Por esto, no se hallan aún bajo el dominio de la historia ni podemos todavía someterlos a su fallo, pues aquella principia donde termina la vida del hombre cuyos hechos se trata de reseñar y de estudiar».

${ }_{92}$ Ibídem, p. I.
} 


\section{d) «La Diócesis de Arequipa y sus Obispos» del Arcediano Santiago Martínez}

Este episcopologio lleva el título «La Diócesis de Arequipa y sus Obispos» ${ }^{93}$, escrito en 1933 por el arcediano Santiago Martínez y que junto con «La Catedral de Arequipa y sus capitulares» del mismo, es el más documentado sobre el tema eclesiástico de los realizados hasta la fecha. En anterior oportunidad llamábamos la atención sobre la necesidad de realizar una detenida comparación entre las obras de Cateriano y Martínez, para poder determinar con precisión sus aportes y la utilidad de sus obras ${ }^{94}$.

Santiago Martínez (1862-1947) canónigo arequipeño, autor de once libros sobre historia de Arequipa publicados entre 1925 y $1946^{95}$; además de numerosos artículos en periódicos y revistas, practicó fundamentalmente la biografía y la genealogía.

Su libro «constituye la continuación de los episcopologios dedicados a los pastores del pueblo arequipéño, iniciados por Travada y continuados por Echeverría, Zamácola y Valdivia», pero cabe agregar, teniendo a la vista también los trabajos de Polo y Cateriano, los que corrige con los documentos que pudo revisar ${ }^{96}$.

Martínez en el Prólogo de la obra escribía: «Al estudiar la Historia de los Obispos de esta Diócesis en Fernández Córdova (Travada), Zamácola, Valdivia, Mendiburu, Paz Soldán, Cateriano, \&, notamos en sus Obras, gravísimos errores, principalmente en lo que se refiere a la citación de fechas. En nuestro deseo de subsanar aquellos defectos, nos dedicamos a estudiar a los Señores Obispos que han regido esta Sede, no en los autores, sino en las fuentes, en los documentos ${ }^{97}$.

$\mathrm{Al}$ igual que Cateriano, Martínez anexa una serie de documentos para confirmar muchas de sus aseveraciones en su plan de corregir a los autores que lo antecedieron en estos estudios.

Indicaba que al no poder acceder a las fuentes primarias esos autores «fueron copiándose unos a otros». Encontraba el origen de muchos errores en el desco-

93 Basado en la obra de Martínez, el misionero franciscano español Francisco Cabré hizo un Episcopologio en su libro «Biografia del Excmo. Mons. Fr. Mariano Holguín, O.F.M. Primer Arzobispo de Arequipa» (Lima, 1959).

94 Álvaro ESPINOZA DE LA BORDA, «Entre la biografía y la genealogía: el Arcediano Santiago Martínez y su contribución a la historia de Arequipa 1862-1947». en: Revista del Archivo Arzobispal de Arequipa, 6, 2001, p. 80.

${ }_{95}$ Sobre sus obras, véase Álvaro ESPINOZA DE LA BORDA, Entre la biografia y la genealogía: el Arcediano Santiago Martínez..., p. 57-100; especialmente de la 76 a la 88.

96 Ibídem, pág. 80.

${ }_{97}$ Santiago MARTínEZ, La Diócesis de Arequipa y sus obispos. Arequipa. Tipografia Cuadros, 1933, p. V. 
nocimiento del Derecho Canónico, señalando «como la fecha del gobierno de un Obispo, la de su entrada, la de su posesión, la de su Fiat o la fecha en que los cabildos entregaban el gobierno de su Diócesis a los Señores Obispos electos, en virtud de la Cédula Real de ruego y encargo». de acuerdo a ello hacía subir su número a 27, mientras que otros estudiosos sostenían que eran $25^{98}$.

Es innegable la importancia de la obra de Santiago Martínez, el doctor Eusebio Quiroz Paz Soldán lo ha llamado «benemérito historiador de Arequipa», reconociendo la valía de sus aportes al conocimiento del pasado a través del estudio de sus hijos ilustres y de sus autoridades ${ }^{99}$.

Señalaba como sus fuentes los libros de actas capitulares, los expedientes que a los obispos se refieren, escrituras, testamentos, libros parroquiales del Sagrario, del Concejo, entre otros ${ }^{100}$. En su propósito de corregir los errores de los autores que lo antecedieron en el estudio de los Obispos, consultó fundamentalmente fuente primaria en los archivos de la localidad, lo cual le permitió elaborar una historia mucho mejor documentada.

Resulta evidente la variedad de documentación que revisó para la elaboración de su obra; sin embargo, la sola afirmación de su objeto que era el de corregir a los otros autores, prueba que los tuvo siempre a la vista, lo que le quitó originalidad y muchas veces limita.

\section{e) Otros estudios}

El doctor José Miguel de La Rosa en el número homenaje $\left(\mathrm{N}^{\circ} 386-389\right)$ a Monseñor fray Mariano Holguín que en 1929 publicó el semanario «La Colmena», escribió una «Serie de los Obispos que han regido o debido regir la Diócesis de Arequipa», en la que, como el título indica incluye a todos los favorecidos con la designación episcopal. Su relación llega a 28, y su finalidad era «reseñar, siquiera someramente, la serie de sacerdotes ilustres que han regido la Diócesis de Arequipa, reseña que por otra parte sirve para demostrar el celo y acierto que siempre tuvo la Iglesia al encomendar este importante Episcopado a personas que, por sus antecedentes demostrativos de sus méritos re-

98 Ibídem, págs. V-VI. Consigna en la mayoría de los casos, un fotograbado de cada obispo, indicando que los había tomado del cuadro de los Obispos de la Diócesis, mandado a hacer por Zamácola, que contenía en el centro la imagen de la Virgen de la Candelaria y abarcaba hasta Goyeneche. En la actualidad en la sala capitular de la catedral arequipeña se conserva una copia que comprende hasta monseñor Rodríguez Ballón y lleva como figura central a la Virgen de la Asunción.

99 Eusebio QUIROZ PAZ SOLDÁN, Mariano Ambrosio Cateriano..., p. 123.

100 Santiago MARTínEZ, La Diócesis de Arequipa..., p. V. 
ales, constituyeran una garantía de acierto en el manejo de los intereses espirituales de la grey arequipeña» ${ }^{101}$.

Se trata de una relación corta de los prelados que ocuparon o no la silla episcopal de Arequipa hasta el momento que se desempeñaba el preclaro monseñor Holguín.

El P. Rubén Vargas Ugarte, benemérito historiador jesuita, también se ocupó de los pastores arequipeños en su «Episcopologio de las Diócesis del Antiguo Virreinato del Perú, (1513-1825)» escrito en 1940, estudiando el desempeño de los prelados que ejercieron los diferentes obispados a lo largo del período colonial. Asimismo en «El Episcopado en los tiempos de la Emancipación Americana» publicado hasta en dos oportunidades (1932 y 1945); además de casos particulares, como el del obispo Gaspar de Villarroel.

Otro es el elaborado por el también jesuita P. Antonio de Egaña en la «Historia de la Iglesia en la América española», en el que a grandes rasgos se ocupa del desempeño de los diocesanos arequipenses para lo cual se vale fundamentalmente de los estudios precedentes, no sin contribuir aportando importantes datos sacados de los archivos peninsulares. Este autor, de manera acertada, se ocupa sólo de los prelados que ejercieron de manera efectiva la silla episcopal sin detenerse en los también designados.

Comprende la lista de prelados que toca, desde Rodríguez hasta Goyeneche, en la que hace referencia de los aspectos más significativos de sus respectivos episcopados.

Más recientemente el P. Enrique Fernández García S.J. en su «Perú Cristiano» ha incluido algunas consideraciones sobre los obispos arequipeños. A través de ellas podemos conocer pormenores que nos ayudan a comprender la actitud de ciertos autores para con los prelados.

Comprende desde los comienzos de la Evangelización del continente americano hasta el año 1900, es decir, en cuanto a los obispos de Arequipa se detiene en monseñor Huerta. Concuerda en considerar únicamente a aquellos que ocuparon la silla obispal. Al igual que el padre Egaña historia la vida de la Iglesia en Arequipa a través de sus obispos.

Existen historias particulares de las distintas órdenes y congregaciones establecidas en Arequipa de las que daremos cuenta en lugar oportuno.

101 José Miguel de LA ROSA, «Serie de los Obispos que han regido o debido regir la Diócesis de Arequipa». en: La Colmena, 386-389. Arequipa, 1929, sp. Una síntesis puede verse en la Biografia del Excmo. Mons. Fr. Mariano Holguin, O.F.M. Primer Arzobispo de Arequipa. Lima, 1959 escrita por el P. Francisco Cabré.

Fundaciones Hispanas

Hispania Sacra 57 (2005) 


\section{LOS OBISPOS Y LA HISTORIA DE LA IGLESIA EN AREQUIPA}

Cabe aclarar que hacemos mención a los «Obispos de Arequipa» y no a los Arzobispos, debido a que durante la mayor parte de su existencia, esta circunscripción eclesiástica fue una diócesis, siendo recién elevada a arquidiócesis en 1943, durante el gobierno de monseñor Mariano Holguín. Además que los episcopologios existentes fueron elaborados antes de la mencionada elevación.

Sin contar a los arzobispos, consideramos que únicamente hubo 25 prelados que ejercieron su episcopado aunque, en algunos casos, su desempeño fuese muy breve ${ }^{102}$.

Debemos tener presente que si bien otros eclesiásticos alcanzaron la mitra de la diócesis «arequipense»; ello solo puede tenerse en cuenta para la vida de estos personajes pero no para el devenir del obispado donde nunca ejercieron funciones.

Los tres últimos Arzobispos de Arequipa, no están considerados en los episcopologios realizados hasta la fecha; es más, podemos afirmar que carecen de estudios sobre sus vidas y obras, a excepción de breves biografías ${ }^{103}$.

Sobre el número de prelados de Arequipa se han vertido una serie de opiniones que no corresponden a la realidad. El doctor José Antonio Benito, si-

102 Antonio de Alcedo en su «Diccionario geográfico-histórico de las Indias Occidentales o América», se ocupó de Arequipa en el tomo I y consigna una relación de 17 mitrados, desde Cristóbal Rodríguez hasta Miguel de Pamplona, indicando en nota al pie que entre Antonio de León y Juan de Otalora, «no hemos podido, a pesar de muchos instrumentos y libros que hemos reconocido, completar la serie de los Obispos que faltan en este intermedion. Esta lista tiene varios errores, en primer lugar incluye a fray Ignacio Garrote, cuando este dominico no alcanzó a tomar posesión, de igual manera a Juan González Melgarejo que tampoco llegó a estos lares. En cambio, no incluye a Juan Cavero de Toledo. En la obra «Geografia del Perú» de Mateo Paz Soldán, aumentada y corregida por su hermano Mariano Felipe, (París, 1862), se consigna un Catálogo de los Obispos de Arequipa que consta de 21 nombres, en el que figuran Juan de Argüelles y Juan Gonzáles Melgarejo, indicando en el caso del primero que murió sin tomar posesión; mientras que en el segundo, dice que fue promovido de Santiago en 1742 gobernando aquí hasta su muerte ocurrida en 1755. Esto es erróneo, pues no llegó a Arequipa, muriendo en Chile donde ejercía el episcopado. V.N. Benavente en su «Historia sintética de Arequipa» incluye a Cabezas Altamirano, Argüelles y González Melgarejo, haciendo un total de 28. El recordado doctor Alejandro Málaga Medina en la «Historia General de Arequipa» hizo una relación de los prelados de la época colonial.

${ }^{103}$ Una biografía sobre Monseñor Leonardo José Rodríguez Ballón fue realizada por el franciscano Guillermo Manero en la Gaceta Eclesiástica, Boletín Oficial del Arzobispado de Arequipa, Año XII, Nº71 de 1961, número extraordinario por sus Bodas de Plata Sacerdotales. Otros datos puede encontrarse en esa misma revista y en D. Zegarra, Diccionario... (2002). Sobre el arzobispo Fernando Vargas Ruiz de Somocurcio S.J. hay una breve reseña en sus Cartas Pastorales publicadas en 1996 y en el «Diccionario» de Dante Zegarra. Monseñor Juan Antonio Ugarte escribió una breve semblanza sobre Mons. Luis Sánchez Moreno Lira que fue publicada dentro de las Notas de Pastoral Litúrgica, Año 2, N6. Arequipa, abril 1996. Véase también el «Diccionario» de D. Zegarra. 
guiendo a Santiago Martínez, señala que se han sucedido 36, incluyendo los tres últimos arzobispos y algunos designados o electos pero que no llegaron a tomar posesión de la sede episcopal.

Recalcamos que consideramos solamente a aquellos que ejercieron el episcopado de manera efectiva, aunque solo fuese por muy breve tiempo. De acuerdo a ello son solamente 25 los prelados que ocuparon la silla diocesana.

Dichos obispos son:

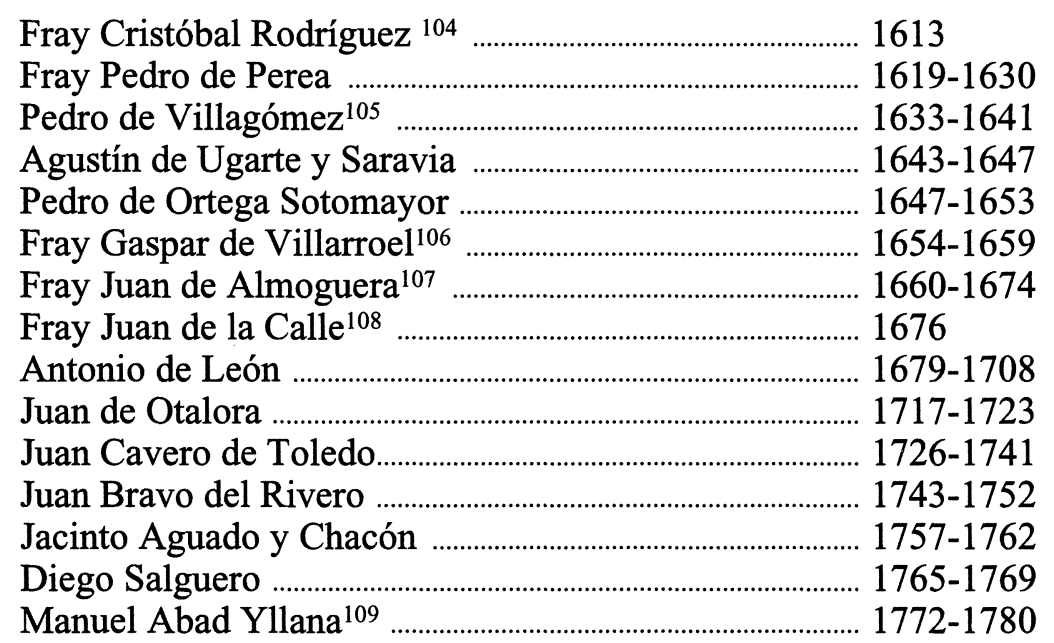

${ }^{104}$ En el N692 del semanario arequipeño «La Luz» se incluye el artículo «Los Obispos de Arequipa», sin indicar autor, en el que se toca brevemente a fray Cristóbal Rodríguez y al también dominico Juan de las Cabezas Altamirano, señalando que igualmente debe considerársele como obispo.

105 Villagómez fue estudiado en «Apuntes para la Historia Eclesiástica del Perú...» (Lima, 1873) por monseñor Manuel Tovar. Existe también la breve biografia de Carlos A. Romero bajo el título «Don Pedro de Villagómez» en el tomo XII de su «Colección de Libros y Documentos referentes a la Historia del Perú» (1919) que contenía las Exortaciones e Instrucciones acerca de la Idolatría de los indios...) cuyo autor es precisamente este prelado.

106 Sobre este preclaro obispo ha escrito una importante biografía el historiador jesuita Rubén Vargas Ugarte en 1938 que titula El Illmo. D. Fray Gaspar de Villarroel, Arzobispo de Charcas.

${ }^{107}$ En el Primer Congreso Peruano de Historia Eclesiástica fueron presentadas las ponencias de Pedro Guibovich «Evangelización e Inquisición en el siglo XVII: El caso del Obispo de Almoguera» y de Lourdes Díaz Trechuelo «Un cordobés en la sede de Arequipa: Juan de Almoguera» Cfr. La evangelización del Perú Siglos XVI y XVII. Actas del... Arequipa, 1990. Antes lo estudió Manuel Tovar en sus "Apuntes para la Historia Eclesiástica del Perú...»

108 Sobre este obispo escribió el Padre Barriga «El Ilustrísimo fray Juan de la Calle y Heredia. Obispo de Trujillo y Arequipa» en el Boletín de la Orden de la Merced. Año XIII, No7-12 Roma, 1925. Fray Pedro N. Pérez lo menciona en su Los Obispos de la Orden de la Merced en América (1601-1926) Santiago de Chile, 1926.

Fundaciones Hispanas

Hispania Sacra 57 (2005) 


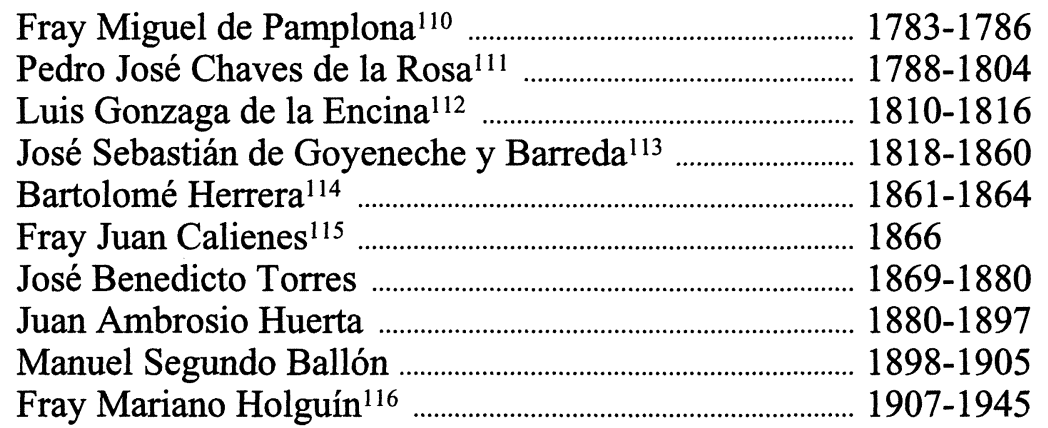

109 Juan Domingo Zamácola y Jáuregui pergeñó la Vida de Monseñor Manuel Abad Illana. Obispo de Arequipa, 1793 publicada recién en Arequipa en 1997. José Antonio Benito ha escrito: «El prelado Abad e Illana, vallisoletano ilustrado en Perú», para la revista Hispania Sacra $\mathrm{N}^{\circ} 47$ el año 1995.

${ }_{110}$ De este capuchino ha escrito Eulogio Zudaire: «Fray Miguel de Pamplona Obispo de Arequipa (1719-1792)», en: Collectanea Franciscana $\mathrm{N}^{\circ}$ 40. Instituto Histórico Cappuchino. Roma, 1970.

${ }^{111}$ Este benemérito prelado ha llamado la atención de los estudiosos, así M.A. Cateriano «Recuerdos del Illmo. Sr. Dr. Don Pedro José Chaves de la Rosa Galván y Amado, ...» (1888). En el Boletín del Museo Bolivariano ( ${ }^{\circ} 14$. Lima, 1930): el «Elogio» de Andrés Martínez, y biografias realizadas por Vicuña Mackena, Manuel de Mendiburu y una síntesis del trabajo El movimiento intelectual de Arequipa a fines del siglo XVIII y principios del XIX que Víctor Andrés Belaunde presentara a un Concurso en 1908, donde resalta su labor educativa. También está el Recuerdo histórico del presbítero Mariano de Alarcón, publicado en la Tipografia Medina de Arequipa en 1940. Del mismo año es un discurso de Luis de la Jara. Otro, «El Obispo P.J. Chávez de la Rosa» de Alejandro Málaga Medina (1975). Más reciente es la tesis de Medalit Arenas Visita de la Diócesis de Arequipa por el... 1788-1794 de 1985 .

112 Le dedicó un estudio el doctor Vladimiro Bermejo que presentó en el Simposio «La Independencia del Perú» organizado por el Instituto Riva Agüero en Lima, titulado «El Iltmo. Señor Luis Gonzaga de la Encina XVIII Obispo de Arequipa y el fidelismo del clero arequipeño», publicado en 1960, conformando el libro: La causa de la Emancipación del Perú. También está de E. Carrión Ordóñez «Pereira y el Perú» en el Boletín del Instituto Riva Agüero, donde se ocupa desde su vida en la península hasta su episcopado y muerte en Arequipa.

${ }^{113}$ Hay una voluminosa biografía escrita por Pedro José Rada y Gamio: El Arzobispo Goyeneche y apuntes para la historia del Perú, hecha en Roma por la Imprenta Políglota Vaticana el año 1917.

114 La bibliografía sobre este obispo es abundante, podemos citar de Jorge Guillermo Leguía un buen artículo como prólogo a la edición de sus Escritos y discursos (1929); Bartolomé Herrera. Educador y diplomático peruano de Oscar Barrenechea R. (1947) y Bartolomé Herrera, pensador político de Agustín de Asís (1954). La más reciente corresponde a Jorge Putnam: Fundamentos teológicos de la actuación pública de Bartolomé Herrera, 1808-1864 (2000), Ricardo Cubas: Una visión católica de la historia del Perú. El pensamiento y la labor peruanista de Bartolomé Herrera (2001), y el realizado por el doctor José A. Benito: Bartolomé Herrera, Maestro del Perú, Obispo de Arequipa (2001), quien sostiene que más de 150 intelectuales lo han estudiado.

115 Sobre su vida ha escrito J.A. Benito «Juan Calienes: Científico, educador y Obispo de Arequipa» en la Revista del Archivo Arzobispal de Arequipa, 6. Script, Arequipa, 2002.

116 Acerca de monseñor Mariano Holguín ha hecho una extensa historia fray Francisco Cabré, titula Biografia del Excmo. Mons. Fr. Mariano Holguín, O.F.M. Primer Arzobispo de Arequipa (Lima, 1959). El semanario arequipeño La Colmena editó en diciembre de 1929 un número Homenaje por 
De considerar dentro de este episcopologio a todos los eclesiásticos designados ${ }^{117}$, incrementaría su número; sin embargo, los personajes que si bien recibieron su nombramiento pero que, por diversas razones no llegaron a la sede, no podemos contarlos porque estamos tratando de la historia de la Iglesia arequipeña y no la de sus biografías.

$\mathrm{Al}$ episcopologio, debemos agregar a los prelados designados para la silla arquidiocesana. Son
Fray Leonardo Rodríguez Ballón OFM ${ }^{118}$........ 1946-1980
Fernando Vargas Ruiz de Somocurcio SJ ${ }^{119}$... 1980-1996
Luis Sánchez-Moreno Lira ${ }^{120}$................................. 1996-2004 y, recientemente:
José Paulino Ríos Reynoso ${ }^{121}$.................................. 2004.

También podemos mencionar a los obispos auxiliares que cooperaron con la labor de algunos de los prelados ${ }^{122}$.

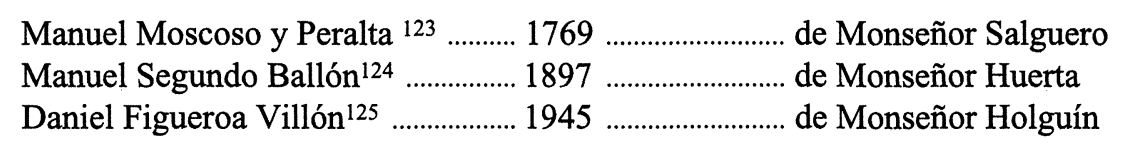

sus Bodas de Plata Episcopales, entre los autores figuran el franciscano fray Buenaventura Uriarte, el Deán Manuel N. Silva, el presbítero Domingo La Rosa, el doctor Emilio Gómez de la Torre, que abordan algunas de sus facetas. Se incluye una relación de sus cartas pastorales, discursos y exhortaciones. También el N ${ }^{\circ} 692$ de $L a L u z$ semanario de los padres dominicos de Arequipa por esa efemérides. Cuando falleció, V.A. Belaunde le dedicó una sentida semblanza publicada en el Mercurio Peruano, Vol. XXVII, N²26 de 1946. Por la elevación a metropolitana se formó una Comisión ProHomenaje que en 1946 editó en los talleres de La Colmena, un Album Homenaje a la Arquidiócesis de Arequipa y su Primer Arzobispo, en el que hay información.

117 Los que no consideramos son: Juan de las Cabezas Altamirano, Juan de Argüelles, Juan González Melgarejo y Juan Manuel Vargas.

118 Renunció en 1980. Falleció el 5 de octubre de 1992, siendo sepultado en la catedral de Arequipa.

119 Renunció cumpliendo las disposiciones del Derecho Canónico en 1995.

120 Tomó posesión del arzobispado en 1996.

121 Cuando escribíamos este trabajo el 30 de noviembre de 2003, llegó la noticia del nombramiento de Monseñor José Paulino Ríos Reynoso como nuevo Arzobispo de Arequipa.

122 Para ayudar a monseñor fray Juan Calienes fue electo como su auxiliar el mercedario fray José Lucas Barranco, el que falleció en marzo de 1866 sin haber recibido la bula de su preconización; por lo que tampoco lo incluimos dentro de la relación.

${ }^{123}$ Luego fue obispo de Córdova (Argentina) del Cusco y arzobispo de Granada en España. Sobre su vida véase Manuel de TORRES MUÑOZ, El Arzobispo Don Juan Manuel Moscoso y Peralta. Arequipa, 1950.

${ }^{124}$ Fue después promovido a obispo titular de Arequipa y Administrador Apostólico de la Arquidiócesis limeña.

Fundaciones Hispanas

Hispania Sacra 57 (2005) 
José Benavides Morriberón ${ }^{126}$ 1969-1983 de Monseñor Rodríguez Ballón Lorenzo Unfried MCCJ 127 1969-1980 de Monseñor Rodríguez Ballón Felipe M. Zalba Elizalde 128 1983 de Monseñor Vargas R. de S.

Estos son en buena cuenta los prelados que han guiado al pueblo católico arequipeño.

\subsection{Una propuesta de periodificación}

La necesidad de comprender y explicar el proceso evolutivo de la presencia de la Iglesia en Arequipa, de más de tres siglos, nos lleva a aplicar cortes en este continuum histórico. Tal periodificación, si bien arbitraria y artificial, nos permitirá superar las simples relaciones de obispos que constituyen las historias que se han hecho hasta el momento.

Si bien se han realizado varios estudios sobre la historia de la Iglesia en América en general y del Perú en particular, es necesario realizar una de orden local que refleje el devenir del pueblo cristiano en Arequipa específicamente.

El padre Antonio de Egaña S.J., dividía la historia de la Iglesia americana en tres grandes épocas en analogía con la historia universal y por la naturaleza intrínseca de los fenómenos en: Antigua (desde la implantación de la Iglesia hasta Carlos V, época de los primeros contactos y fundación de las primeras diócesis), Media (desde Felipe II hasta Carlos II, período de la casa Habsburgo de consolidación y expansión de la Iglesia), y, Moderna (desde Felipe $\mathrm{V}$ hasta la emancipación de las nuevas nacionalidades, período de la casa de Borbón) ${ }^{129}$.

Como bien señalaba este autor, esa división no siempre corresponde a la evolución de los hechos y además peca de genérica. Por otro lado, solo abarca hasta la independencia de las repúblicas americanas.

Fernando de Armas Medina en su «Cristianización del Perú 1532-1600» historia el proceso evangelizador en su primer siglo, estudiándolo por temas. ${ }^{130}$ En

${ }_{125}$ S.S. Pío XII lo hizo obispo de Huancayo una vez que Rodríguez Ballón fue elevado a la silla de Arequipa.

${ }_{126}$ Antes había sido obispo de Chachapoyas de donde renunció. Continuó como auxiliar de Vargas R. de S.

127 Fue nombrado obispo de Tarma en 1980.

128 Luego fue obispo de la prelatura de Chuquibamba, en cuyo desempeño murió en 1999.

129 Antonio de EgAÑA, Historia de la Iglesia en la América española. Desde el Descubrimiento hasta comienzos del siglo XIX. Hemisferio Sur. Madrid, Biblioteca de Autores Cristianos, 1966, pág. XXI.

130 Fernando de ARMAS MEDINA, Cristianización del Perú 1532-1600. Sevilla, Escuela de Estudios Hispano Americanos, 1953. Algo similar es la estructura del libro La Iglesia y los eclesiásticos 
cambio, el padre Fernández García lo hace de acuerdo a un criterio cronológico, haciendo cortes cada cien años, esta división secular, es más general incluso.

El padre Vargas Ugarte, presenta la particularidad que luego de dividir la historia de la Iglesia peruana por períodos de más de 50 años pero sin llegar al siglo; pasa luego a hacerlo secularmente con el XVIII y el XIX ${ }^{131}$. Algo similar ocurre con el padre Fernández que subdivide el siglo XVI en tres momentos: $1532-1552,1552-1567$ y $1568-1583^{132}$. Por su parte Marzal encuentra también tres etapas en el proceso evangelizador ocurrido en los siglos XVI y XVII al que llama de aculturación religiosa andina ${ }^{133}$.

En «La Iglesia en el Perú» el padre Klaiber se ocupa de historiar la época republicana, donde emplea un esquema interpretativo, resaltando los rasgos más característicos sin hacer cortes radicales sino cambios ambientales ${ }^{134}$, en base a lo cual divide su proceso evolutivo en seis etapas: Crisis y restauración (1821-1855), la Iglesia Militante (1855-1930), el Laicado militante (19301955), la Iglesia moderna (1955-1968), la Iglesia social-política (1968-1975) y la Iglesia social-pastoral (1975...).

Pedro Borges plantea tres criterios para estudiar la historia de la Iglesia: geográfico, cronológico y temático ${ }^{135}$. Por su parte, tratando la historia del Perú colonial Teodoro Hampe distingue tres maneras para aplicar segmentaciones en la historia: Por simple cronología, por sumarización de las esencias de una época y por teorizaciones globales ${ }^{136}$.

Resulta evidente que los acontecimientos y estructuras sufren variaciones en el tiempo, mostrando etapas reconocibles. Hasta 1609 la jurisdicción de la ciudad de Arequipa era una vicaría del obispado del Cusco; es decir, formaba parte de la estructura diocesana cuzquense; mientras que a partir de esa fecha con la creación de la diócesis se opera un cambio en su organización eclesiástica al ser desmembrada de aquella.

\footnotetext{
españoles en la empresa de Indias de Antonio YBOT LEÓN. Barcelona, 1954-1962 y la de A. NIETO VÉLEZ, La Iglesia...

131 Rubén Vargas Ugarte, SJ., Historia de la Iglesia en el Perú. Burgos, 1962. Sus cinco tomos abarcan respectivamente los períodos 1511-1568, 1570-1640, 1640-1699, 1700-1800 y 1800-1900.

132 Enrique FERNÁNDEZ GARCÍA S.J., Perú Cristiano..., p. 76.

133 Tales etapas son de Evangelización intensiva (1532-1606), de Lucha contra las idolatrías (1608-1660) y de Cristalización de la religión andina (1660-1700). Manuel MARZAL S.J., La transformación religiosa peruana. Lima, PUCP, 1988 pp. 57-61.

134 Jeffrey KLAIBER S.J., La Iglesia en el Perú. Su historia social desde la Independencia. Lima, PUCP, 1988 p. 35.

135 Pedro Borges, Historia de la Iglesia en Hispanoamérica y Filipinas. Biblioteca de Autores Cristianos. Madrid, 1992, Tomo I, p. 12.

136 Teodoro HAMPE M., «Hacia una nueva periodificación de la historia del Perú colonial. Factores económicos, políticos y sociales». En: Jahrbuch für Geschichte von ... Lateinamerikas. 29. Böhlau-Verlag, 1992, p. 49.
}

Fundaciones Hispanas

Hispania Sacra 57 (2005) 
En este sentido podemos apreciar tres etapas en la estructura eclesiástica arequipeña, una pre- diocesana dependiente del Cusco, otra diocesana con prelados propios que se encargan de su conducción y una tercera, arquidiocesana constituyéndose en una de las provincias en que ha sido dividida la Iglesia peruana. Arequipa ahora, cuenta con diócesis sufragáneas.

Asimismo, en el desarrollo de la Iglesia arequipeña, encontramos tres etapas, en cuanto a la participación de la feligresía. Hasta 1868 podemos apreciar que fueron los obispos los grandes conductores del pueblo cristiano arequipeño, desarrollando una función protagónica en su ordenamiento, mientras la colectividad es un ente más presencial, limitándose a intervenir en las diferentes funciones religiosas a través de cofradías-hermandades o en forma particular-familiar. En tanto que, a partir de ese año, si bien los prelados continuaron con su labor ayudados por el clero, los laicos comenzaron a tener cada vez mayor parte en la tarea evangelizadora y ayuda social a los más necesitados. $Y$ es desde la segunda mitad del siglo XX cuando los sectores marginales comienzan a organizarse en torno a instituciones creadas por la Iglesia que le han dado una nueva imagen y perspectiva.

Sin embargo, tales criterios son todavía muy amplios y significarían olvidar o prestar poca atención a hechos de la mayor trascendencia que han significado cambios en la marcha del pueblo de Dios en esta diócesis.

Preferimos basarnos en hechos creadores de época, distinguiendo factores (personas y hechos) que significan cambios en el proceso evolutivo de la Iglesia en Arequipa, así podemos observar: a) Llegada de la fe y predominio de los religiosos; b) Establecimiento y ordenamiento del obispado; c) Consolidación y reordenamiento; d) Debilitamiento y crisis; e) Resurgimiento y respuesta militante; y f) Modernización y nuevos desafios.

Tales elementos consideramos que son, en primer lugar, los grandes obispos: Villagómez, León, Goyeneche, Huerta y Holguín a quienes les cupo la tarea de organizar la Iglesia arequipeña y llevar adelante la tarea evangelizadora. Otros, son los sínodos diocesanos realizados y que, a diferencia de otros lugares se han dado en Arequipa tan solo en tres oportunidades: 1638, 1684 y 1883. Así como hechos extraños a la religión pero que han repercutido poderosamente en su marcha: llámese reformas borbónicas, luchas por la independencia, entre otros.

Así podemos apreciar en un primer período el establecimiento de parroquias y doctrinas con la labor desarrollada por diferentes órdenes religiosas en consonancia con las disposiciones emanadas por los prelados del Cusco. El segundo comienza con la creación del obispado que tuvo que esperar varios años para poder contar con una debida organización, obra del obispo Villagómez. Dicha organización sin embargo, necesitó de ajustes y correcciones que 
fueron realizadas por el obispo León en el sínodo de 1684 y que significa un nuevo corte en la historia eclesiástica arequipeña. En cuanto al cuarto, resulta evidente que la injerencia del poder político tanto monárquico como republicano ocasionó un sensible debilitamiento y crisis de la Iglesia que solo pudo ser superado gracias al accionar y prudencia del obispo Goyeneche. Un quinto período, de resurgimiento, comienza paradógicamente en 1868 cuando Arequipa se encontraba en ruinas a consecuencia de un terremoto pero que, debido a la acción conjunta del clero encabezado por sus obispos y la colectividad, la diócesis se convirtió en la abanderada de la defensa de la fe. Y finalmente, un último período en el que se han producido profundos cambios en la sociedad arequipeña por lo que la Iglesia ha debido modernizarse para superar los problemas y desafíos que se le han presentado.

\subsubsection{Llegada de la fe.y predominio monacal (1539-1609)}

Constituido por el tiempo comprendido desde la llegada de los españoles a los valles arequipeños hasta la creación del obispado. Caracterizado por la dependencia que tenía la ciudad y sus términos con el obispado del Cusco, cuyos pastores eran los que normaban su desenvolvimiento. Epoca de predominio de la violencia, imposición e improvisación de los evangelizadores, en un primer momento, para luego organizarse con método y orden.

La presencia de los prelados se dio a través de vicarios y quizás de algún visitador, punto este último que no podemos confirmarlo dada la destrucción del primitivo archivo eclesiástico arequipeño en el incendio ocurrido en la catedral en 1620.

Debió regirse la entonces vicaría siguiendo lo estipulado en las constituciones emanadas de los sínodos celebrados por los obispos Sebastián de Lar$\operatorname{taun}^{137}$, Gregorio de Montalvo en $1591^{138}$ que anuló las del anterior, y las de Antonio de la Raya de $1601^{139}$.

En el tercer sínodo cuzquense se redactaron 41 constituciones, siguiendo la línea del anterior sínodo del obispo Moltalvo ${ }^{140}$, que velaba por el cumplimiento de los preceptos religiosos, la administración de los sacramentos, la conducta de los sacerdotes, entre otros.

137 El 4 de julio de 1578 el ayuntamiento cuzqueño nombró dos capitulares y un letrado para que en su nombre asistiesen al sínodo que trataba de celebrar el obispo. Diego de ESQUIVEL Y NAVIA, Noticias cronológicas de la gran ciudad del Cuzco..., Tomo I, p. 239.

138 Fueron dadas a conocer el 29 de septiembre y el 6 de octubre de ese año. Ibídem, Tomo I, pág. 262.

139 Se publicaron el 8 de febrero de dicho año. Ibídem., Tomo II, p. 1.

140 Antonio de EGAÑA, Historia de la Iglesia en la América española..., p. 310. 
Fernando de Mendoza, jesuita, fue el siguiente prelado designado para el Cusco. Envió visitadores a las provincias de Condesuyos, Collaguas, Camaná, Arica y Moquegua ${ }^{141}$. Durante su episcopado se produjo la desmembración de Arequipa de su diócesis.

Este período coincide más o menos con la primera etapa de la evangelización planteada por el padre Manuel Marzal S.J. ${ }^{142}$ a la que llama etapa de la Cristianización Intensiva desarrollada a lo largo del siglo XVI, pero considera que arranca una vez finalizadas las «Guerras Civiles» hasta la muerte del arzobispo santo Toribio de Mogrovejo en 1606.

Momento de neta predominancia de las órdenes monásticas que desarrollaron la labor misionera ante la escasez de sacerdotes seculares y la falta de seminarios para su formación.

Destacaron en este campo tanto dominicos como franciscanos. Los primeros se hicieron cargo de las doctrinas de la Chimba (Yanahuara, Cayma, Tiabaya), Chiguata y Paucarpata en el valle de Arequipa y Atiquipa en Camaná; mientras que los frailes de la orden seráfica estaban en el valle del Colca en: Chivay, Yanque, Coporaque, Achoma, Tuti, Sibayo, Callalli, Tisco, Lari, Madrigal, Ichupampa, Maca, Pinchollo, Cabanaconde, Canocota, Huambo y Caylloma. De suerte que en 1560 establecieron conventos en Yanque y Callalli ${ }^{143}$, quedándose finalmente al frente de los ocho primeros pueblos. Los mercedarios tenían Characato y sirvieron algún tiempo en Vítor. Luego los Jesuitas que cobrarían creciente importancia.

Sin embargo, para poder llevar a cabo su misión cristianizadora la Iglesia requirió organizarse en torno a los obispados, como bien señala Rafael Sánchez-Concha ${ }^{144}$. Su organización corrió a cargo de los prelados en su calidad de pastores del pueblo de Dios.

\subsubsection{Establecimiento y ordenamiento del obispado (1609-1676)}

Luego de la frustrada creación del obispado en 1577, Arequipa fue elevada a diócesis en 1609, realizándose la demarcación de su jurisdicción en 1614. Asimismo se produjo una serie de enfrentamientos entre la autoridad episcopal

\footnotetext{
141 Ibídem, p. 319.

142 Manuel MARZAL S.J., La transformación religiosa peruana. Lima, PUCP, 1988 p. 57.

143 Julián HERAS OFM, «Los Franciscanos en el valle del Colca (Arequipa) dos siglos y medio de evangelización». en: La evangelización del Perú Siglos XVI y XVII. Actas del Primer Congreso Peruano de Historia Eclesiástica, Arequipa, 1990, p. 382, 390.

144 Rafael SÁNCHEZ-CONCHA, «Virreinato: Instituciones y vida cultural». en: Historia del Perú. Barcelona, Lexus Editores. 2000, p. 593.
} 
y los miembros de su cabildo catedralicio, lo que sería finalmente superado con la nueva erección de la catedral, la dación de constituciones sinodales y la elaboración de la Regla Consueta de la Catedral.

Empieza la serie de obispos de Arequipa, el dominico fray Cristóbal Rodríguez quien murió en Camaná cuando se hallaba en camino a su sede sin llegar a recibirse. Aquí surge un problema; pues, nosotros no consideramos en la relación episcopal a Juan de las Cabezas Altamirano, Juan Argüelles y Juan González Melgarejo precisamente por no haberse recibido. En este caso pese a tampoco haberlo hecho Rodríguez al llegar a los términos de su diócesis y comenzar a realizar su labor pastoral, consideramos que si lo fue, pues ejerció el cargo.

En la Relación de 1649 solamente se menciona su lugar de nacimiento. Travada por su parte señala ese mismo dato (Salamanca), sus padres, su carrera eclesiástica dentro de la orden dominica, la fecha de su elección como obispo de Arequipa ( 7 de octubre de 1611) y las circunstancias de su muerte en Camaná. Afirma Travada que como no había sido erigido el cabildo «se resolvió le sucediese en la jurisdicción el obispo más cercano, que fue el del Cuzco en que quedó no por modo de debolución, sino de conserbación ${ }^{145}$.

Por su parte Echeverría aporta datos precisos sobre su ordenación, designación episcopal y el poder que otorgara al cura Pedro Alonso Bajo quien tomó posesión en su nombre. Dice además: «Aún no entró en Acarí, cuando comenzó a visitar y a celebrar el Sacramento de la Confirmación a los naturales que no habían conocido Obispo» ${ }^{146}$. Este es precisamente el punto en el que nos basamos para considerarlo dentro de los prelados arequipeños. Echeverría también cita la fecha de su muerte y la del traslado de su cuerpo al nuevo panteón en 1738.

La información que proporciona Zamácola es la misma que los anteriores no aportando mayores datos, e incluso obviando las fechas ${ }^{147}$.

El Deán Valdivia, en cambio, hace una síntesis de la información que proporciona Echeverría, pues recoge el dato de la visita que comenzó a hacer y de las confirmaciones que iba realizando. Cita también la fecha de su muerte y la del traslado de sus restos. Polo se limita a indicar las fechas de su elección y toma de posesión por poder, y a que murió en Camaná, «sin hacer su entrada solemne».

145 Ventura Travada, Suelo de Arequipa convertido en Cielo. [1750] Lima, Ignacio Prado Pastor, 1993 p. 256. Sobre el cabildo véase Santiago MARTínEZ, La Catedral de Arequipa y sus capitulares. Arequipa, 1931.

146 Memorias para la Historia de Arequipa...., Tomo IV, p. 201.

147 REVISTA CATÓliCA. №24 Arequipa, 2 de marzo 1878, p. 163. 
Mariano Ambrosio Cateriano incrementa los datos sobre este obispo, cuando dice que escribió el «Oficio de Santa Inés del Monte Poticiano» en buen latín y corrección de estilo. El arcediano Santiago Martínez menciona los preparativos acordados por el cabildo de Arequipa para su recibimiento, corrige a Travada y a Zamácola el año de la muerte del obispo y rectifica el aserto de Travada sobre la vuelta de la jurisdicción al Cuzco, probando que fue el Arzobispo de Lima quien se hizo cargo de su gobierno ${ }^{148}$.

Sobre el religioso agustino fray Pedro de Perea, la mayoría de los autores hacen hincapié en el pleito que sostuvo con los canónigos. El informe de 1649 se limita a proporcionarnos algunos datos personales, el tiempo de ejercicio de su episcopado y a que escribió el libro «Certeza de la pureza de la Virgen en su concepción» ${ }^{149}$. Travada, en cambio, centra su atención en el mencionado conflicto por lo que monseñor Perea viajó a Lima, donde murió.

La información de Echeverría es concisa pero con abundantes datos sobre su persona y carrera eclesiástica. Asimismo los diferentes actos de su episcopado que se centraron en las visitas que realizó, creación de curatos y obras de caridad; además de su fallida erección catedralicia. Los litigios que tuvo con los canónigos es el tema al que Zamácola da principal atención y menciona someramente la instalación del seminario, la erección de la Catedral y el comienzo de su construcción. J. G. Valdivia sigue fielmente la información de Echeverría, cometiendo si algunos errores al consignar nombres ${ }^{150}$.

Las «Memorias» de Mariano A. Cateriano contienen los mismos datos brindados por los anteriores, pero los supera en el sentido que colaciona una serie de documentos. En «La Diócesis de Arequipa y sus Obispos» Santiago Martínez proporciona una gran cantidad de datos y fechas, así como también los entre telones de su disputa con los canónigos.

Su labor fue el inicio de la construcción de la catedral, la erección de una parroquia especial para los indígenas, la realización de la visita general de la diócesis en la que confirmó en la ciudad y sus contornos a más de 10.000 personas, y dividió algunas doctrinas ${ }^{151}$.

Informó en 1623 «que en la diócesis existían 54 doctrinas, de las cuales 14 estaban regentadas por regulares, y que emitió un auto clausurando los conventos

\footnotetext{
148 Dice el padre Enrique Fernández: «Por el fallecimiento de fray Cristóbal Rodríguez OP, volvió a tomar la jurisdicción de Arequipa, (el Obispo del Cuzco) a excepción del Cercado de la ciudad. Envió visitador a Arica, Camaná, Collaguas, Condesuyos y Moquegua, por lo que el cabildo arequipeño reclamó ante el Metropolitano...» (Perú Cristiano..., p. 240), lo cual daría la razón a ambos autores. XIII.

149 Marcos JiMÉNEZ DE LA EsPADA, Relaciones Geográficas de Indias..., Tomo II, Apéndice II, p.

150 En sus Apuntes..., Polo consigna una serie de datos que fueron objetados por Cateriano.

151 Antonio de EGAÑA, Historia de la Iglesia en la América española..., p. 321.
} 
con menos de ocho miembros, como el de Camaná, que solo contaba con uno o dos, y el de Arica con cuatro religiosos, ambos de mercedarios». Pensaba que las doctrinas atendidas por regulares debían pasar al clero diocesano como solución al problema de su exención al pago de los diezmos ${ }^{152}$.

El verdadero organizador de la diócesis fue monseñor Pedro de Villagómez, pues le tocó hacerlo, dado que el corto desempeño de Rodríguez y los conflictos en los que se vio envuelto Perea, impidieron que ello se realizase. Se constituye en el obispo representativo de este momento, a pesar de su corta permanencia en esta diócesis.

Punto interesante resulta ser el que Travada pareciese dudar de la realización del primer sínodo diocesano en Arequipa, dato que recoge de Echave y Dávila, cuando señala que «los citados autores dicen que celebró sinodales»; esto por la afirmación del obispo Antonio de León quien en el sínodo por él realizado dijo «que nunca hubo hasta su tiempo leyes municipales ni sinodales», mas luego se corrige en una cita marginal en la que indicaba que había «memoria en el archivo de esta Santa Iglesia, i pienso serían mui diminutas» ${ }^{153}$. Ya en la relación de 1649 se indicaba que «celebró sínodo en que estableció santísimas leyes a todos estados y especial a su clero». Echeverría por su parte, afirma como fecha de realización del sínodo el año 1638. Valdivia le sigue en esta información.

De la misma manera, Zamácola indica que convocó a un sínodo diocesano «cuyas sesiones redujo a un libro, que aunque no se verificó su impresión, sabemos de cierto que existen en Arequipa algunos ejemplares sepultados, tal vez, entre el polvo y la polilla.... ${ }^{154}$ Asimismo, señaló que con su sola presencia se tranquilizaron la cosas con el cabildo.

Polo sigue esa misma información y dice que formó las primeras Sinodales a fines de 1638. Asimismo sostenía que «acabó de hacer la erección de su diócesis», - punto este rebatido por Cateriano- «y escribió en su defensa unos doctos Apuntamientos» ${ }^{155}$.

Es M.A. Cateriano quien amplía la información sobre este acontecimiento de la mayor importancia por constituir el primer ordenamiento de la iglesia arequipeña, consignando las fechas de las sesiones, algunos de los acuerdos tomados y los conflictos que suscitó su realización, transcribiendo además la primera sesión conciliar ${ }^{156}$. Martínez a la par que expone la misma informa-

152 Idem.

153 Ventura TRAVAdA, Suelo de Arequipa convertido en Cielo...,

154 J.D. ZAMÁCOLA, «Biografias de los señores obispos...», en: Revista Católica. N 28 Arequipa, 30 de marzo de 1878 , p. 228.

155 José Toribio POLO, Apuntes sobre la historia eclesiástica de Arequipa...., p. 328.

156 Mariano A. CATERIANO, Memorias de los Ilustrísimos Señores Obispos..., pp. 29-35. 
ción que los anteriores, realiza correcciones a algunos datos proporcionados por Carlos Romero en una biografía de Villagómez y los dados por Zamácola.

Sobre las Constituciones, apuntaba Egaña: «Aunque redactadas con cuidado, no evitaron que los ariscos capitulares elevaran su protesta, la cual, al no ser oída, motivó la consiguiente apelación a la Audiencia por vía de fuerza, pero sin resultado, pues ésta sentenció a favor del sínodo. Novedad del mismo fue la determinación adoptada de hacer catecismo en lengua puquina, hablada, junto con el quechua y el aimara, en la región de la actual provincia de Moquegua, y la cláusula sinodal de crear escuelas en los poblados indígenas $\rangle^{157}$.

$\mathrm{Su}$ labor ordenadora también se manifiesta con la nueva erección canónica de la catedral y la elaboración de su Regla Consueta (1639) que habría de regirla por trescientos años, la misma que no fue impresa sino hasta 1862, por mandato del obispo Bartolomé Herrera.

Otros obispos de este período son Agustín de Ugarte y Saravia, Pedro de Ortega Sotomayor, el agustino Gaspar de Villarroel, el trinitario Juan de Almoguera y el mercedario Juan de la Calle.

Un ejemplo de lo interesante que resulta ser el testimonio contemporáneo constituye la relación de 1649. A pesar de lo conciso que es Francisco de Palacio Alvarado, sobre el obispo Ortega Sotomayor, en la mayoría de los casos, da mejores datos que otros autores. Además de informarnos sobre la vida del prelado y su desempeño en la diócesis de Trujillo, acerca de su ejercicio en Arequipa sostiene que visitó la mayor parte del obispado descubriendo en su periplo «cuatro notables sacerdotisas, por cuyo diabólico ministerio se averiguó habérsele ocasionado una peligrosa caída de la mula en que discurría visitando, y se ve que si fue diabólica la obra de enfermarle, ha sido milagrosa la de sanar de tan mortal accidente» ${ }^{158}$.

Ventura Travada por su parte abunda en datos personales sobre este obispo, corrigiendo la fecha de toma de posesión del obispado a Dávila, pero no menciona nada sobre su visita ni del incidente mencionado y es muy escueto en proporcionar información sobre su ejercicio episcopal. F.J. Echeverría y Morales en cambio nos brinda mayor información sobre su actuación en Arequipa, informa de su paso por Collaguas, su apoyo a los conventos de Santa Catalina y La Recoleta; al parecer, estaba mucho mejor documentado.

Juan D. Zamácola dice que embelleció la catedral y apoyó a los conventos. En tanto que Juan G. Valdivia reproduce los datos del arcediano Echeverría.

157 Antonio de Egaña, Historia de la Iglesia en la América española..., p. 323

158 Francisco de Palacio Alvarado, Relación del Obispado de Arequipa. [1649] En: Jiménez de la Espada, Madrid, 1885.

Fundaciones Hispanas Hispania Sacra 57 (2005) 
Ambos, como el resto de autores hacen referencia a la ayuda que brindó a dos huérfanas que encontró en Collaguas.

José T. Polo tampoco menciona nada con respecto a la visita que realizó y si su labor de embellecimiento de la catedral. Dice también que «en 1651 mandó al Rey el 'Teatro histórico de la Iglesia de Arequipa', pedido por cédula de 8 de noviembre de 1648; y dejó manuscrita la 'Vida del venerable don Juan del Castillo' médico limeño que murió en $1637 \gg^{159}$.

Mariano A. Cateriano nos proporciona, aparte de los ya mencionados datos, el de ser el autor del «Teatro histórico...», a petición de Felipe IV». Del Arcediano Martínez, la información más valiosa sobre este prelado es la que se basa en la documentación notarial que recolectó en sus investigaciones y también que su «Teatro...», debe encontrarse en el archivo de Sevilla ${ }^{160}$. Los dos ignoran el incidente con las hechiceras, ocurrido en la referida visita.

El aludido «Teatro históriço de la Iglesia de Arequipa» debió ser escrito sobre la base de la Relación de 1649 o se trata del mismo.

Fray Juan de Almoguera fue el obispo que más tiempo gobernó en este período (1660-1674), mostró gran preocupación por los indios tan explotados por los corregidores de lo cual se informó a través de la visita que realizara. La opinión que del clero americano tenía no era favorable, sobre todo de los miembros del cabildo. Esta situación lo llevaría a escribir «Instrucción de sacerdotes con aplicación a curas y eclesiásticos de las Indias» que, impreso en España fue mandada recoger por la Inquisición limeña, por estimar que en ella denigraba al clero ${ }^{161}$.

La obra constituye una denuncia del estado de corrupción del clero y contiene además una invocación a las autoridades metropolitanas y a los propios sacerdotes para que tomen conciencia de la necesidad de llevar a cabo una reforma ${ }^{162}$. Ante la convulsión ocasionada por los sucesos de Laicacota, fue enviado para pacificar la zona, cabiéndole una opaca actuación.

Consagró la catedral y mandó construir su altar mayor. Fue trasladado a Lima como arzobispo, un hecho anecdótico sobre su elección lo trae Travada, tradición que fue recogida por Ricardo Palma con el título «El obispo del libro y la madre Monteagudo».

\footnotetext{
159 José Toribio Polo, Apuntes sobre la historia eclesiástica de Arequipa..., p. 330.

${ }^{160}$ Santiago MARTÍNEZ, La Diócesis de Arequipa..., p. 97. 490-491.

${ }^{161}$ Lourdes DíAZ TRECHUELO, Un cordobés en la sede de Arequipa: Juan de Almoguera..., pp.

162 Pedro GuIBOVICH, Evangelización e Inquisición en el siglo XVII: el caso del obispo Almogue$r a \ldots$, p. 268. Este autor trae a colación el reconocimiento por parte del inquisidor decano Juan de Huerta Gutiérrez sobre la veracidad de las afirmaciones del obispo. Polo sostiene incorrectamente que fue puesto en el Index.
} 
Dice el padre Egaña: «De todo este tiempo fue, sin duda, el prelado arequipense que por sus cualidades pastorales y por sus doce años de gobierno, grabó más profunda huella en la ciudad blanca del Misti, atento sobre todo a la formación de un clero de tipo tridentino» ${ }^{163}$. Con fama de orador eximio y obispo celante llegó a Lima donde había sido promovido como arzobispo.

Los otros obispos, Ugarte, Villarroel y de la Calle no pudieron realizar mayor labor por lo reducido de su episcopado pese a sus grandes méritos, mostrando si una gran preocupación por los pobres y desvalidos, además de la labor constructora de los dos primeros.

Este tiempo fue de esplendor de la religiosidad del pueblo. Prueba de ello fue la santidad de hombres y mujeres. Se produce también una «peruanización» del clero y órdenes religiosas.

\subsubsection{Consolidación y reordenamiento (1679-1765)}

Este momento lo domina la figura del obispo Antonio de León reorganizador de la Iglesia en Arequipa, de la que fuera pastor durante largo tiempo, aunque sin desmerecer la gran labor constructora y social desarrollada por el obispo Juan Cavero de Toledo.

A poco de iniciarse el episcopado de monseñor León, según una relación oficial de 1680 la situación del clero en la diócesis era alentadora: el cabildo contaba con 13 miembros, había 105 religiosos en cinco casas, sin contar La Recoleta, vivían 60 sacerdotes en la capital, y 50 en la diócesis, había 52 parroquias: 36 regentadas por el clero diocesano y 16 por religiosos. También, otros dos conventos en Arica, uno en Moquegua ${ }^{164}$ y uno en Camaná. Además, estaba el convento de Santa Catalina que albergaba una población de 319 mujeres, de las cuales 106 eran religiosas o aspirantes ${ }^{165}$. A ellos se agregarían otros dos conventos.

Culminación de este período fue la fundación de conventos: Santa Rosa en 1747 y el establecimiento de los hermanos de San Camilo en $1756^{166}$, los que habían sido precedidos por el monasterio del Carmen (Santa Teresa) en $1710^{167}$.

\footnotetext{
163 Antonio de EGAÑA, Historia de la Iglesia en la América española..., p. 326.

${ }^{164}$ En Moquegua se establecieron 4 cenobios, sobre su fundación véase Juan A. MONTENEGRO Y UBALDI, Noticia de la ciudad de Santa Catalina de Guadalcázar de Moquegua (1840). Moquegua, 1992.

165 Antonio de EGAÑA, Ibídem, pp. 327-328.

166 Virgilio GRANDI OSC, San Camilo de Arequipa. Historia de un convento y de una iglesia (1756-1881). Arequipa, Parroquia del Pilar, 1983, p. 11. Los padres Crucíferos o de la Buena Muerte recién alcanzaron la autorización regia para la fundación de la casa el 27 de noviembre de 1801 .

167 Basilio A. de SANTA TERESA OCD, El Monasterio del Carmen de la ciudad del MistiArequipa. Lima, 1957.
} 
Del obispo madrileño Antonio de León, el autor de «Suelo de Arequipa...» reseña detalladamente su vida, recogiendo incluso algún hecho anecdótico, la destrucción de Panamá en 1670 descrita por León, cuya reconstrucción y traslado le fue encargada como presidente gobernador y obispo al mismo tiempo, labor en la que puso mucho entusiasmo y celo, logrando su cometido. Ejerció luego, aunque brevemente el obispado de Trujillo, siendo trasladado finalmente al de Arequipa.

Aquí desempeñó el episcopado por cerca de tres décadas (1679-1708), reformó las costumbres del clero, realizó conferencias moralizadoras, legó su biblioteca ${ }^{168}$, fundó una escuela para niños, cuidó por la moral pública. Visitó su obispado corrigiendo abusos, hasta en dos oportunidades, celebró un sínodo «en que dio tan piadosas leyes municipales, que redujo a recoleta de perfectísima observancia el gobierno de su obispado» dice Travada. Fueron publicadas en 1688 y rigieron la iglesia arequipeña durante casi dos siglos.

Tuvo gran amistad con la beata Ana de los Angeles, siendo recogidos por Travada varios pasajes de la vída de esta religiosa relacionados con algunos de los obispos mistianos. Su biografía es extensa pues abarca dos capítulos.

Echeverría es conciso en la información que proporciona, no toca su labor constructora en Panamá y señala algunos de sus principales actos en Arequipa, como su ayuda a la construcción de un puente y el inicio de los procesos de beatificación de Alonso Baez y «María» de los Angeles ${ }^{169}$. Consigna además el epitafio que rezaba en el sepulcro de este obispo.

Zamácola es más ilustrativo al señalar que «llegó a verse la ciudad de Arequipa y todo el Obispado con tal reforma de costumbres, cual nunca se había visto hasta aquella época». Trató con cierto detenimiento su accionar en Panamá y su rápido paso por la diócesis de Trujillo. Remarcó su actividad y su gran empeño por la instrucción de la juventud. Además menciona que en su tiempo se crearon las sillas de doctoral y magistral dentro del cabildo catedralicio.

Monseñor Valdivia reproduce los datos dados por Echeverría, pero agrega que como Juez medidor y compositor de tierras «asignó en el valle de Tambo, pago de la Pampilla, 80 topos para el pueblo e iglesia». Y sobre el sínodo de 1684 , comenta «que aunque no tiene aprobación real, como debía para servir de ley, se acomodan a su observancia los clérigos» ${ }^{170}$.

168 El Padre Barriga en el tomo IV de sus «Memorias para la historia de Arequipa», transcribió el inventario de la «Librería de la Santa Iglesia que le donó el Ilustrísimo Señor Don Antonio León» que hizo Echeverría en 1804. Donación que se hizo ante el escribano Diego de Silva en 1705.

${ }^{169}$ Echeverría aquí comete un error al señalar que el nombre de la religiosa arequipeña, hoy beata, era el de «Sor María de los Angeles», y no sor Ana como realmente es. Lo mismo hace Zamácola, véase «Biografia de los señores Obispos...» en: Revista Católica. 이 32 Arequipa, 27 de abril de 1878, p. 281.

170 J.G. VALDIVIA, Fragmentos..., pág. 190. Ignoramos el por qué de esta afirmación, pues, autores tan minuciosos como Cateriano y Martínez, que además eran abogados no hubieran dejado pasar 
Este cuerpo normativo reunía la legislación real expedida al amparo del Regio Patronato, los dispositivos del Concilio de Trento, los sínodos de Lima (1613), La Paz (1638), Toledo (1613 y 1622), Lugo (1632), Albarracín (1602 y 1604), Hortana (1627) y, Canarias; además de los cinco Concilios Provinciales Limenses, el Tercero Mexicano, los Motu Propio y Bulas de los Pontífices $\mathrm{y}$ también declaraciones cardenalicias y opiniones de reputados teólogos ${ }^{171}$. Impresas en Lima en 1688, divididas en cinco libros, a lo largo de sus diversos títulos se discurre por los sólitos puntos ya tratados particularmente en el concilio III limense y por el arzobispo Lobo Guerrero en 1613 y por Villagómez en la misma Arequipa en 1638. Se nota que aún preocupaba a los sinodales la persistencia de la idolatría en zonas menos cultivadas, probablemente del interior; ${ }^{172}$ por ello se recomienda a los curas la mayor providencia y se les faculta a proceder aún por vía criminal, según la necesidad, dice Egaña ${ }^{173}$.

Cateriano trae el dato de su negativa a aceptar el obispado de Panamá, teniendo que intervenir su diocesano que lo compelió a hacerlo «bajo precepto formal de obediencia». Y su firme actuación para el traslado de esa ciudad, empleando para ello incluso la artillería. Dice que en Arequipa realizó tres visitas. Trae también la décima que figuraba en el antiguo retrato existente en la catedral y que se quemó en el incendio de 1844.

Santiago Martínez es el que más parco se muestra en brindar información sobre este prelado antes de su llegada a Arequipa. Ocupa buenos párrafos en la monja catalina Ana de los Angeles Monteagudo y resalta las renuncias que hizo al obispado de Quito y al arzobispado de Santa Fe por permanecer con su grey arequipeña.

Juan Cavero de Toledo es otro de los grandes prelados de este período que gobernó la diócesis un considerable tiempo (1726-1741). Antes ya lo había sido de Santa Cruz de la Sierra. Destacó por su labor social, mejoró el hospital,

sin señalarlo. Asimismo, el doctor Valdivia, como se nominaba en sus primeros tiempos, llamó equivocadamente a la monja arequipeña elevada a los altares, María de los Angeles Monteagudo y no Ana como realmente lo es. Incluso en la vida de Ortega de Sotomayor se lee «la monja María Catalina de los Angeles Monteagudo». Pero esto tampoco es original de Valdivia, pues Echeverría y Zamácola hicieron lo propio, como ya lo hemos referido. Polo es más conciso, cita la fecha de su traslado a Arequipa y la creación de los dos cargos en la catedral.

171 Dante ZEGARRA LÓPEZ, «La Evangelización en Arequipa a la luz de las disposiciones del Sínodo Diocesano de 1684». en: La evangelización del Perú Siglos XVI y XVII..., p. 529.

172 Sobre Idolatrías en Arequipa puede verse Catherine JULIEN, Las Huacas Pacariscas de Arequipa y el volcán Misti. (Arequipa, 2002); María MARSILLI, The devil in the family. Heresy, witchcraft and paganism in the $17^{\text {th }}$ century Arequipa (Cleveland, 2003); Piere DUVIOLS, Un Proces d'idolatrie Arequipa, 1671 (Lima, 1966) y Frank SALOMON, Culto a los ancestros y resistencia frente al Estado en Arequipa entre los años 1748-1754 (Lima, 1990).

${ }^{173}$ Antonio de EGAÑA, Historia de la Iglesia en la América española..., p. 328. 
estableció varias casas para asilo de pobres, fundó un monte de piedad y repartió limosnas con profusión. Además de realizar obras de mejoramiento en la ciudad, hermosear la catedral y comprar el terreno para la fundación del monasterio de Santa Rosa. También en Moquegua colaboró eficazmente a la del hospital betlemítico que tuvo gran acogida de la población ${ }^{174}$.

El padre Egaña recogiendo la opinión de la época citaba: «Durará por muchos años en Arequipa el nombre del señor don Juan Cavero, porque a la verdad pocos o ningún obispo habrá habido en las Américas ni más laborioso ni más profícuo en beneficio del público» ${ }^{175}$.

Donde es particularmente detallado el estudio de Travada es en el desarrollo de la vida de Juan Bravo de Rivero, ocupando hasta tres capítulos, este prelado fue el fundador del monasterio de Santa Rosa, hecho que, precisamente, lo motivó a escribir el «Suelo de Arequipa convertido en cielo». Se ocupa de su origen y estudios, su desempeño dentro de la administración colonial, en la que de 24 años fue nombrado oidor de la audiencia de Charcas, tocándole además, la misión de medir tierras en esa provincia. Hechos los votos sacerdotales se incorporó al cabildo catedralicio de Chuquisaca; de allí fue elevado al obispado de Santiago de Chile en 1735, cuyo desempeño es tratado extensamente; siendo promovido a Arequipa en 1743, a la que ingresó en noviembre de ese año, resaltando su celo por la conducta del clero y la fundación del mencionado convento ${ }^{176}$.

El cura Zamácola pondera su celo por la calidad del clero y su ardiente caridad que practicaba siempre, es el caso de la visita que realizó en que repartió mucha ropa. Apoyó la fábrica de varios templos, en especial la del monasterio de Santa Rosa que fundó. Polo manifiesta que «dotó su iglesia de alhajas y paramentos y fabricó las torres de su catedral arruinadas por un terremoto». Cateriano aporta por su parte, el dato que fue casado y al fallecer su esposa, optó por la vida religiosa.

174 Ibídem..., pág. 856. Fue fundado en 1726 por el presbítero Antonio Isidro Maldonado y Raya. Juan A. MONTENEGRO Y UBALDI, Noticia de la ciudad de Santa Catalina..., pp. 16-17.

175 A. EGAÑA, Ibídem, pág. 857. Este dato lo trae J.D. ZAMÁCOLA, «Biografias de los señores obispos...» en: Revista Católica. $\mathrm{N}^{\circ} 40$ Arequipa, 22 de junio de 1878, p. 408.

176 Los datos que proporciona Echeverría sobre este obispo son los mismos que los anteriores, haciendo énfasis en el cuidado que puso en la conducta de los sacerdotes y las buenas costumbres de su pueblo. Añade si la fecha del fallecimiento de monseñor Bravo de Rivero. Valdivia se limita a tomar los mismos datos que Echeverría escribiera.

Fundaciones Hispanas

Hispania Sacra 57 (2005) 


\subsubsection{Debilitamiento y crisis (1765-1868)}

Durante este período se desempeñaron los prelados: Diego Salguero, Manuel Abad Yllana, fray Miguel de Pamplona, Pedro José Chaves de la Rosa, Luis Gonzaga de la Encina, José Sebastián de Goyeneche, Bartolomé Herrera y fray Juan Calienes.

En este período podría incluirse al descontentadizo Jacinto Aguado quien llegó a proponer la conveniencia de designar obispos a peninsulares por carecer los nativos de salud y libertad de actuar por estar relacionados con su pueblo, y que, fuera de realizar una visita trunca, no hizo mayor obra. De él y de su sucesor el anciano Diego Salguero, decía el jesuita Egaña que sus cortos gobiernos (ineficaz el de Aguado) significaron un momento de desorden que vivía Arequipa, el cual tuvo que afrontar y corregir Chaves de la Rosa ${ }^{177}$.

Lo cierto es que algunos prelados de esta época o se hallaban limitados por su edad o no estuvieron preparados para desempeñar la mitra en momentos en que sobre la Iglesia se cernía el embate de la Ilustración con toda la secuela de trastornos que ello significaba.

Corresponde a tiempos convulsos ocasionados por los constantes levantamientos y luchas independentistas que se sucedieron en la segunda mitad del siglo XVIII y las primeras décadas del XIX. Posteriormente, al constituirse en república soberana el Perú atravesó por momentos difíciles. La Iglesia no estuvo exenta a ello. Durante estos tiempos, proliferaron las ideas liberales, regalistas y anticlericales que la afectaron considerablemente.

Cuando los Borbones asumieron la corona española una nueva era comenzaba para sus posesiones en ultramar. Las nuevas ideas imperantes en Europa representadas por la Ilustración provocarían una actitud marcadamente opuesta a la Iglesia ${ }^{178}$.

La expulsión de los jesuitas fue el hecho más significativo de fines del siglo XVIII y muestra clara de la tendencia de la corona para con la Iglesia. Fue durante el episcopado del señor Salguero que se dispuso el extrañamiento de los hijos de san Ignacio de Loyola (1767), ocasionando el cierre de sus casas, que en el caso de este obispado, las había en la ciudad de Arequipa, en Moquegua y en Arica.

177 Antonio de EgAÑA, Historia de la Iglesia en la América española..., p. 860.

178 Sobre esta época puede verse Mary GALLAGHER, Imperial Reforms and the Struggle for Regional Self-determination: Bishops, Intendants and Creole Elites in Arequipa, Perú 1784-1816, New York, 1978. También Sarah CHAMBERS, De súbditos a ciudadanos: honor, género y politica en Arequipa, 1780-1854. Lima, 2003, pp. 141-153. 
Conscientes los soberanos de la influencia que la Iglesia ejercía, se preocuparon por el tipo de obispo a presentar ante la Santa Sede, Klaiber, refiriéndose a prelados representativos de esta época como Chaves de la Rosa, Martínez de Compañón y Moscoso y Peralta, observa que no fueron escogidos solamente por sus dotes de piedad, sino que también porque se adecuaban al perfil de sus altos funcionarios: inteligentes, eficaces y leales ${ }^{179}$.

Sin embargo, a pesar de dichas cualidades, no siempre les fue bien en el desempeño de sus funciones episcopales, el mismo Klaiber señala el fracaso de Chaves de la Rosa en su intento de reformar el convento de Santa Catalina debido a la oposición de parte de la comunidad religiosa apoyada por la sociedad arequipeña, como manifestación de las rivalidades entre criollos y peninsulares que se venían experimentando desde hacía tiempo ${ }^{180}$, motivadas también por la política desarrollada por los Borbones, de colocar en los principales cargos a personajes de origen hispano en desmedro de los naturales de Indias.

Claro ejemplo de ello es el caso del arcediano Echeverría, quien pese a ser fidelista, deja ver su poca simpatía para con don Pedro José Chaves de la Rosa, se observa su parquedad en proporcionar información de este preclaro obispo al que conoció personalmente, y lo que remarcó fue que «se agitaron en su gobierno muchos pleitos que le consumieron el tiempo y lo apartaron del ministerio» obligándolo a renunciar ${ }^{181}$; obviando su gran labor cultural al reformar el seminario que fue cuna de grandes personalidades en ese tiempo y su labor social representada en la fundación que hizo de la casa de huérfanos.

Chaves de la Rosa representa el intento frustrado de reforma del clero que se encontraba en franca decadencia y la preocupación por la cultura y la niñez abandonada.

Juan Domingo de Zamácola que fue su secretario, se ocupa con detenimiento de quien «durante su gobierno benefició con liberalidad en todo su Obispado, sacando a muchos... del polvo de la tierra al teatro del mundo...». Realizó la visita completa de la diócesis, resolvió un conflicto que se suscitó en el colegio de misioneros de Moquegua, reformó el seminario al que dio «nuevas constituciones y plan de estudios». Además cuidó mucho por la educación de la juventud, la fundación del hospicio, la división de curatos, etc. Los varios conflictos que tuvo, los atribuye Zamácola a que «fue tan celoso de

179 S.J., KLAIBER Jeffrey. La Iglesia en el Perú..., p. 29.

$180 \mathrm{Idem}$. Chambers añade que también se debió a que iba contra las costumbres de la sociedad arequipeña.

${ }^{181}$ Francisco Xavier ECHEVERRÍA Y MORALES, Memoria de la Santa Iglesia de Arequipa..., p. 215. Donde se notó más estos enfrentamientos fue entre los camilos en Lima, donde incluso un grupo abandonó el convento refugiándose en San Francisco. Virgilio GRANDI OSC, San Camilo de Arequipa..., p. 34 .

Fundaciones Hispanas Hispania Sacra 57 (2005) 
su dignidad y tan amante de su propia opinión que casi tocaba en capricho» ${ }^{182}$. Cansado de tantos pleitos renunció en 1804.

El deán Valdivia también pondera «la reforma del Seminario y su gran biblioteca, el brillante clero que formó y dejó, la casa de huérfanos que fundó y dotó y los personajes que educó personalmente» ${ }^{183}$. Para su establecimiento - del orfanato- tuvo que superar muchos obstáculos. Esta institución tenía como entradas en 1805,3949 pesos y sus salidas pasaban de 6500 , el déficit fue cargado sobre el peculio particular del obispo, siendo el refugio de 1431 niños entre expósitos y huérfanos de ambos sexos entre los años 1788 y $1804^{184}$.

Cateriano a su vez destaca el desempeño de este obispo gaditano, señalando el interés que tuvo en el cuidado del cumplimiento por el clero de sus obligaciones y el correcto culto por parte del pueblo ${ }^{185}$. La reforma del seminario, es sin duda, la más importante de sus obras, labor a la que dedicó varios años y al que donó su biblioteca, que «fue desde entonces el foco de luz que irradió esplendente cerca del medio siglo» ${ }^{186}$.

Este autor es claro en señalar las causas por las cuales renunció: falta de colaboradores, oposición del cabildo eclesiástico, siendo Echeverría uno de sus más tenaces opositores y la resistencia de las monjas de Santa Catalina a aceptar las reformas por él planteadas ${ }^{187}$.

La situación del clero no era halagüeña, si bien numeroso estaba concentrado en la ciudad y fuera de ella y de Moquegua, Tacna y Chuquibamba apenas había un cura fuera del párroco, notábase gran ignorancia por lo que como resultado de los exámenes sinodales que se tomaron se tuvo que suspender por

182 Juan D. de. ZAMÁCOLA, «Biografías de los señores obispos...» en: Revista Católica N58 Arequipa, 19 de octubre de 1878, pp. 261-262.

183 J.G. VALDIVIA Fragmentos..., p. 195. Polo por su parte, reduce sus datos a señalar las fechas de su consagración, toma de posesión y renuncia, limitándose a repetir su trabajo en el seminario y en favor de los huérfanos.

184 Antonio de EGAÑA, Historia de la Iglesia en la América española..., p. 864. Según el Calendario y Guía de Forasteros de la República Peruana para el año de 1847 escrito por el capitán de navío Eduardo Carrasco, hasta 1843 «se habían expuesto y lactado 4591 niños de diferentes edades y sexos» y existían en ese momento 392. Lima, 1846, p. 228.

185 En la sección Manuscritos de la Biblioteca Nacional del Perú se encuentra una pastoral dirigida a los religiosos sobre lo tocante al culto en los días de Semana Santa (C-4173) y otro sobre las procesiones de dicha solemnidad (C-4146).

${ }^{186}$ La relación de libros que componían su biblioteca, fue consignada en Fuentes Documentales para la Historia de Arequipa. El Obispo P.J. Chaves de la Rosa editado en 1975 por A. Málaga Medina.

187 Mariano Ambrosio CATERIANO, Memorias de los Ilustrísimos Señores Obispos..., p. 222. Martínez en cambio, es conciso en el caso de este obispo, abundando si en fechas y datos referenciales, resaltando la visita que hizo a su diócesis y las obras ya mencionadas, y algunas cláusulas de su testamento, calificando de fructífero su episcopado. Concluye esta biografía diciendo que «dejó en Arequipa regueros de luz y patriotismo». 
irregulares más de 25 , mientras que muy pocos clérigos regulares se presentaron a rendirlo; a lo cual se sumaba la escasa cantidad de seminaristas y los que había mostraban pocas cualidades ${ }^{188}$.

$\mathrm{Su}$ labor cultural en Arequipa es de todo punto de vista encomiable puesto que la reforma del seminario significó un "despertar a la cultura» de una ciudad que carecía de un instituto de estudios superiores, cuyo fruto serían los principales pensadores y políticos de los primeros años de la república.

La influencia de Chaves de la Rosa fue decisiva en el desarrollo de las ideas liberales en Arequipa. Al reorganizar el seminario no solo pone a disposición de la juventud un centro de estudios superiores, sino que en él se permite el intercambio de ideas, convirtiéndose en el centro de formación de patriotas ${ }^{189}$.

Como bien señalaba el doctor Málaga Medina no todos los alumnos que pasaron por el seminario de San Jerónimo alcanzaron el presbiterado, en sus aulas se formó una brillante generación que desde 1810 tomó parte decisiva en la vida del país, algunos de sus integrantes son: Francisco de Paula González Vigil, Mariano José de Arce, José María Corbacho, Benito Laso, Andrés Martínez, Evaristo Gómez Sánchez, Francisco Quirós, entre otros ${ }^{190}$.

Sin embargo, como sostenía Egaña, el final de su labor en el obispado por propia decisión significó un ocaso con sombras tras una jornada luminosa de un pontificado espléndido de cultura y beneficencia ${ }^{191}$. Esas sombras eran la crisis del clero secular y regular.

Acontecimiento importante de este tiempo fue la llamada «secularización de las doctrinas». Por Real Cédula de 1 de febrero de 1753 se ordenaba a los regulares separarse de sus curatos y doctrinas a su cargo, y entregarlos a los clérigos seculares ${ }^{192}$. En virtud de esta disposición serían entregadas en forma paulatina. Dicho mandato, por cierto, había sido solicitado desde hacía mucho por diversos prelados, siendo recién escuchado en estas fechas ${ }^{193}$.

En este sentido los franciscanos dejaron las ocho doctrinas que tenían en el Colca, mientras que los dominicos se retiraron de los pueblos que doctrinaban

\footnotetext{
188 Antonio de EGAÑA, Historia de la Iglesia en la América española..., p. 863.

189 Alejandro MÁlaga MEDINA, «Seminario de San Jerónimo de Arequipa». en: Revista Peruana de Historia Eclesiástica, 1. Cuzco, 1989, p. 42.

190 Ibidem, p. 53.

191 Antonio de EGAÑA, Historia de la Iglesia en la América española..., p. 866.

192Severo APARICIO, «Los mercedarios en la evangelización del Perú (siglos XVI-XVIII)». en: La Orden de la Merced en el Perú. Roma, Estudios. Instituto Histórico de la Orden de la Merced. 1997, p. 127.

${ }^{193}$ La causa de esa actitud de los prelados para con los regulares se debía a que no estaban sujetos a su autoridad. Obispos como Goyeneche les criticaba su quebrantamiento del voto de pobreza y que no hacían vida en común.

Fundaciones Hispanas Hispania Sacra 57 (2005)
} 
en el área rural de la ciudad y los mercedarios de Characato que conservaron hasta 1786 por especial concesión.

También está el cierre de conventos. En el caso de los franciscanos, como las comunidades que formaban los Colegios Apostólicos encargados de misiones estaban integradas por personal de origen peninsular, con el resultado de la guerra independentista abandonaron estos centros. Colegios como el de Moquegua no pudieron superar la crisis de estos años, pues desapareció cuando aún no terminaba la lucha, siendo luego convertido en escuela y ya no se pudo recuperarlo pese a que los pobladores desearan su restauración ${ }^{194}$. La Recoleta se salvó de ser cerrada en repetidas oportunidades debido al apoyo de la ciudadanía y autoridades ${ }^{195}$.

Los regulares eran considerados por los ilustrados como un producto de la corrupción de la Iglesia y al «no ser útiles» plantearon su reforma y la desamortización de sus bienes ${ }^{196}$.

Elemento capital de la crisis monástica fue la supresión de las provincias religiosas, pasando las comunidades conventuales a la jurisdicción de los ordinarios.

Con relación a las casas religiosas femeninas ocurrió otro tanto, el número de vocaciones disminuyó drásticamente, en el antiguo convento de Santa Catalina por ejemplo, en el lapso de 1822 a 1833 no se produjo ninguna profesión ni toma de hábitos ${ }^{197}$. La población monacal de los tres conventos entre 1847 y 1878 se incrementó ligeramente de 85 a 101 religiosas ${ }^{198}$.

En medio de esta debacle se yergue la figura del obispo Goyeneche, quien supo afrontar lo difícil de la situación. Caritativo y prudente, prefirió sufrir con los suyos el «doloroso nacimiento» del nuevo Perú antes de irse a la tranquila sede que le ofrecieron en España ${ }^{199}$.

$\mathrm{Al}$ proclamarse la Independencia se produjo el retiro o renuncia de cuatro prelados, vacancias que duraron 15 años en Lima y Trujillo, 17 en MaynasChachapoyas, 21 en Huamanga y 19 en el Cusco ${ }^{200}$. Hay pues carencia de pasto-

\footnotetext{
194 Odorico SAIZ OFM, Restauración de la Orden Franciscana en el Perú en el siglo XIX. Lima, Provincia Misionera de San Francisco Solano. 1993, pág. 60.

195 Luis ARROYO OFM., La Recoleta de Arequipa. Lima, Imprenta C.M. Leoncio Prado, 1951 págs. 117-127.

196 Pilar GARCÍA JORDÁN, Iglesia y poder en el Perú contemporáneo. CERA Bartolomé de las Casas, Cusco, 1989, p. 41.

197 Dante Zegarra López, Monasterio de Santa Catalina de Sena de Arequipa y Da. Ana de Monteagudo Priora. Lima, Editorial DESA, 1985 p. 509.

198 Pilar GARCíA JORDÁN, Iglesia y poder en el Perú contemporáneo..., p. 160.

199 José Antonio BENITO, Arequipa Católica, la Roma del Perú..., p. 14.

200 José DAMMERT BELLIDO, «Diócesis peruanas en el siglo XIX». en: Revista Peruana de Historia Eclesiástica, 5. Cuzco, 1996, p. 15.
} 
res. «De los obispos que quedan es innegable el rol protagónico que jugará Mons. Goyeneche de Arequipa. Será durante varios años el único obispo en la región sur de América hispana, prestando servicios episcopales a toda la región ${ }^{201}$.

José Sebastián de Goyeneche es sin duda, uno de los más destacados obispos no solo de Arequipa sino del Perú. Esto, sin embargo, no se refleja en los episcopologios que se ocupan de él. Echeverría solo proporciona algunos datos que no constituyen mayores aportes para el conocimiento de su ejercicio episcopal y si sobre su familia y la primera etapa de su vida.

Zamácola, por su parte, es poco lo que aporta al conocimiento de este obispo, alarmado por la situación creada por las luchas libertarias decía: «...según el aspecto que han tomado las cosas podrá ser el Exmo. Señor Goyeneche el último Obispo católico, Apostólico Romano que gobernó Arequipa» ${ }^{202}$. A pesar de ser contemporáneo suyo, Valdivia se contenta con decir que era natural de Arequipa y ocupaba la sede desde 1817.

Polo se limita a indicar que gobernó la diócesis entre 1818 y 1860 y que extendió «también su ministerio a los obispados de Córdova, Santa Cruz, Chuquisaca, La Paz, Cuzco, Huamanga, Trujillo y Santiago». Cateriano ${ }^{203}$ es sintético al tratar su pontificado. Martínez consigna además de información personal, transcripciones de documentos relacionados a él, señala que dio inicio a la reconstrucción de la catedral destruida por el incendio de 1844 y las donaciones que hizo o que dejó ordenadas en su testamento. A comparación de su largo episcopado (1817-1860), dichos autores no realizaron una biografía más completa.

Consideramos que su mayor logro fue mantener su diócesis a pesar de lo difícil de la situación; en medio de los embates en su contra «se mantuvo y trató de cortar distancias, tranquilizar los ánimos y sembrar paz en aquel erial de discordias civiles $\rangle^{204}$. En esos duros años supo conservar la verdadera neutralidad que corresponde a un obispo, con sentido de la realidad circundante, que se impuso sobre sus ideologías personales y supo sacrificar en aras del bien de su Iglesia; prudente y sacrificado, modesto en medio de sus grandezas eclesiásticas y civiles ${ }^{205}$. De contemporizador lo ha calificado P. García Jordán ${ }^{206}$.

201 Bruno A. VAN DER MAAT, Las ordenaciones sacerdotales en Arequipa alrededor de la Independencia (1820-1827) Arequipa, Universidad Católica de Santa María. 2000, p. 23.

202 J.D. ZAMÁCOLA, «Biografias de los señores obispos...» en: Revista Católica. 63 Arequipa, 23 de noviembre de 1878 , pág. 351 .

${ }^{203}$ Este autor sostenía: «... sería imposible contener en el estrecho espacio de este escrito la historia de un episcopado de 54 años, durante los cuales se realizaron en el país los más grandes acontecimientos políticos y sociales...», Memorias de los Ilustrísimos Señores Obispos..., p. 233.

${ }^{204}$ Antonio de EGAÑA, Historia de la Iglesia en la América española..., p. 868.

205 Ibídem, p. 869.

206 Pilar GARCÍA JORDÁN, Iglesia y poder en el Perú contemporáneo..., p. 31. 
Su accionar posibilitó la existencia de sacerdotes para la atención de los fieles durante estos años, al ser prácticamente el único obispo, acudieron aspirantes al sacerdocio de diferentes lugares para recibir la ordenación de sus manos. Entre 1820 y 1827 se ordenaron cerca de dos centenares de sacerdotes (174) de los que más de dos tercios eran originarios de otras diócesis y la gran mayoría destinados a otros lugares. «No es difícil imaginarse lo que hubiera pasado con la Iglesia sino se quedaba Goyeneche en ese período» ${ }^{207}$. «Padre espiritual de Sud América» lo llamó Rada y Gamio ${ }^{208}$.

El reconocimiento que se granjeó y su apoyo a la idea de la Confederación Peruano-Boliviana hizo que se pensase en proponerlo como prelado principal del estado Sud-peruano y ya en 1822 al estar dominado el norte del Perú por las fuerzas patriotas, el virrey La Serna lo designó metropolitano para el territorio sujeto a él ${ }^{209}$.

Goyeneche dictó disposiciones para la formación de la estadística civil, sobre la corrección de los libros parroquiales', administración de los sacramentos, pago de diezmos, sobre inventario de los bienes parroquiales, obras pías, arancel eclesiástico, visita pastoral, establecimiento de cementerios en los pueblos, fomento de escuelas de primeras letras ${ }^{210}$.

Durante ese tiempo se sucedieron en el Perú una serie de acontecimientos de la mayor importancia. Veamos los referentes a la religión.

La Reforma de Regulares decretada en 1826 fue el factor determinante para la desaparición de muchos conventos y el retiro de no pocas órdenes religiosas; así como la secularización de numerosos religiosos.

Ya en 1786 la corona española había ordenado la extinción de los conventos que no tuviesen por lo menos ocho religiosos. Sin embargo, gracias a diversos mecanismos empleados por las órdenes muchas de esas casas pudieron seguir existiendo. Ejemplo del caso es la provincia mercedaria del Cusco, que en definitorio acordó solventar la permanencia del número de religiosos requerido donde se lo necesitase, evitando así su clausura ${ }^{211}$.

Pero con la declaración de autonomía de los conventos que acarreó la supresión de sus provincias en 1826, aquella asistencia desapareció ocasionando

\footnotetext{
207 Bruno A. VAN DER MAAT, Las ordenaciones sacerdotales en Arequipa..., pp. 23-24. Los ordenados eran originarios de: Arequipa (53), Lima (34), Cuzco (10), Huamanga (3), Trujillo (1), La Paz (20), Charcas (20), Santa Cruz (9), Chile (10), Córdova (1); no contándose con datos de 13.

208 Pedro J. RADA Y GAMIO, El Arzobispo Goyeneche..., p. 238.

209 José DAMMERT BELLIDO, Diócesis peruanas en el siglo XIX..., p. 25.

210 Pedro J. RaDA Y Gamio, El Arzobispo Goyeneche..., p. 459.

211 Eleuterio Alarcón BEJEARANO, «Los conventos mercedarios del Perú y la legislación canónico-civil en el siglo XIX». en: Analecta Mercedaria Vol.I Instituto Histórico de la Orden de la Merced, Roma, 1992 pp. 166-167.
} 
el cierre de los «conventos pensionados» que en el caso de Arequipa eran las casas mercedarias de Camaná y Arica.

Igual situación debieron correr los conventos de San Francisco de Arica, del Santísimo Rosario (dominico) de Moquegua y el Betlemita también de esta última ciudad.

Caso particular es el convento agustino de San Nicolás de Tolentino establecido en la ciudad desde 1574, el que, a pesar de superar largamente el número de conventuales requerido ${ }^{212}$, fue clausurado por Bolívar, estableciéndose en su local varias instituciones de carácter cultural.

La suerte de los hermanos hospitalarios fue un tanto distinta pues su ausencia de Arequipa se debió más a la secularización de sus miembros. Para 1825 los hijos de san Camilo habían abandonado su casa según la afirmación del Deán Valdivia ${ }^{213}$.

En 1840 solo se hace referencia entre los conventos existentes a los de San Francisco, La Recoleta, Santo Domingo, San Juan de Dios y La Merced de Arequipa y los de dominicos y betlemitas de Moquegua ${ }^{214}$. Para 1846, según la Guía de Forasteros había en el obispado los conventos de Santo Domingo, San Francisco, La Merced, Recolección Franciscana y San Juan de Dios; con 34, $36,34,41$ y 5 religiosos, respectivamente ${ }^{215}$.

Luego de Goyeneche vienen los episcopados de Bartolomé Herrera y fray Juan de la Cruz Calienes, bastante cortos, sobre todo el de este último que no llegó al año.

\subsubsection{Resurgimiento y respuesta militante (1868-1945)}

La prudencia y sagacidad del obispo Goyeneche hizo posible a la Iglesia superar lo difícil de su situación al advenimiento de la república. Si bien la reorganización de la Iglesia comenzó a realizarse desde la época de dicho obispo, todavía se encontraba convaleciente y muy debilitada. En tanto que los resultados de los esfuerzos de Bartolomé Herrera solo se verían después.

\footnotetext{
${ }^{212}$ En el «Expediente sobre la sujeción de Regulares al Ordinario» formado en 1822 se indica que habitaban el convento 30 religiosos, 23 de los cuales eran sacerdotes. Archivo Arzobispal de Arequipa. (AAA.) Administrativo, 1814-1824.

213 Juan Gualberto VALDIVIA, Fragmentos para la Historia de Arequipa..., p. 86 . En 1821 el convento había pasado a manos de las autoridades civiles y eclesiásticas y devuelto, aunque por breve tiempo en 1824. Virgilio GRANDI OSC, San Camilo de Arequipa..., pp. 47-48.

214 Arturo Villegas Romero, Apuntes de un decenio de la historia de Arequipa 1830-1840. Arequipa, Impresora Mimeograph, 1945, p. 222.

215 Eduardo CARRASCO, Calendario y Guía de Forasteros de la República Peruana para el año de 1847, Lima, Imp. de Instrucción Primaria por Félix Moreno, 1846, pp. 307-308.
} 
Consideramos que el resurgimiento de la Iglesia en Arequipa fue notoriamente perceptible a partir del año 1868, en el que, a pesar que el violento terremoto del 13 de agosto devastó muchas poblaciones de la diócesis y destruyó o dañó seriamente todos los templos, gracias a la llegada de nuevas congregaciones religiosas y al retorno de otras le dieron un nuevo impulso; ejemplo de ello son los misioneros franciscanos quienes emprendieron una serie de campañas catequizadoras ${ }^{216}$ que recuperaron muchos pueblos a la influencia de la religión.

Asimismo, por primera vez, los laicos organizadamente asumieron una actitud más identificada con la Iglesia cobrando un rol protagónico en su defensa.

Como resalta Klaiber, «una de las tareas más importantes que la Iglesia comenzó a asumir a partir de la segunda parte del siglo XIX fue la elaboración de un sentido de su propia identidad. Al mismo tiempo, se esforzó en inculcar en los fieles un sentido de pertenencia a la Iglesia» ${ }^{217}$.

A partir de ese año (1868) se dio inicio a la formación de instituciones integradas por laicos con gran empuje en defensa de la Iglesia ${ }^{218}$ y la realización de una intensa labor social en bien de los más necesitados. Los grupos más representativos son: la Sociedad Católica, la Hermandad del Señor San José, la Señoras de la Caridad, la Unión Católica y la Acción Católica.

A decir del padre Enrique Fernández García S.J. se produjo una renovación religiosa debida a la acción conjunta de consagrados y laicos que revitalizaron la vida cristiana y colaboraron con la obra apostólica ${ }^{219}$.

Pese a su efímera existencia la Sociedad Católica realizó dos reuniones en 1868 y 1869 en las que se discutió sobre la actitud que debían asumir frente a los enemigos de la religión.

Fueron sin duda la Hermandad de San José y la de Señoras de Caridad, las instituciones que desarrollaron una intensa labor. Los primeros destacaron por su empeño en la difusión de las ideas católicas a través de la prensa, editando la «Revista Católica», (1877-1880) «El 19 de Marzo» (1887) y realizando varios certámenes literarios de índole religiosa, además del establecimiento de escuelas gratuitas para obreros.

Pero es fundamentalmente la Sociedad de Señoras de Caridad, la institución que realizó infatigable labor en beneficio de los más necesitados, entre 1878 y 1928 asistió a 88827 enfermos, realizó 128777 visitas a domicilio, entregó 169293 bonos de botica, 563539 bonos de comestibles, 6400 piezas de ropa, 1884 colchones, 1374 frazadas, 163 enfermos fueron enviados a Jesús y Yura,

\footnotetext{
216 Luis ARroyo OFM., La Recoleta de Arequipa..., pp. 139-145, 176-183, 211-215.

217 J. KLAIBER, La Iglesia en el Perú..., p. 27.

218 Es precisamente debido a este movimiento debido al cual Klaiber denomina Iglesia Militante

219 Enrique FERNÁNDEZ S.J., Perú Cristiano..., p. 385.
} 
costearon 76 operaciones, regalaron 15 catres y 114 niños fueron puestos en escuelas $^{220}$. Posteriormente, entre 1933 y 1940 asistieron a cerca de diez mil personas y repartieron más de 90000 vales $^{221}$. Similar labor cumplía la «Compañía de María» fundada en 1870.

Aparte de ellas hubo otras instituciones de bien social como la Pía Unión de San Antonio y el Pan de los Pobres, la Acción Social Franciscana, la Hermandad de Socorros Mutuos de San Francisco, la Juventud Antoniana, la Sociedad de Caridad Santa Rosa de Mollendo.

Mención aparte merece la Unión Católica, fundada en 1887 que con una mejor organización pudo sacar adelante durante varias décadas el periódico El Deber y mantuvieron una escuela nocturna para obreros. Sin duda la rama que mostró mayor actividad en esta institución fue la femenina con el establecimiento de escuelas para niños pobres, los bazares de caridad, el cuidado del culto y los templos a través de la «Obra de los Tabernáculos», la catequesis con las «Escuelas Dominicales», la defensa de la fe mediante la publicidad por el «Apostolado de la Prensa», ayuda a los enfermos con «Enfermeras a Domicilio», y la regularización de la vida familiar con la «Obra de San Francisco de Regis». La integraban las familias más distinguidas.

Fruto de esas experiencias surgió en 1925 la Acción Católica, diez años antes de su fundación nacional, era promovida por los Papas, y fue su fundador el futuro cardenal Juan Gualberto Guevara. Uno de sus fines era coordinar todas las actividades católicas, unificarlas, dándoles orientación y eficacia. Su labor fue diversificada conferencias, prensa, labor social, (durante buen tiempo se hicieron cargo de refectorios escolares establecidos en la ciudad), círculos de estudio. Crearon la Unión Nacional de Estudiantes Católicos y la Juventud Obrera Católica.

Supuso también - este período- la llegada de nuevas congregaciones religiosas Lazaristas, Salesianos, Hijas de la Caridad, las Hermanas de los Ancianos Desamparados ${ }^{222}$, Franciscanas y el retorno de otras como los Jesuitas.

Después de 1875 se dejó sentir la escasez de sacerdotes ocasionada por las convulsiones de las primeras décadas del siglo, la pobreza de recursos, el desprestigio sacerdotal, la pérdida del espíritu cristiano, además de otros factores $^{223}$. Consideramos que a ello se debió la convocatoria a esas congregaciones y a la participación de los laicos.

220 MEMORIA a grandes rasgos de los trabajos de la Sociedad de las Señoras de Caridad de San Vicente de Paúl durante los primeros cincuenta años, 1878-1928. Arequipa, 1928, pp. 11-12.

221 Puede revisarse las memorias correspondientes a esos años.

222 Véase Cumbres De CARIDAD. Bodas de Diamante de las Hermanitas de los Ancianos Desamparados. Arequipa, La Colmena, 1948.

223 Enrique FERNÁNDEZ S.J., Perú Cristiano..., p. 389. 
Corresponde a los años finales del siglo XIX la apertura de varios colegios formados por religiosos como el célebre San Vicente de Paúl del padre Hipólito Duhamel ${ }^{224}$ que fue un semillero de sacerdotes algunos de los cuales llegaron a ocupar la alta dignidad de obispos e incluso el primer cardenal del Perú salió de sus aulas; el San Pedro Pascual de los mercedarios; el Don Bosco de los Salesianos 225 , el San José de los Jesuitas y La Salle de los Hermanos de las Escuelas Cristianas. Para mujeres se encuentran: Nuestra Señora del Rosario (1874), Sagrados Corazones (1887), Sagrado Corazón-Sophianum (1900), las Esclavas (1927), la Asunción (1928). Si bien estos colegios eran de clase alta y media, también procuraron dar formación a las clases más modestas, es el caso de los hermanos de La Salle que regentaron el colegio Manuel Muñoz Nájar.

La labor de los franciscanos fue de gran importancia, por un lado con la fundación de un colegio apostólico en el convento de La Recoleta ${ }^{226}$, habrían de formar a buen número de religiosos y por otro la realización de campañas misionales populares a lo largo y ancho del obispado. Recurrieron también a la fundación de hermandades de la Tercera Orden, en muchos pueblos, cuyos integrantes «laicos», darían un nuevo impulso de vida cristiana donde no había sacerdotes permanentes ${ }^{227}$. Si bien estas hermandades tenían dirigencias constituidas, en la práctica, «era necesario consultar cuanto se hiciera de alguna importancia» al Padre Rector ${ }^{228}$.

Destacaron entre otros, fray Elías del Carmen Passarell, autor de más de un centenar de obras, fray Francisco Cabré publicista e infatigable defensor de la causa católica, y el propio monseñor fray Mariano Holguín.

El retorno de los jesuitas constituye otro de los grandes acontecimientos de este período, de manera incierta al comienzo por las campañas antijesuíticas desatadas $^{229}$, correspondió al padre Ildefonso del Olmo la tarea de establecer un colegio el año 1898 en una casa alquilada y con unos 97 alumnos ${ }^{230}$.

224 Francisco Rubén BERroA, La Obra Pedagógica del Reverendo Padre Hipólito Duhamel. Lima, Sanmarti. 1945. La abnegada labor de los Padres Lazaristas y las Hijas de la Caridad merecen un estudio aparte.

225 Sobre su actuación, Véase Jorge ATARAMA SDB., La Congregación Salesiana y su aporte a la educación técnica en Arequipa 1896-1956, Arequipa, 2000.

226 La ceremonia fue el 19 de septiembre de 1869. Luis ARROYO OFM., La Recoleta de Arequipa..., pp. 167-168.

227 Entre 1887 y 1944 establecieron 36 hermandades en Arequipa, Moquegua, Tacna, Arica e incluso en Puno. Fernando DOMINGUEZ, «Las Terceras Ordenes dependientes del Convento de La Recoleta de Arequipa. Apuntes históricos». en: Florecillas de San Antonio. Año XXXVII, N442. Arequipa, 1948.

228 Fernando (Manuel) DoMINGUEZ, La Orden Franciscana Seglar en el Perú. Pasado y Presente. Lima, Provincia Misionera de San Francisco Solano, 1992, pág. 11.

${ }^{229} \mathrm{La}$ nueva expulsión de que fueron objetos los Padres ocasionaron grandes protestan en Arequipa y fue una de las causas de la creación de la Unión Católica..

230 Armando NIETO VÉLEZ S.J., «Los Jesuitas del Perú en el siglo XIX». en: Revista Peruana de Historia Eclesiástica, 5. Cuzco, 1996, p. 184. 
Los Padres de la Compañía trabajaron en la predicación, ejercicios, Congregaciones Marianas, Apostolado de la Oración, Catecismo de colegios fiscales y particulares, confesionario y dirección espiritual, visitas a enfermos y al hospital, en la Acción Católica y sobre todo el fomento de las vocaciones. Se hicieron cargo de la Urbanización Obrera María Isabel, construyendo la hoy parroquia de Nuestra Señora del Pilar, donde además de los servicios litúrgicos, daban el catecismo dominical de niños y la escuela nocturna de la Coalición Obrera. También el Catecismo de Laneras y el de Pobres de San José. Llevaban la palabra los primeros viernes a la cárcel y el catecismo para los menores allí detenidos ${ }^{231}$.

Es la época de las grandes encíclicas sociales Rerum Novarum (1891) y Quadragésimo Anno (1931) que marcaron la pauta en la actitud de la Iglesia frente al creciente materialismo y a la explotación de los trabajadores.

Otro de los actos trascendentes de este momento fue la realización —en pleno conflicto con Chile - de un tercer sínodo que significó la promulgación de unas nuevas Constituciones Sinodales que normarían el desempeño del clero en el obispado durante buen tiempo.

Dos serán las grandes figuras prelaticias de este período: Juan Ambrosio Huerta y fray Mariano Holguín.

A monseñor Torres le tocó la tarea de afrontar la reconstrucción de los edificios eclesiásticos y convocar a nuevas congregaciones y al laicado para tomar parte en la tarea de la difusión de la fe. En tanto que al doctor Manuel Segundo Ballón le correspondió afrontar una serie de ataques realizados por sectores anticlericales que atormentaron y acortaron su episcopado ${ }^{232}$.

Uno de los más importantes obispos de Arequipa fue Juan Ambrosio Huerta (1880-1897), su labor fue muy destacada, Cateriano señala el traslado del seminario, la realización del tercer sínodo diocesano, cuyas constituciones alcanzaron a ser impresas ${ }^{233}$, y el fomento de instituciones piadosas. El arce-

${ }^{231}$ ALBUM HOMENAJE a la Arquidiócesis de Arequipa y su Primer Arzobispo Excmo. Mons. Fr. Mariano Holguín. Arequipa, Editorial La Colmena, 1946, pp. 89-90.

${ }^{232}$ Esos ataques motivaron la respuesta del obispo que entre sus numerosas cartas pastorales escribió Exhortación Pastoral que el Ilustrísimo y Reverendísimo Señor Obispo de Arequipa dirige al Clero y fieles de su Diócesis con el objeto de evitar irreverencias que se cometen en los templos y Carta Pastoral que el Iltmo. y Rvmo. Señor Obispo de Arequipa dirige al Clero y fieles de su Diócesis, prohibiendo la lectura de publicaciones impías e inmorales. Ambas publicadas en Arequipa por la Tipografia Medina en 1900. A su sucesor, Monseñor Holguín le tocó afrontar también los temas del matrimonio civil, el divorcio y la relación Iglesia-Estado.

${ }^{233}$ Constituciones sinodales del obispado de Arequipa dadas y promulgadas en el sinodo diocesano celebrado por su obispo propio... Arequipa, Imprenta de La Bolsa, 1883. 
diano Martínez amplía la información y transcribe párrafos de algunas de sus pastorales y otros hechos de su episcopado.

Tema del que no hacen alusión ninguno de los dos autores es la difusión hecha por este obispo de la encíclica Rerum Novarum (1891) que marcó el inicio del magisterio pontificio sobre los problemas sociales ni hacen mención de las numerosas pastorales que dirigió a su grey. Los prelados de esta época mostraron gran interés por estar cerca de su pueblo manifestado en la realización de visitas y la elaboración de numerosas cartas pastorales.

Como respuesta al llamado del Papa se estableció en 1896 el Círculo de Obreros Católicos a iniciativa del entonces fraile Mariano Holguín ayudado por el señor Cayetano Arenas, institución que entre sus servicios ofertaba una escuela nocturna, biblioteca, socorros mutuos, conferencias, galería de tiro. Posteriormente se formarían la Sociedad de Obreros del Santísimo Rosario (1902) y la Sociedad de Obreros del Sagrado Corazón de Jesús (1924).

A consecuencia del conflicto con Chile el Perú sufrió la pérdida de los territorios de Tarapacá e Iquique; y la particular situación de cautiverio de las provincias de Tacna y Arica ${ }^{234}$.

Se dio un auge de las publicaciones católicas, el ya mencionado «El Deber» que sería en su momento el único diario católico del Perú, «El Amigo del Pueblo» publicado por la Curia, «La Luz» publicación dominica que obtendría la medalla de plata de la ciudad, «La Colmena» de larga duración, «Florecillas de San Antonio» que alcanzó un tiraje de 12000 ejemplares en $1940^{235}$, entre otras.

Uno de los más grandes obispos que ha tenido Arequipa es sin duda fray Mariano Holguín que gobernó la diócesis por largos años, llegando a ver su elevación a arquidiócesis. Franciscano, había alcanzado fama de eximio orador e incansable misionero cuando fue designado obispo de Huaraz de donde fue prontamente promovido a su tierra natal en $1906^{236}$.

Se preocupó por el mantenimiento del seminario y la calidad del clero parroquial, fomentó la enseñanza del catecismo con el establecimiento de escuelas dominicales y apoyó la fundación de escuelas de catequistas. Pero destacó sobre todo en la acción social, labor a la que se abocó desde antes de ocupar el

${ }^{234}$ Tanto monseñor Ballón como Holguín defendieron su jurisdicción sobre las provincias cautivas. En el caso del primero puede verse El Iltmo. y Rmo. Dr. D..., Obispo de Arequipa y las provincias de Tacna y Arica. Arequipa, Tipografia Muñiz, 1901.

235 guía oficial del II congreso eucarístico nacional celebrado en Arequipa del 23 al 27 de octubre de 1940. Arequipa, Editorial La Colmena, 1940, p. 182.

236 Lamentablemente Martínez en su meticuloso estudio no desarrolla acertadamente la vida y obra de Holguín, para ser uno de sus colaboradores y testigo del accionar del prelado franciscano; limitándose solo a incluir dentro de su libro la biografía que saliera en el diario católico El Deber en 1929 como homenaje a sus bodas de plata episcopales. 
episcopado; así trajo a las Franciscanas Misioneras de María para que se hiciesen cargo del cuidado de las mujeres encarceladas y las en depósito preventivo. En su tiempo se establecieron las Hermanas de los Ancianitos Desamparados, las Madres Dominicas dedicadas a la educación de niñas, las Siervas de María cuyo fin es asistir enfermos a domicilio, las Madres del Buen Pastor que regentaban una Escuela correccional de niñas y veló por el establecimiento y régimen de varios hospicios de mujeres pobres ${ }^{237}$.

Hubo de auspiciar la fundación de un Partido Católico en 1913, con el fin de lograr una representación política que velase por los intereses de la Iglesia, ante el momento que se vivía.

$\mathrm{Al}$ igual que su antecesor, tuvo que afrontar los problemas ocasionados por la ocupación chilena de Tacna y Arica ${ }^{238}$, ciudades pertenecientes a la diócesis, defendiendo su jurisdicción ante el intento del invasor de colocar capellanes castrenses y protestó por la expulsión de los sacerdotes peruanos. Le cupo recibir Tarata y Tacna devueltas en 1925 y 1929.

Ante la renuncia de monseñor Emilio Lissón al arzobispado de Lima, lo asumió en calidad de Administrador Apostólico entre 1931 y 1933 por especial encargo de Pío XI.

Si bien no llegó a realizar un sínodo diocesano ${ }^{239}$ en el que se elaborasen unas nuevas constituciones más acordes con los tiempos que rigiesen la diócesis, llegó a promulgar un Auto de Visita Pastoral en 1921, ajustado al nuevo Código de Derecho Canónico que por esos tiempos se había dado, el que normaba el actuar del clero, y a modo de Apéndice una serie de reglamentos que lo complementaban ${ }^{240}$. Dio también un decreto de 1 de abril de 1921 que disponía la división de la Diócesis hasta en 14 Vicarías Foráneas ${ }^{241}$.

Organizó el Segundo Congreso Eucarístico Nacional en 1940, siendo elevada la catedral a basílica menor ese año y la sede a Arquidiócesis el 23 de mayo de 1943. Coronó a la Virgen de los Dolores «La Napolitana» y se celebró un Congreso de la Juventud de la Acción Católica en 1945.

A fines de este período se percibe un agotamiento en muchas instituciones, es el caso del Círculo de Obreros Católicos que en 1942 pierden a su órgano de

${ }^{237}$ Francisco CABRÉ OFM., Biografia del Excmo. Mons. Fr. Mariano Holguín, O.F.M. Primer Arzobispo de Arequipa. Editorial San Antonio, 1959, pág. 156.

238 J. Vitaliano Lima, BERROA BERNEDO, El Problema Religioso durante la Ocupación chilena de las Parroquias Irredentas de la Diócesis de Arequipa. Lima, Talleres Gráficos La Confianza, 1957.

${ }^{239}$ Tenía dispuesto la celebración de un sínodo diocesano en 1920, pero ese año se produjeron una serie de incidentes que lo impidieron. Francisco CABRÉ OFM., Ibídem, pág. 151.

240 Auto de la visita pastoral. Arequipa, Tipografía Cuadros, 1921.

${ }^{241}$ Ibídem., pp. 87-88. Ya en las Constituciones Sinodales de 1883 el obispo Huerta dispuso la creación 10 vicarías incluyendo Tarapacá y Arica. A comienzos del siglo XX había 11.

Fundaciones Hispanas

Hispania Sacra 57 (2005) 
difusión «La Colmena» que durante décadas llevó la voz de la Iglesia a un importante sector de la sociedad arequipeña ${ }^{242}$; así como al fracaso de su proyectado «Barrio Obrero» que no pudo realizarse en largos años ${ }^{243}$. La Unión Católica es todavía mencionada en el Segundo Congreso Eucarístico Nacional pero no era ya el grupo pujante de otros tiempos.

\subsubsection{Modernización y Nuevos Desafios (1946...)}

Corresponde este período al desenvolvimiento de la Iglesia arequipeña ya como arquidiócesis, en cuya conducción se han desempeñado tres prelados: el franciscano Leonardo Rodríguez Ballón, el jesuita Fernando Vargas Ruiz de Somocurcio y Luis Sánchez-Moreno Lira del Opus Dei.

La duración de los períodos de los prelados de estos tiempos se caracterizan por lo extensos que han sido sobre todo los casi 35 años de episcopado de monseñor Rodríguez Ballón y los 16 de Vargas Ruiz de Somocurcio frente a los relativamente cortos 7 de Sánchez-Moreno.

Rodríguez Ballón inició su episcopado con gran impulso. Es el caso de la realización de un Congreso Mariano en 1947 que culminó con la Coronación Pontificia de la Virgen de la Candelaria de Cayma, alcanzando el evento gran $\operatorname{acogida}^{244}$.

Desde la época de monseñor Holguín se venía contemplando la necesidad de elaborar una nueva Regla Consueta de la Catedral ${ }^{245}$, razón por la que Rodríguez Ballón en vista de la elevación de la sede a Metropolitana y Basílica a la catedral, encargó a su cabildo la revisión y reforma convenientes; aprobándolas definitivamente y ordenando su cumplimiento en 1949246.

242 Años después en 1954, fundarían un nuevo vocero llamado «Labor», pero de corta duración.

243 Aunque la edición de Labor hacía albergar esperanzas de un resurgimiento, para 1955 el Círculo se había convertido en una suerte de asociación pro vivienda, siendo su principal motivación las obras en el denominado barrio León XIII (Puede verse el diario El Deber en sus ediciones correspondientes al 8 de marzo de 1956, 3 de marzo de 1959, etc.). La misma fundación a comienzos de marzo de 1958 del Movimiento Sindical Cristiano, de carácter orientador mas no gremial, así lo revela.

244 Los pormenores de este evento puede verse en Francisco CABRÉ O.F.M., Crónica del Congreso Mariano y Coronación Pontificia de Ntra. Señora de Caima. (Arequipa, 1947) Arequipa, Tipografía O'Brien, 1949.

245 Nombró una comisión integrada por los canónigos Juan G. Guevara (futuro Cardenal) y Mariano Ochoa, quienes hicieron un nuevo estatuto que fuera puesto «Ad experimentum» por tres años, no recibiendo una aprobación definitiva.

246 Estatutos del cabildo arquidiocesano de arequipa. Arequipa, Editorial El Deber, 1952. 
A fines de 1944 fueron desmembradas de la diócesis Tacna y Moquegua para erigirse un nuevo obispado ${ }^{247}$. Luego, en 1957 y 1962 con la creación de las prelaturas de Caravelíi ${ }^{248}$ y Chuquibamba ${ }^{249}$, respectivamente, vería disminuido su ámbito jurisdiccional.

Durante su período se comenzaron a crear nuevas parroquias con la finalidad de atender a la cada vez más creciente población arequipeña, establecida en barrios populares marginales. En la actualidad hay más de medio centenar de parroquias en la provincia de Arequipa ${ }^{250}$, donde hasta 1921 no llegaban a 20. Este proceso comenzó en 1949 con la creación de las de San Lázaro, el Pilar y Tingo.

Rodríguez Ballón puso gran interés en las obras sociales, se instaló el Hogar Clínica de San Juan de Dios para niños y la Escuela de N.S. del Pilar para niños ciegos, estableció la obra de becas escolares y útiles gratuitos, la Obra Pax Christi para alimentar a muchachos pobres, el establecimiento de las Hermanitas de la Asunción para la atención gratuita de obreros enfermos, se abrió una escuela de corte y confección para señoritas a cargo de Pax Christi y una escuela gratuita para el servicio doméstico, además de un Hogar para la Joven Obrera en Tingo ${ }^{251}$, entre otras acciones.

Por otro lado, monseñor Rodríguez Ballón dio gran impulso a algunas festividades religiosas en especial la Semana Santa en la ciudad, dando gran realce a las procesiones que se comenzaron a realizar todos los días.

Le tocó afrontar los daños ocasionados por los terremotos de 1958 y 1960. Además de otros sismos como uno en 1979 que deterioró algunos templos. Apoyó la fundación de la Universidad Católica de Santa María, obra del padre Williams Morris.

Desde 1969 contó con la colaboración del misionero comboniano de origen alemán monseñor Lorenz Unfried como obispo auxiliar, quien a partir de entonces y hasta 1980 varias veces se hizo cargo del arzobispado, desarrollando una activa labor pastoral. Funciones que también desempeñó monseñor José Benavides Morriberón, antiguo obispo de Chachapoyas.

${ }^{247}$ La erección corresponde al 18 de diciembre de 1944. Su primer prelado fue Monseñor Carlos A. Arce Masías.

${ }^{248}$ Fue su primer obispo Mons. Federico Kaiser de la Congregación de Misioneros del Sagrado Corazón de Jesús.

249 En junio de 1962 se conocía el nombramiento como primer Prelado Nullius del carmelita maltés Mons. Renato Gauci. Se le asignaron las provincias de Condesuyos y La Unión, desmembradas de la Prelatura de Caravelí.

250 Son 68 las parroquias según el Directorio de la Arquidiócesis del 2002, pp. 18-27.

${ }^{251}$ Carlos S. POZZO S.J., «Monseñor Rodríguez Ballón y las obras sociales». en: Gaceta Eclesiástica Boletín Oficial del Arzobispado de Arequipa, Año XIII, 71. Arequipa, 1960, p. 77.

Fundaciones Hispanas

Hispania Sacra 57 (2005) 
A pesar del impulso que significó el concilio Vaticano II (1962-1965) en la modernización de la Iglesia, manifestado en grandes cambios en cuanto al clero diocesano se refiere, la gran labor cultural desarrollada por muchos de sus miembros se ha reducido completamente ${ }^{252}$.

Se nota a su vez, una disminución de la actividad de las antiguas órdenes religiosas llámese dominicos ${ }^{253}$ y mercedarios ${ }^{254}$, tan destacadas antes.

Si bien conservan parte de su obra, sobre todo la relacionada a la educación, los franciscanos han perdido mucho de la vitalidad mostrada en épocas pasadas $^{255}$. Para 1971 la antes muy extendida Tercera Orden Franciscana estaba muy venida a menos, ese año en la visita realizada por los religiosos de La Recoleta de Arequipa se habla solo de las fraternidades de Tacna, Ilo, Arequipa y Chuquibamba ${ }^{256}$. Mención especial merece la gran labor de promoción social desarrollada por el padre Carlos Lafuente en la parroquia de Huanca en el área del Colca, apoyado por las Hermanas Franciscanas Misioneras de María $^{257}$, tarea continuada en parte por sus hermanos de orden.

Otros son los Hermanos de La Salle que, como hemos señalado, dirigían el colegio Manuel Muñoz Nájar hasta la década de 1980 en que lo dejaron.

Los cambios en la liturgia, la apertura a distintas formas culturales, la libertad religiosa y el ecumenismo, la separación de Iglesia y Estado, representaban grandes retos que en muchos casos no supieron afrontar.

En este sentido, es muy significativa la convocatoria a un sínodo por parte de monseñor Fernando Vargas en 1986 que finalmente no se llevó a cabo.

$\mathrm{El}$ interés de los prelados por lo social se mantuvo a través del llamamiento a la solidaridad y justicia social; en la Carta pastoral de Rodríguez Ballón sobre el «Derecho de Propiedad» ${ }^{258}$ y los escritos de Vargas Ruiz de Somocurcio

${ }^{252}$ En 1962 desaparecería El Deber, periódico que durante más de medio siglo fuera el abanderado de la causa católica y el vocero de la curia, dejando un vacío que hasta la fecha no ha podido ser cubierto por ninguna publicación promovida por la Iglesia.

${ }^{253} \mathrm{Nada}$ queda de las obras por ellos realizadas durante las primeras décadas del siglo XX. Véase al respecto Tomás MANCHEGO O.P., Breve reseña histórica del convento de San Pablo de Predicadores de Arequipa. Arequipa, Tipografia Valverde, 1940.

${ }^{254}$ En 1954 establecieron el Instituto Pedagógico Mercedario, que dejaron años después. Algo de la historia del convento en Víctor M. BARRIGA, «Fragmentos históricos». En: Alborada Mercedaria 12. Arequipa, 1918, pp. 436-460.

${ }^{255}$ Los padres franciscanos de la Provincia de los XII Apóstoles que desde 1962 tenían la parroquia de Nuestra Señora de las Angustias en su convento, la renunciaron en el 2000.

${ }^{256}$ Fernando (Manuel) Dominguez, La Orden Franciscana Seglar en el Perú..., p. 167.

257 Puede verse Carlos LAfUENTE L. OFM., La Parroquia de Huanca y Lluta (CayllomaArequipa) Apuntes para la historia, Arequipa, 1996, págs. 79-103. 1961.

258 «Carta Pastoral del Excelentísimo Señor... sobre el Derecho de Propiedad», El Deber, Arequipa, 
recopilados en «Caminos de Reconciliación Social» 259 , además de sus pastorales. También con la realización de la Segunda Semana Social del Perú en 1961 y la Semana Social de Arequipa en $1987^{260}$. Pero sobre todo mediante el apoyo a instituciones creadas para ayudar a los más necesitados, como Cáritas y CIRCA.

La llamada Iglesia militante de la segunda mitad del siglo XIX y la primera del XX conformada fundamentalmente por grupos de clase alta y media ${ }^{261}$ con la incorporación de los sectores populares ha dado paso a una Iglesia que si bien muestra distinciones impuestas por la sociedad, ha cobrado un notable desarrollo con gran proyección y dinamismo.

La Federación de Círculos Sociales Católicos de Arequipa, «CIRCA» como es más conocida fue fundada el 29 de junio de 1959 por el jesuita Carlos Spallarrossa Pozzo, el «Padre Pozzo», es una de las instituciones más vigorosas, inicialmente grupo de reflexión católica, pronto procedió a abrir colegios, comedores, casas, postas médicas, guarderías, clubes de madres. Hasta 1982 habían construido 1840 casas,' 20 escuelas primarias y 3 secundarias, además de 11 capillas y 2 postas $^{262}$. En el I Congreso de Maestros de CIRCA (realizado en marzo de 1998) se reunieron más de 512 profesores que atendían a más de 13428 alumnos ${ }^{263}$.

Como bien señala Klaiber los nuevos grupos de religiosos que llegaron en este período «han buscado formas de servicio que tengan un sentido más palpablemente social y pastoral que el trabajo en colegios tradicionales o en hospitales y otras instituciones semejantes» ${ }^{264}$.

Se ha diversificado la labor desarrollada por las diferentes instituciones que dependen del Arzobispado manifestada en comedores, cunas, centros de rehabilitación, talleres, etc.

La cada vez más notoria falta de vocaciones sacerdotales y religiosas creó un vacío en la atención de los fieles que fue aprovechado por los protestantes que empezaron a llegar en mayor número. Se observa una fuerte presencia de nuevos credos y confesiones impulsados y financiados desde el extranjero,

\footnotetext{
259 Caminos de Reconciliación Social. Arequipa, COAMCOS, 1991.

260 Algunas de las ponencias en: Enseñanza Social de la Iglesia. Actualidad y desafio. Lima, 1988.

261 José L. BUSTAMANTE Y RIVERo les observaba una caridad de compasión o piedad en vez de justicia. Véase José L. BUSTAMANTE Y RIVERo, Mensaje al Perú. Perú, Estructura Social, Lima, 1960.

262 Jeffrey KLAIBER S.J., «Arequipa católica: La «Roma de América». en: Debate 17. Lima pág. 33. Esta información no es exacta completamente pues en el diario arequipeño El Pueblo del 16 de octubre de 1978, se afirmaba que había proporcionado casa propia a 3000 familias, construido 22 colegios y 13 capillas.

263 Julio CORAZAO S.M., «La CIRCA». en: El Destape, Año XXI, N 1021. Federación de Círculos Sociales Católicos de Arequipa, 21 de junio de 1998, sp.

264 J. KLAIBER, La Iglesia en el Perú..., p. 459.
}

Fundaciones Hispanas

Hispania Sacra 57 (2005) 
fundamentalmente Norteamérica ${ }^{265}$. Numerosos templos de estas confesiones se han construido en toda la ciudad. De estas iglesias podemos mencionar la evangélica, la adventista, la mormona, testigos de Jehová.

Según el Plan Pastoral de 1995 los principales problemas que la Iglesia debía de superar en Arequipa eran la secularización y la invasión de las sectas.

Para afrontarlos, el clero diocesano está compuesto por 78 sacerdotes, mientras que el regular por 113; número ciertamente insuficiente para atender a una población que bordea el millón de habitantes. De ellos 62, es decir, el $40 \%$ son extranjeros ${ }^{266}$. Dice el padre Klaiber: «... un siglo y medio después de la Independencia, la Iglesia peruana prácticamente se ha convertido en una Iglesia 'misionera' con una notable presencia de extranjeros en su seno» ${ }^{267}$.

Si el recordado franciscano Carlos Lafuente desarrolló su apostolado en el área rural andina, el también ya desaparecido padre Eloy Arribas volcó su labor misionera en la zona marginal de la ciudad, al frente de la parroquia Cristo Obrero, trabajó intensamente por el bienestar de los pueblos a través de: instalación de agua y desagüe, electricidad, construcción de colegios y locales sociales, creación de comedores populares, puestos sanitarios y bibliotecas, comunicación social con el boletín Amakella y radio Yaraví, etc. ${ }^{268}$ Cabe precisar que ambos sacerdotes eran españoles.

La Reforma Agraria implementada por el denominado Gobierno Revolucionario de la Fuerza Armada encabezado por el general golpista Juan Velasco Alvarado significó la pérdida de las posesiones que la Iglesia conservaba todavía en las áreas rurales, ocasionándole un mayor empobrecimiento ${ }^{269}$, limitando su accionar.

${ }^{265}$ Incluso «han aparecido religiones que pueden considerarse peruanas, como la Iglesia cruzada, católica, apostólica, evangélica y peruana, que fundó en la selva Francisco de la Cruz, la iglesia Alfa y Omega que fundaron en Lima Luis Antonio Soto y Antonio Córdova y la Misión israelita del nuevo pacto universal, que fundó y difundió Ezequiel Ataucusi Gamonal». Manuel MARZAL S.J., Religión y sociedad peruana del siglo XXI. Lima, P.U.C.P. 1995 pp. 11-12. Dice Matos: «Transgrediendo los límites de la religión tradicional encuentran formas de liberarse de la tutela de las autoridades eclesiásticas, multiplicando los grupos católicos pentecostales en los que desaparece la distinción entre clérigo y laico o constituyendo iglesias evangélicas de fórmula propia...» José MATOS MAR, Desborde popular y crisis del estado. El nuevo rostro del Perú. Lima, CONCYTEC, 1988 p. 91.

266 Directorio de la arquidiócesis de Arequipa 2002, Arequipa, 2002.

267 J. KLAIBER, La Iglesia en el Perú..., p. 17.

268 Justino CRUZ, Eloy: «Un sembrador de nuestro tiempo». en: Eloy Arribas Misionero. Pedrajas de San Esteban (Valladolid), 2002, pp. 13-16.

269 Ejemplo de ello es Characato, donde la Virgen de la Candelaria había sido objeto de varias donaciones a lo largo del tiempo, llegando a más cien topos de tierra que eran alquilados para su cultivo, que fueron expropiados de resultas de dicha ley; además de otras propiedades. Debido a ello, ante la necesidad de derribar el templo seriamente dañado por los sismos de 1958 y 1960, hubo de pasar mucho tiempo, ante la carencia de recursos, para poder realizar su edificación. 
Los daños ocasionados por los terremotos de 1958, 1960 y 2001 han requerido de la acción del arzobispado a fin de conseguir ayuda para la reconstrucción de templos e infraestructura dañada o destruida.

Quizás la mayor esperanza pero a la vez un reto para la Iglesia represente la religiosidad popular. «Si el Perú sigue siendo un país mayoritariamente católico según los censos, no es tanto por el dinamismo del clero y demás agentes de pastoral, como porque la evangelización colonial se hizo cultura, es decir un modo de ver la vida y de construir el mundo, que se trasmite en la socialización» ha dicho el padre Marzal ${ }^{270}$.

Como bien señala este autor, el catolicismo popular es la religión de las grandes mayorías del pueblo que tienen un escaso cultivo religioso, por falta de mayor atención de la Iglesia institucional o porque dichas mayorías no buscan más atención religiosa. Está formada por un conjunto peculiar de creencias, ritos, sentimientos, formas de organización y-normas éticas que el pueblo aceptó y reinterpretó en la evángelización ${ }^{271}$.

Buen ejemplo de ello es la festividad de la cruz que es una de las que más profundamente ha calado en el poblador andino cuyo culto se halla muy difundido. Es el caso de la parroquia de Huanca-Lluta, donde el padre Carlos Lafuente contó hasta $83^{272}$. Las fiestas patronales, por otro lado, son los acontecimientos más importantes de la vida de los pueblos. Otra celebración religiosa de gran arraigo es la Semana Santa que muestra características propias en cada lugar.

Pero sin duda el culto a la Candelaria es el más importante en la región, destacando la imagen que se venera en el pueblo de Chapi que congrega año a año miles de peregrinos que acuden a su fiesta.

Advierte sin embargo, el jesuita José L. Idígoras, que con la influencia de los medios de comunicación, este catolicismo popular ha de sufrir una constante debilitación ${ }^{273}$. Se da también una sustitución y rotación de patronos en la vida religiosa de Arequipa ${ }^{274}$. En décadas pasadas la festividad de la Candelaria en Cayma y Characato era bastante concurrida, en la actualidad se encuentran muy

270 Manuel MARZaL S.J., Religión y sociedad peruana del siglo XXI..., p. 15. A ello se refiere precisamente el llamado del Papa: «... debidamente purificada, la religiosidad popular por su arraigo profundo en el pueblo, quitaría base a la crítica, opondría sólida resistencia al secularismo y al proselitismo sectario y sería eficaz antídoto frente a los movimientos religiosos foráneos.» Citado en el plan pastoral arzobispado de Arequipa, 1995, pág. 13.

271 Manuel MARZAL S.J., Religión y sociedad peruana del siglo XXI..., p. 15.

272 Carlos LAFUENTE L. OFM., La Parroquia de Huanca y Lluta..., pp. 117-118.

273 José L. IDÍGORAS S.J., «Mirada prospectiva a la religión en el Perú». en: Perú, identidad nacional. Lima, CEDEP, 1979, p. 413.

274 Se da a la par con la sucesión de fenómenos naturales según el antropólogo E. Motta. Véase Edmundo Motta ZamalloA, El Agua, la Serpiente y la Candelaria de Arequipa. Lima, Universidad Nacional Mayor de San Marcos, 1985, p. 69.

Fundaciones Hispanas

Hispania Sacra 57 (2005) 
disminuidas. Otro es el caso del Nazareno, celebrado en diferentes distritos, antes rurales, hoy ya incorporados a la urbe. Así, respecto a Tiabaya en 1945 se decía: «...es muy visitado por miles de gentes devotas que vienen desde lejanos pueblos a rendir culto a Jesús Nazareno... estableciéndose así la solemne fiesta de Cuasimodo, que en sus primeros años hasta hace poco, constituía una gran feria a la que acudían de las provincias circunvecinas de Arequipa y formaban grandes carpas y toldos en la plaza. Hoy todo esto ha desaparecido, pero las fiestas religiosas revisten, si cabe, mayor solemnidad ${ }^{275}$. Algo similar ha ocurrido en Yanahuara, donde hasta hace unas décadas la llamada procesión del «Encuentro» del Martes Santo convocaba a numerosos fieles que acudían desde la ciudad a presenciarla; actualmente son muy pocos los concurrentes, mayormente lugareños ${ }^{276}$.

Algo diferente ocurre con la devoción al Señor de los Milagros, introducido en Arequipa en la década de 1950 que ha cobrado gran acogida de los fieles y se puede hablar que casi no hay parroquia que no cuente con esta efigie ${ }^{277}$.

Aunque no se ajusta completamente la afirmación que hiciera el padre Marzal sobre el desplazamiento en la devoción local de Ica y Lima a santos tradicionales por «santitas» y «beatitas» de origen popular no reconocidas por la Iglesia como los casos de la Melchorita o Sarita Colonia ${ }^{278}$; si se ha visto el culto en algún momento a la "Chavela» mujer alcohólica de comienzos de siglo XX y al fusilado por uxoricida Víctor Apaza, con fama de «milagreros» ${ }^{279}$. En su tiempo se dio la superstición del llamado «San Gil de Cayma».

En medio de esta problemática y estos desafíos se han desempeñado los dos últimos arzobispos, Vargas Ruiz de Somocurcio y Sánchez-Moreno.

Monseñor Fernando Vargas Ruiz de Somocurcio S.J. ${ }^{280}$ ha sido uno de los prelados más queridos en Arequipa, donde llegó luego de haber ejercido el

275 ALBUM HOMENAJE a la Arquidiócesis de Arequipa y su Primer Arzobispo Excmo. Mons. Fr. Mariano Holguín. La Colmena. Editorial Arequipa, 1946, p. 76.

276 El padre Rodrigo Sánchez Arjona S.J. ha estudiado las vicisitudes de la devoción al Sagrado Corazón de Jesús en el Perú y señala que la causa de su decadencia se debe a la obra de prelados, sacerdotes y religiosos que no la vieron con buenos ojos luego del Concilio Vaticano II. Véase $E l$ Corazón de Cristo en el Perú. Bogotá, Instituto Internacional del Corazón de Jesús, 1983, p. 129

277 Debe tenerse presente sin embargo, que la gran difusión de este culto ha significado la realización de muchas pero muy pequeñas procesiones nada comparables a las realizadas en Lima.

278 Manuel MARZAL S.J., «Religión católica e identidad nacional». en: Perú, identidad nacional. Lima, CEDEP, 1979, p. 159.

279 «Extraño culto» ha llamado Marzal al caso de Apaza. M. MARZAL S.J., Idem. Puede verse Jordán RoSAS V., «Víctor Apaza Quispe: o del fusilamiento a la santificación». en: Revista Ciencias Sociales 1. Arequipa, UNSA, 1982; y Lorenzo PEÑALVA S., Consideraciones sociales acerca del mito de «La Chavela». Arequipa, UNSA, 1985.

280 Nació en Arequipa el 8 de marzo de 1918. Falleció el 8 de diciembre del 2003 día de la Inmaculada. 
episcopado en Huaraz, diócesis que le tocó levantar luego de su destrucción en 1970 y brevemente en Piura en 1978.

Una de sus principales preocupaciones fue la formación sacerdotal por lo que brindó gran ayuda al seminario y fomentó nuevas vocaciones. Dejó establecido los límites parroquiales y las proyecciones de las futuras parroquias. En 1983 llevó la imagen de la Candelaria de Chapi a la ciudad, hecho que fue todo un acontecimiento en la historia de la Iglesia en Arequipa. Poco después, en 1985 se produjo la visita del Papa Juan Pablo II que beatificó a la monja Ana de los Angeles Monteagudo y coronó a la Virgen de Chapi.

Buscó iluminar la convivencia de su pueblo desde la enseñanza social de la Iglesia, mostrando el camino de la reconciliación a través de sus cartas pastorales «Seguimiento social de Cristo» (1989), «Centenario de la Rerum Novarum» (1991) y otros escritos reunidos en «Caminos de Reconciliación Social» (1991). Además de la organización de la Primera Semana Social de Arequipa en agosto de 1987. Pero sobre todo a través de instituciones creadas para ayudar a los ne$\operatorname{cesitados}^{281}$. Las asociaciones de laicos merecieron su total apoyo ${ }^{282}$.

Monseñor Vargas mostró un gran interés por la cultura al organizar en 1990 el Primer Congreso Peruano de Historia Eclesiástica y la creación del Archivo Arzobispal de Arequipa en 1984, abierto al público en 1992.

Poco antes de dejar el cargo, hizo publicar el Plan Pastoral de la Arquidiócesis buscando orientar su accionar en procura de dar una respuesta al esfuerzo de la «Nueva Evangelización» pedida por el Papa y a la toma de conciencia del proceso de cambio cultural ${ }^{283}$.

Durante su permanencia en el arzobispado (1980-1996), promovió el acercamiento a instituciones - como la universidad - que durante mucho tiempo estuvieron sino alejadas en franca oposición a la Iglesia. Característica de monseñor Fernando Vargas fue su apertura para con el pueblo sin distinciones de ningún tipo, estuvo en contacto cercano con la gente, hecho que lo hizo muy apreciado por la colectividad que acudió en masa a su despedida de la ciudad en $1996^{284}$.

\footnotetext{
281 En 1993 el Arzobispado atendía 109 obras sociales y 96 centros educativos.

282 Durante el episcopado de Monseñor Vargas se establecieron diversas asociaciones laicales como el Opus Dei, Sodalicio de Vida Cristiana, Cruzados de Santa María, etc.; de tan dinámica actividad.

283 Plan pastoral arzobispado de Arequipa. 1995, p. 7.

${ }^{284}$ En junio de 2002 le tocó ser mediador entre el gobierno peruano y las autoridades y representantes populares arequipeños que encabezaban una protesta contra aquél, logrando la firma de un acuerdo.
} 
Luis Sánchez-Moreno también arequipeño de nacimiento ${ }^{285}$, se hizo cargo de la arquidiócesis, luego de ejercer el episcopado en Cañete donde realizó una gran tarea pastoral, fundando el seminario San José y el Instituto Superior Pedagógico de esa localidad.

La labor de monseñor Sánchez-Moreno se ha orientado fundamentalmente a la reforma y reorganización de la curia, el seminario, Cáritas y la creación de órganos para apoyar la labor pastoral como el Instituto Arquidiocesano para el sostenimiento del clero. Dio un nuevo estatuto al cabildo catedralicio y le tocó organizar la celebración del Jubileo del año 2000. Durante su episcopado se ha fundado la Universidad Católica San Pablo obra del Sodalicio de Vida Cristiana que contó con su apoyo y reconocimiento canónico.

El nombramiento de monseñor José P. Ríos Reynoso augura un renovado impulso en la labor social de la Iglesia con un mayor acercamiento hacia el pueblo.

\section{UNA REFLEXIÓN FINAL}

Es evidente que falta por hacer la historia de la Iglesia en Arequipa, los estudios que se han hecho hasta la fecha, complementan o corrigen la información vertida por sus primeros historiadores llámese Travada en su libro tantas veces mencionado, Echeverría y su sólida y documentada obra, Zamácola con su sencillez y precisión. Valdivia y Polo que difundieron la historia de Arequipa en general y de sus obispos en particular. Y Cateriano y Martínez que aportan un gran trabajo de investigación y variedad de información. Es necesario, por tanto, alejarse de las simples repeticiones y escritos encomiásticos.

Han sido los prelados los que han concitado el mayor interés de los investigadores porque al ser la cabeza de la Iglesia en Arequipa, son referentes obligados para reconstruir la historia del pueblo católico arequipeño. Algunos de ellos cobraron merecida fama por su santidad de vida así como su capacidad organizativa. Otros fueron autores de libros en los que demostraron sus dotes intelectuales. Pero todos, se preocuparon de socorrer a los necesitados física y espiritualmente.

Sin embargo, podemos apreciar que los historiadores eclesiásticos de los siglos XVII, XVIII y XIX e incluso del XX centran su atención muchas veces en pasajes familiares de la vida de los obispos dejando de lado los aspectos más significativos para la historia del obispado-arzobispado de Arequipa que debiera ser el tema principal.

${ }^{285}$ Nació el 12 de noviembre de 1925. Por límite de edad presentó su renuncia en el año 2000.

Fundaciones Hispanas Hispania Sacra 57 (2005) 
Estos trabajos, aún los específicos no sólo contienen información sobre los prelados e institutos que ejercieron su labor en la histórica ciudad de Arequipa, sino que a su vez, proporcionan valiosos datos sobre la misma; así podemos ver personajes, instituciones, acontecimientos y muchos otros elementos que conforman los hechos históricos. Es por ello que estas obras constituyen también historias de la ciudad.

La Iglesia en Arequipa ha sido y es elemento constituyente de su identidad y es por ello necesario conocerla y apreciarla, a través de sus prelados, de su clero, de sus comunidades religiosas y de su pueblo y su religiosidad. Es decir, hay que ver a la Iglesia Católica en su doble dimensión de Iglesia-institución e Iglesia-pueblo. 